\author{
UNIVERSIDADE DE SÃO PAULO \\ FACULDADE DE ODONTOLOGIA DE BAURU
}

CAMILLA GUARNIERI

CURSO ONLINE PARA TREINAMENTO DE FONOAUDIÓLOGOS NA INTERVENÇÃO EM LINGUAGEM INFANTIL 

CAMILLA GUARNIERI

\section{CURSO ONLINE PARA TREINAMENTO DE FONOAUDIÓLOGOS NA INTERVENÇÃO EM LINGUAGEM INFANTIL}

Tese apresentada à Faculdade de Odontologia de Bauru da Universidade de São Paulo para obtenção do título de Doutor em Ciências no Programa de Fonoaudiologia, na área de concentração Processos e Distúrbios da Comunicação.

Orientador: Profa. Dra. Simone Aparecida Lopes-Herrera 

Guarnieri, Camilla CURSO ONLINE PARA TREINAMENTO DE FONOAUDIÓLOGOS NA INTERVENÇÃO EM LINGUAGEM INFANTIL / Camila Guarnieri. -Bauru, 2020.

176 p. : il. ; $31 \mathrm{~cm}$.

Tese (doutorado) -- Faculdade de Odontologia de Bauru, Universidade de São Paulo, 2020.

Orientadora: Profa. Dra. Simone Aparecida Lopes-Herrera

Autorizo, exclusivamente para fins acadêmicos e científicos, a reprodução total ou parcial desta dissertação/tese, por processos fotocopiadores e outros meios eletrônicos.

Assinatura:

Data:

Comitê de Ética da FOB-USP

Protocolo no: 2.062.999

Data: 15 de maio de 2017 



\section{ERRATA}



FOLHA DE APROVAÇÃO 



\section{DEDICATÓRIA}

Aos meus pais e ao meu irmão, que sempre me incentivaram a seguir meus sonhos.

Ao meu avô Marcello, in memorian, e a minha avó Ercília que sempre estiveram presentes na minha vida, me apoiando, me incentivando e comemorando as minhas vitórias.

Ao Bruno, que dividiu comigo todo o processo dessa tese e que foi meu porto seguro nesse período. 



\section{AGRADECIMENTOS}

à Profa. Dra. Simone Ap. Lopes-Herrera, minha orientadora desde a graduação e minha referência de pessoa e profissional. Agradeço-lhe por ter acreditado em mim desde o começo, me ajudado e desenvolver habilidades como pesquisadora e fonoaudióloga, e pela sua generosidade em sempre abrir novas oportunidades. Agradeço ainda por todo carinho, confiança, parceria e amizade que me deu nesse tempo.

ao Dr. Howard Goldstein, que me recebeu de braços abertos durante o meu doutorado sanduíche na University of South Florida, por toda a confiança, orientação e dedicação que teve comigo e com o meu projeto. A oportunidade de convivência só aumentou a minha admiração como pesquisador, professor e ser humano.

à Profa. Dra. Aline Roberta Aceituno Costa, por todo a confiança que demonstrou ter mim e por todo auxílio, parceria e disponibilidade em participar como professora do curso online.

à Profa. Dra. Deborah Viviane Ferrari pela confiança em iniciar meu percurso do doutorado como orientadora temporária, por toda ajuda com as questões burocráticas do doutorado sanduíche e pelo intermédio para que as gravações do pudessem ser realizadas no estúdio do setor de tecnologia educacional.

Ao Bruno, por todo apoio, parceria acadêmica e de vida, paciência e suporte técnico e emocional. Sem você esse projeto não estaria como ele está hoje.

à toda a minha família que sempre me apoio e serviu de exemplo para que eu continuasse evoluindo profissionalmente. Agradeço por todo suporte, amor e estrutura que sempre me proporcionaram.

Ao Programa de Pós-Graduação em Fonoaudiologia, bem como a seus professores que proporcionaram minha formação como pesquisadora. 

à todos os funcionários do setor de tecnologia educacional pelo suporte com as gravações das videoaulas do curso online.

Aos funcionários da secretaria do departamento de Fonoaudiologia pela organização, disposição e ajuda com as inscrições do curso online, em especial a Karina e a Teka. Vocês foram essenciais para que este curso online pudesse acontecer.

Aos queridos amigos Jorge e Mateus, que formam comigo o nosso "trio dinâmico" pela amizade, apoio, momentos de descontração e compartilhamento de crescimento profissional e pessoal durante essa fase da minha vida.

Aos colegas de laboratório e professores da University of South Florida, em especial ao Jack e a Yagmur, que me receberam tão carinhosamente e me auxiliaram neste projeto e na adaptação durante a mudança, e que hoje tenho o prazer de chamar de amigos.

O presente trabalho foi realizado com 0 apoio da Coordenação de Aperfeiçoamento de Pessoal de Nível Superior - Brasil (CAPES) - Código de Financiamento 001. E também teve apoio financeiro para análise de dados na University of South Florida pelo programa 194 - PDSE - Programa de Doutorado Sanduíche no Exterior da Capes sob número do processo: 88881.188969/2018-01. 

"You are never too old to set another goal or to dream a new dream". 



\section{RESUMO}

A educação continuada de profissionais é amplamente discutida na literatura e uma das estratégias utilizadas são os cursos de extensão universitária (especialização, aprimoramento, difusão e atualização). Os cursos de atualização, nos quais este trabalho foi focado, objetivam aprimorar as habilidades do profissional e atualizá-lo sobre as novas descobertas científicas e tecnológicas. Dados referentes à educação continuada de Fonoaudiólogos mostram baixos percentuais de profissionais especializados (que continuam a se atualizar depois da graduação) e distribuição heterogênea desses profissionais pelas regiões do Brasil, trazendo indícios de que cursos de extensão universitária se concentram na região sudeste. Uma ferramenta descrita na literatura para minimizar as barreiras geográficas na educação é o Ambiente Virtual de Aprendizagem (AVA), no qual cursos podem ser oferecidos à distância com o suporte necessário para a construção do aprendizado. O objetivo desta pesquisa foi desenvolver, validar e aplicar um curso online para o treino de fonoaudiólogos em intervenção na Linguagem Infantil por meio de um AVA. Esta pesquisa foi divida em três estudos: 1) Entrevista Semiestruturada com Fonoaudiólogos (construção colaborativa do AVA); 2) Desenvolvimento do curso online que envolveu as etapas de planejamento (revisão da literatura, seleção e elaboração dos materiais teóricos), execução (Configuração do curso no Moodle (AVA) e aplicação em curso em fonoaudiólogos clínicos ( $n=74)$; 3) Avaliação da eficácia do curso, em que foram analisados dados de satisfação dos alunos, evolução durante o curso e a melhora de retenção de conhecimentos teóricos comparando situações pré e pós curso. A análise dos dados se deu de forma independente para cada um dos estudos sendo: Estudo 1) análise de conteúdo temático-categorial (estudo qualitativo); 2) Descrição dos resultados e relato de experiência (pesquisaação); Estudo 3) análise estatística envolvendo o uso de medidas de tendência central, clusters, coeficiente de correlação de Spearman e Wilcoxon pareado (estudo quantitativo). Como resultado desta pesquisa, teve-se o desenvolvimento colaborativo do curso online, onde houve satisfação dos participantes e melhora nos aspectos mensurados.

Palavras-chave: Fonoaudiologia; Ensino; Materiais de Ensino; Educação; Simulação de Pacientes. 



\section{ABSTRACT \\ Online course to train speech-language pathologists in child language intervention}

Lifelong learning for professionals has been widely debated in the literature, and one of the used strategies is professional development courses linked to a university (such as academic specialization, professional improvement course, diffusion of knowledge course, refresher course). Refresher courses - which this research will focus on - aim to improve professional abilities and update them regarding new scientific and technological findings. Related data for speech-language pathologists' (SLPS) lifelong learning show low rates of specialized professionals who studying after their completing their undergraduate. A heterogeneous distribution of these professionals is also observed across Brazilian regions, indicating a concentration of professional development courses in the southeast region. A tool to minimize geographical barriers in education was described in the literature; this tool is the virtual learning environment (VLE), where courses can be offered at a distance with the necessary support for learning construction. The aim of this research is to develop, apply and assess an online course for training of SLPs in child language intervention. This research was divided into three studies: 1) a semi-structured interview with SLPS (online course collaborative construction); 2) online course development, which includes planning (literature review, selection and elaboration of theoretical materials), execution (online course configuration in Moodle (VLE) and application (in 74 SLPs); 3) Efficacy study, which some aspects as well as SLPs satisfaction and improvement in theoretical info withholding pre and post online course were carried out. Data analysis took place independently for each of the studies, being: Study 1) content analysis by themes and categories (qualitative study); 2) Description of results and experience report (action research); Study 3) statistical analysis involving the use of measures of central tendency, clusters, correlation coefficient of Spearman and paired Wilcoxon (quantitative study). As a result of this research, an online course was developed, with participants' satisfaction and improvements in the measured aspects.

Keywords: Speech, Language and Hearing Sciences; Teaching; Teaching Materials; education; Patient Simulation. 



\section{LISTA DE ILUSTRAÇÕES}

Figure 1 - Densidade demográfica brasileira e a concentração de instituições de ensino superior em Fonoaudiologia (Instituto Brasileiro de Geografia e Estatística, 2011)

Figura 2- Nuvem de Palavras da categoria Experiência no curso de bacharelado em Fonoaudiologia.

Figura 3 - Nuvem de Palavras da subcategoria Suporte teórico. .55

Figura 4 - Nuvem de Palavras da categoria Seguranças e inseguranças na prática clínica. .58

Figura 5 - Nuvem de Palavras da subcategoria Atraso de linguagem....................59

Figura 6 - Nuvem de Palavras da categoria Desenvolvimento profissional...............61

Figura 7 - Nuvem de Palavras da subcategoria Experiências.................................61

Figura 8 - Etapas e processos executados neste estudo ...................................... 81

Figura 9 - Exemplo de exibição dos materiais complementares ….........................94

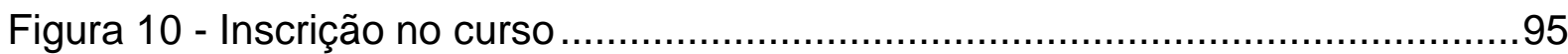

Figura 11 - Exemplo de um tutorial do curso sobre o uso de fóruns de discussões..96

Figura 12 - Distribuição de frequências das respostas dos participantes da pesquisa

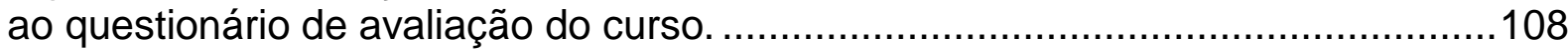

Figura 13 - Dendograma dos participantes da pesquisa. ..................................115

Figura 14 - Soma de quadrados total dentro dos clusters, de acordo com o número de clusters.

Figura 15 - Diagrama de dispersão entre as notas na prova diagnóstica pré e no questionário de aquisição e desenvolvimento de linguagem de acordo com o cluster. 



\section{LISTA DE TABELAS}

Tabela 1. Número de fonoaudiólogos brasileiros vs os que tem especialização em Linguagem (Conselho Federal de Fonoaudiologia, 2017a, Conselho Federal de

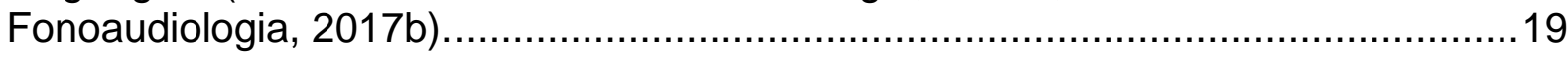

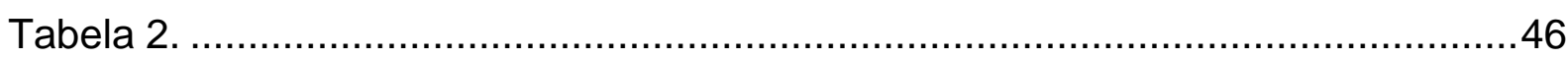

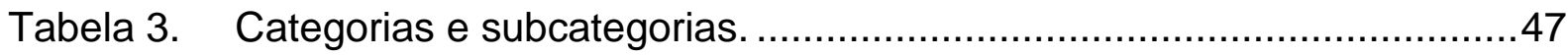

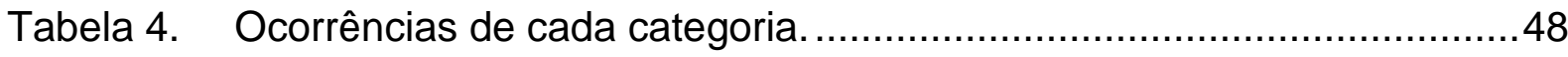

Tabela 5. Categoria Experiência no Curso de Bacharelado.................................53

Tabela 6. Categoria Seguranças e inseguranças na prática clínica. .....................56

Tabela 7. Categoria Desenvolvimento profissional............................................59

Tabela 8. Ações desenvolvidas na etapa de planejamento..................................78

Tabela 9. Ações desenvolvidas durante a etapa de construção e transformação

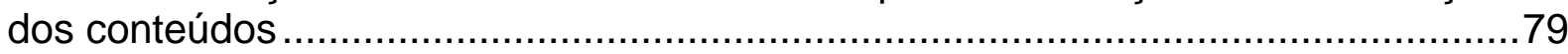

Tabela 10. Ações desenvolvidas na etapa de dinâmica do curso .........................80

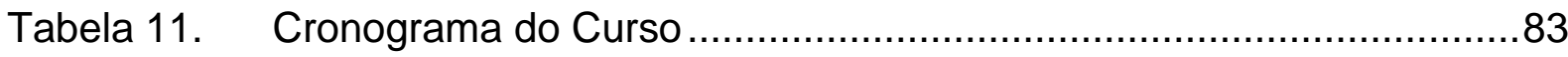

Tabela 12. Número de Fonoaudiólogos interessados no curso por região. ..........98

Tabela 13. Distribuição de frequências das variáveis de caracterização dos participantes da pesquisa...............................................................................105

Tabela 14. Medidas descritivas da nota dos participantes da pesquisa nas questões do questionário de aquisição e desenvolvimento de linguagem. .............107

Tabela 15. Resultados dos testes de correlação entre as notas dos módulos e a nota geral (pré e pós) dos participantes da pesquisa...........................................110

Tabela 16. Resultados dos testes de correlação entre as notas e os acessos de cada módulo dos participantes da pesquisa.........................................................111

Tabela 17. Resultados dos testes de correlação entre o acesso geral e a nota geral (pré e pós) dos participantes da pesquisa.

Tabela 18. Resultados dos testes de comparação entre as notas dos participantes da pesquisa na prova diagnóstica pré e pós. .....................................112

Tabela 19. Número de observações por cluster..............................................116

Tabela 20. Média (desvio padrão) das variáveis, por cluster. ...........................117 



\section{LISTA DE ABREVIATURA E SIGLAS}

ABA Applied Behavior Analysis

ADL Avaliação do Desenvolvimento da Linguagem

AVA Ambiente Virtual de Aprendizagem

CoCEx Conselho de Cultura e Extensão Universitária

DEL Distúrbio Específico de Linguagem

EaD Ensino a Distância

EUA Estados Unidos da América

FOB Faculdade de Odontologia de Bauru

Mbps Mega bits por segundo

MOOC Massive Open Online Course

PECS Picture exchange communication system

PRISMA Preferred Reporting Items for Systematic Reviews and Meta-Analyses

PROMPT Prompts for Reestructuring Oral Muscular Phonetic Targets

PUC Pontifícia Universidade Católica

RBCC Revista Brasileira de Cirurgia Cardiovascular

TEA Transtorno do Espectro Autístico

UNESP Universidade Estadual Paulista

Unorp Centro Universitário do Norte Paulista

Unifesp Universidade Federal de São Paulo

UNIP Universidade Paulista

USP Universidade de São Paulo 

1 - INTRODUÇÃO

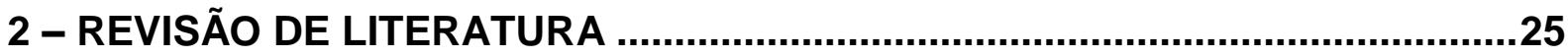

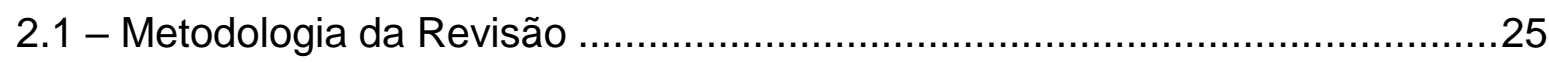

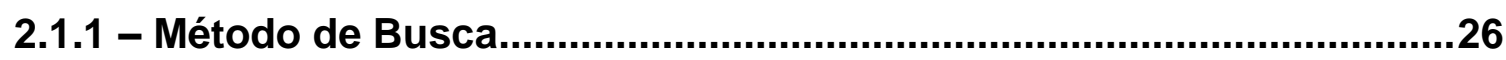

2.1.2 - Procedimentos de Seleção e Critérios ...........................................28

2.1.2.1 - 1를 Etapa: Seleção e Catalogação Preliminar: ................................29

2.1.2.2 - 2 $2^{\text {a }}$ Etapa: Remoção das publicações duplicadas: .........................29

2.1.2.3 - 3 ${ }^{\text {a }}$ Etapa: Seleção das Publicações Relevantes pelo Abstract:......29

2.1.2.4 - 4a Etapa: Seleção das Publicações Relevantes pelo Texto Completo: .30

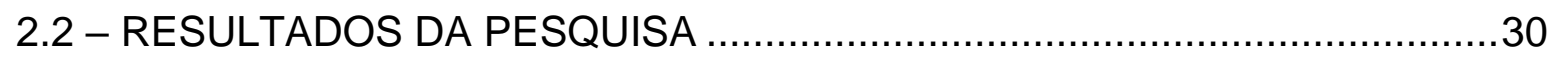

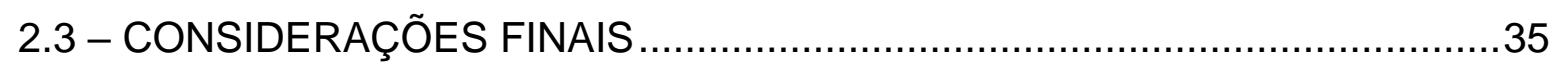

3 - OBJETIVO

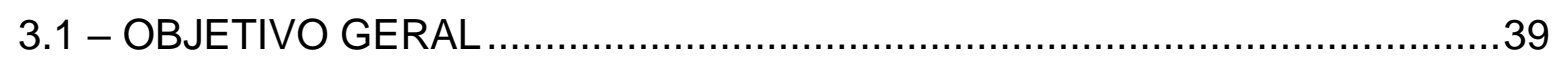

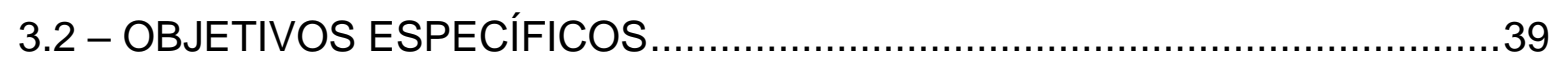

4 - ESTUDO 01: EXPERIÊNCIAS E PERSPECTIVAS DE FONOAUDIÓLOGOS QUANTO À FORMAÇÃO E PRATICA PROFISSIONAL NA INTERVENÇÃO DAS

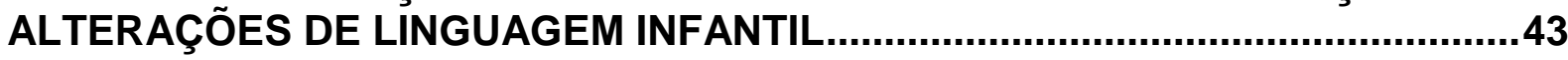

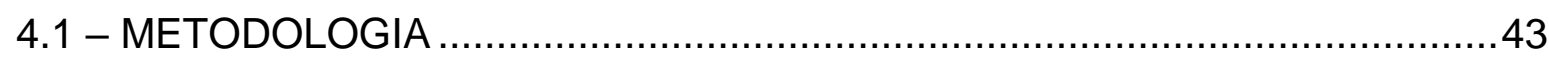

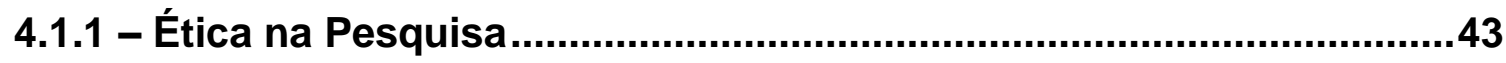

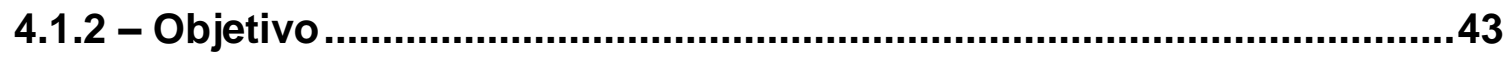

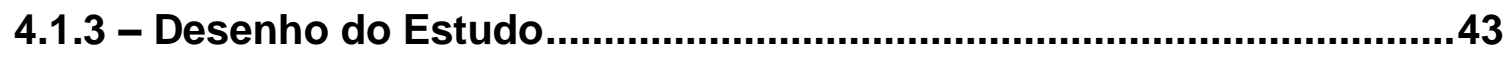

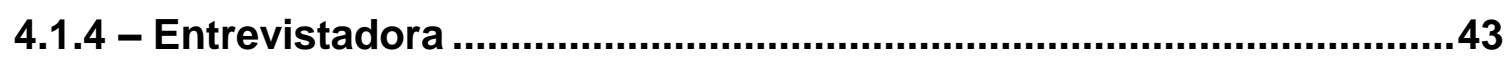

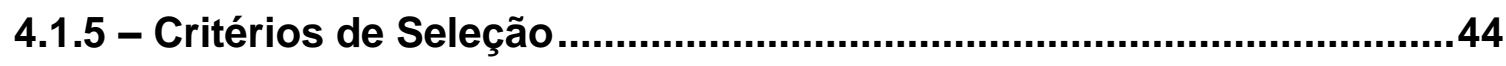

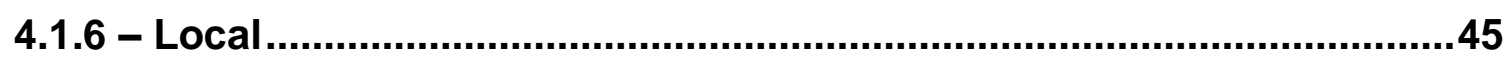

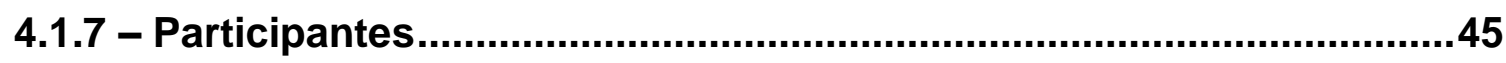

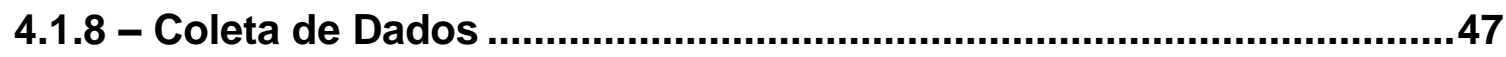

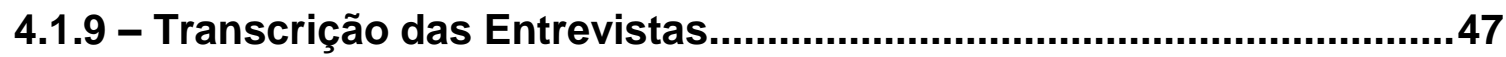

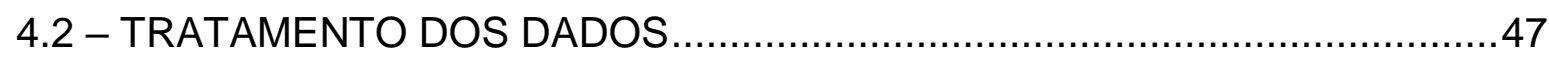

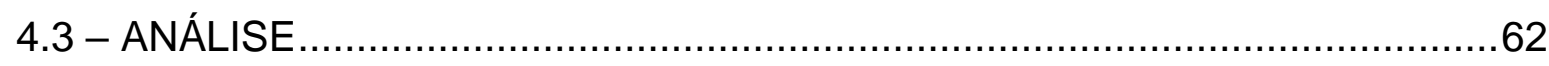

4.3.1 - Experiência no Curso de Bacharelado .............................................62

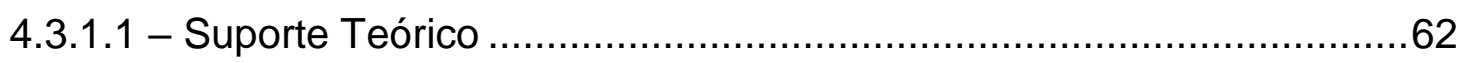

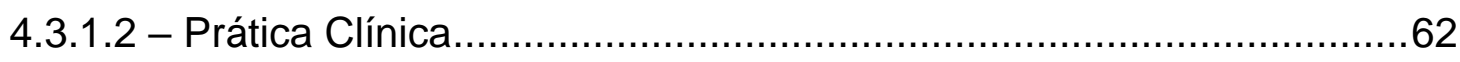

4.3.1.3 - Preparação para o Mercado de Trabalho .......................................63

4.3.2 - Seguranças e Inseguranças na Prática Clínica ..................................64

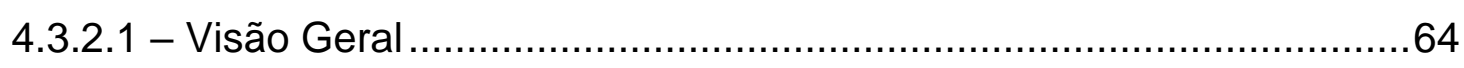

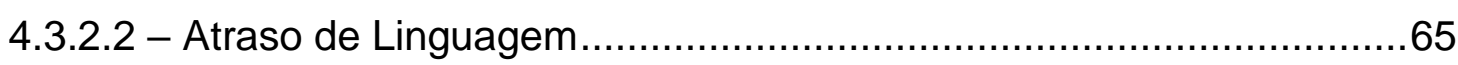




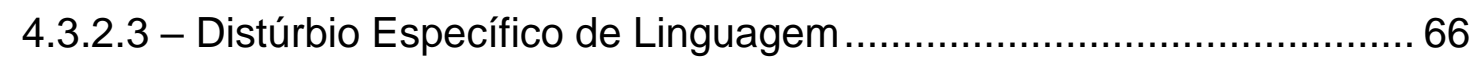

4.3.2.4 - Transtorno do Espectro Autístico (TEA) ..................................... 67

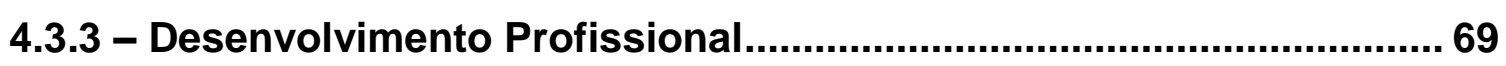

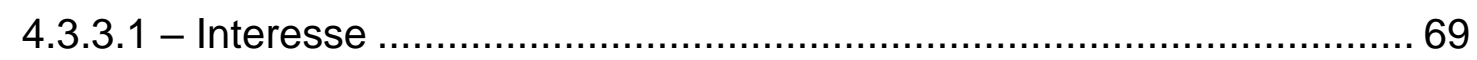

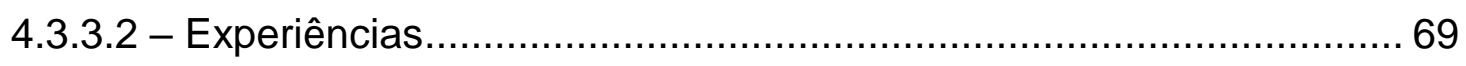

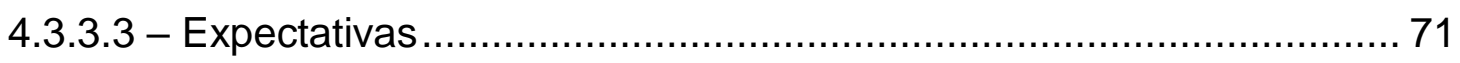

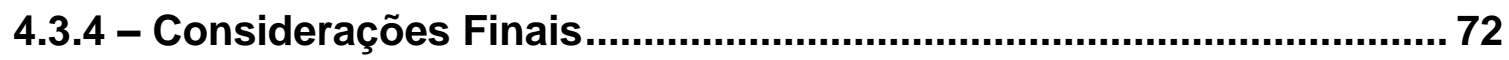

\section{5 - ESTUDO 02: DESENVOLVIMENTO DE UM CURSO ONLINE PARA} EDUCAÇÃO CONTINUADA DE FONOAUDIÓLOGOS SOBRE INTERVENÇÃO EM

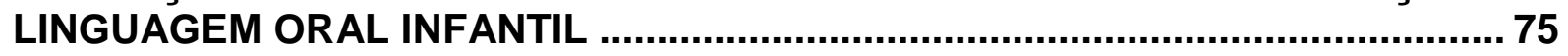

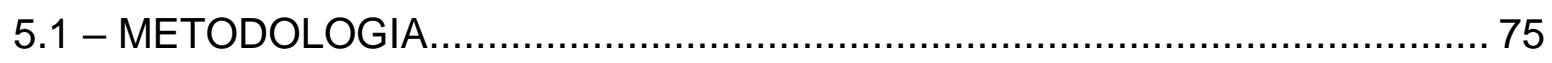

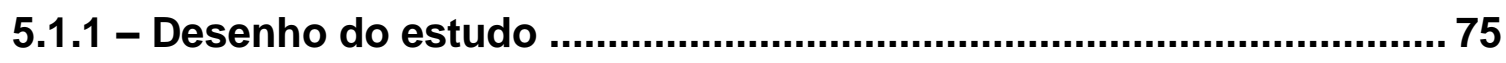

5.1.1.1 - Etapa 1 - Planejamento ........................................................ 75

5.1.1.2 - Etapa 2 - Construção e Transformação dos Conteúdos ............... 76

5.1.1.3 - Etapa 3 - Desenvolvimento da Dinâmica do curso ........................ 76

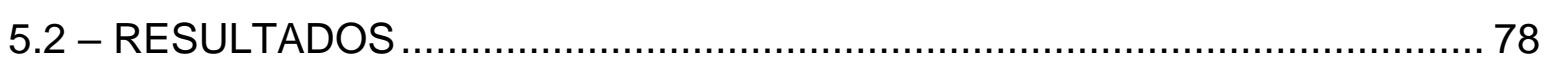

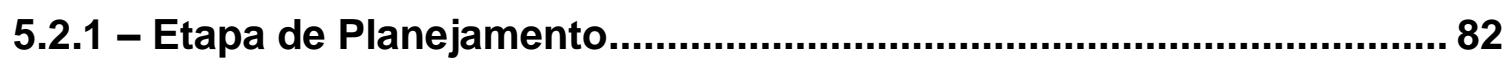

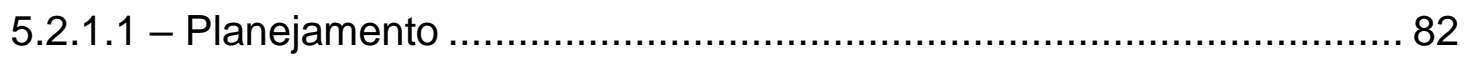

5.2.1.2 - Desenvolvimento dos Conteúdos ............................................. 86

5.2.1.3 - Desenvolvimento das Avaliações................................................ 91

6 - ESTUDO 03: AMBIENTE VIRTUAL DE APRENDIZAGEM PARA O TREINO DE FONOAUDIÓLOGOS EM LINGUAGEM INFANTIL............................................. 101

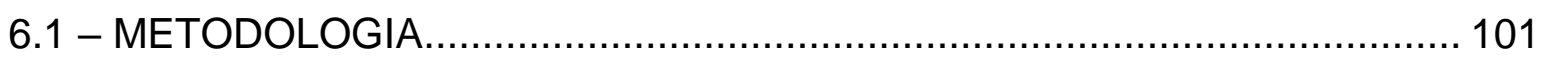

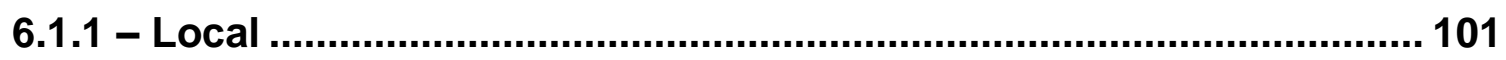

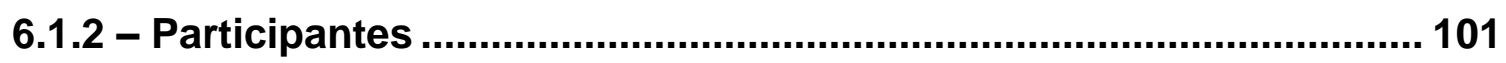

6.1.2.1 - Critérios para a seleção da amostra ......................................... 101

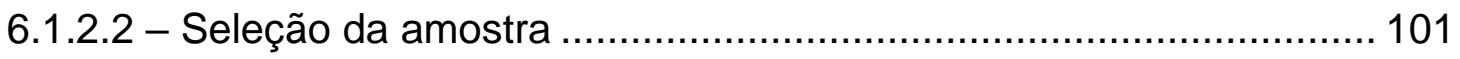

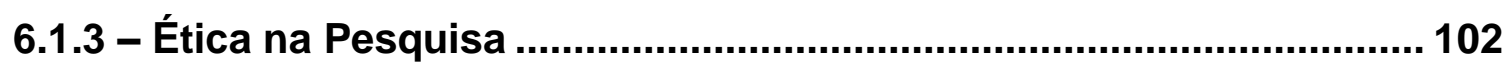

6.1.4 - Procedimentos De Coleta De Dados ........................................... 102

6.2 - FORMA DE ANÁLISE DOS RESULTADOS .............................................. 102

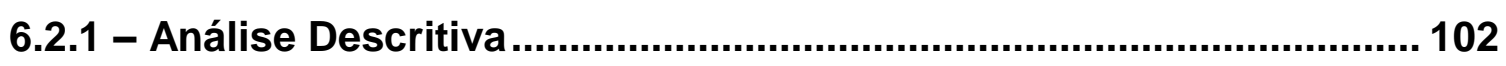

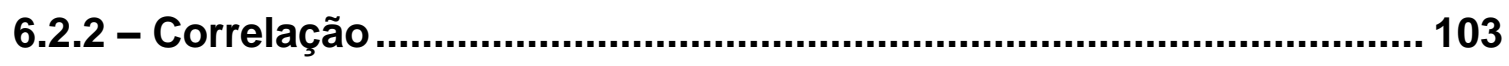

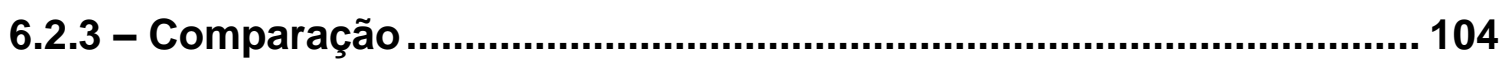

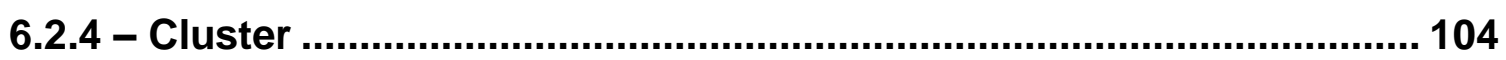

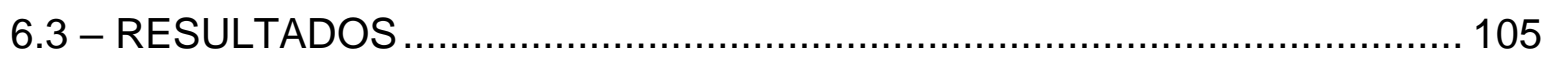

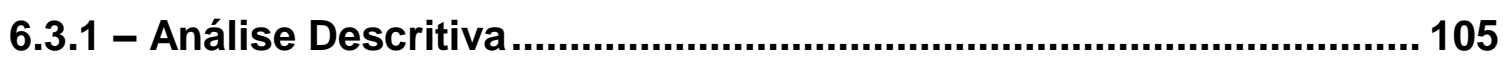

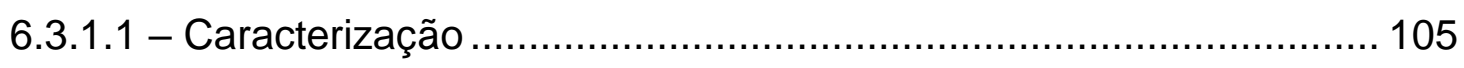


6.3.1.2 - Conhecimentos prévios sobre Aquisição e desenvolvimento de linguagem

6.3.1.3 - Avaliação do curso ...........................................................108

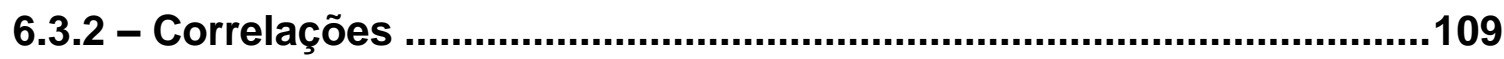

6.3.2.1 - Nota na avaliação pré-pós treinamento x Nota por módulo ............110

6.3.2.2 - Nota por módulo x Acesso por módulo .........................................111

6.3.2.3 - Nota na avaliação pré-pós treinamento x Acesso geral..................112

6.3.3 - Comparações..................................................................................112

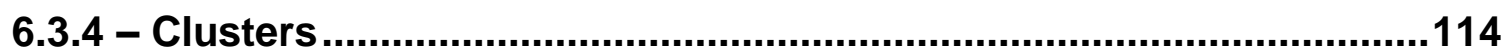

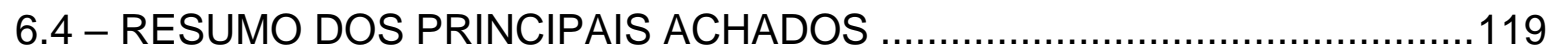

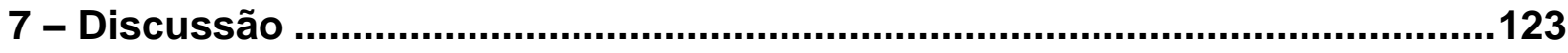

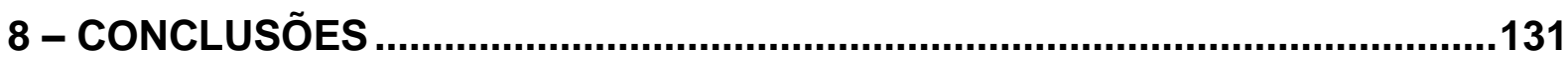

APÊNDICE A - TERMO DE CONSENTIMENTO LIVRE E ESCLARECIDO ..........145

APÊNDICE B - ROTEIRO DAS ENTREVISTAS …..........................................148

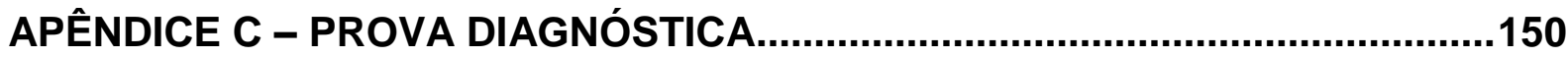

ANEXO A - APROVAÇÃO PELO COMITÊ DE ÉTICA EM PESQUISA.................165

ANEXO B - APROVAÇÃ O DO CURSO PELA PRÓ-REITORIA DE CULTURA E

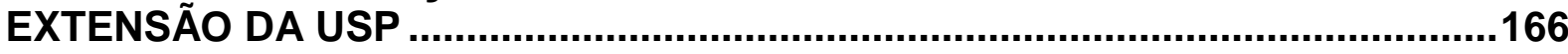

ANEXO C - QUESTIONÁRIO DE INCIDENTES CRÍTICOS................................168

ANEXO D - QUESTIONÁRIO ATTLS.........................................................169

Anexo E - Questionário COLLES versão "expectativas e experiência efetiva" 



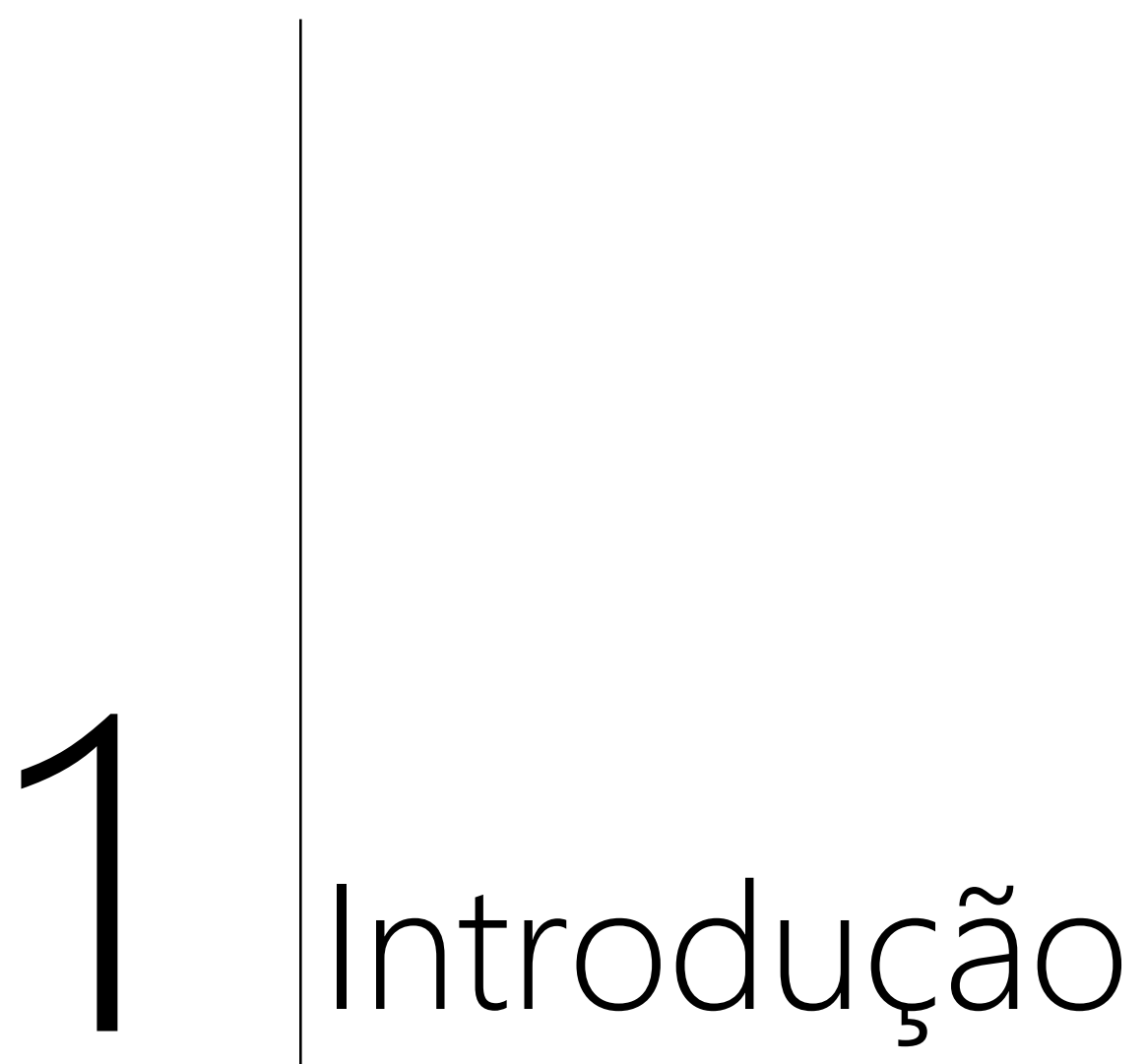





\section{1 - INTRODUÇÃO}

Os cursos de atualização são uma modalidade de curso de extensão universitária que, por sua vez, tem como objetivo a educação continuada dos profissionais, visando ao aprimoramento de suas habilidades e à atualização das novas descobertas científicas e tecnológicas na área (SHARPLES, 2000; PASCHOAL; MANTOVANI; MÉIER, 2007; SILVA; SEIFFERT, 2009). Dentro da Universidade de São Paulo (USP), o curso de atualização tem currículo mínimo de uma disciplina, sendo que sua ementa deverá ser previamente analisada pelo Conselho de Cultura e Extensão Universitária (CoCEx), com uma carga horária mínima de 30 horas (Resolução no 6667 do CoCEx de 19 de dezembro de 2013)

Além da estruturação e currículo do curso, outra característica extremamente importante é como passar uma informação, de modo que vire conhecimento e tenha repercussão na prática profissional daquele indivíduo. Sendo assim, existem descritos na literatura diversas metodologias, técnicas e processos de ensino que têm como objetivo melhorar a qualidade do mesmo (OLIVEIRA; PONTES, 2011).

Dentre as metodologias amplamente discutidas, principalmente no ensino em saúde, estão as denominadas metodologias ativas de aprendizagem, uma alternativa aos modelos antigos de ensino nos quais o aluno era um elemento passivo e o professor o detentor do conhecimento, ou seja, o processo de aprendizagem é visto como uma via de mão única. O professor passa as informações para o aluno que apenas recebe as mesmas. Nas metodologias ativas de aprendizagem, o aluno é um agente no processo de aprendizagem do qual ele participa de todo o processo de busca, acomodação e generalização da informação recebida. Nesse caso, o processo de aprendizado acontece numa via de mão dupla, no qual aluno e professor coletam, transmitem e recebem novas informações (OLIVEIRA; PONTES, 2011; SOBRAL; CAMPOS, 2012).

Existem diversos estudos, inclusive no âmbito nacional (CYRINO; TORALLES PEREIRA, 2004; GOMES et al., 2010), que comprovam que as metodologias ativas de aprendizagem se mostraram úteis no ensino em saúde, 
demonstrando que os alunos ficaram satisfeitos quando a metodologia era aplicada a alguma disciplina. Eles relataram também que as ferramentas avaliativas utilizadas eram mais justas e que, quando precisaram das informações apresentadas em aula, a mesma foi relembrada com facilidade. Para os professores envolvidos houve maior participação e melhor desempenho por parte dos alunos.

Há muitas técnicas e ferramentas empregadas nas metodologias ativas de aprendizagem. Dentre elas, a problematização, a qual vem sendo usada com êxito em alguns projetos da área de ensino em saúde. Isso pode ser justificado pelo fato de que a problematização depende de situações reais relativas à sociedade para ser desenvolvida. Na Fonoaudiologia, entretanto, não existem muitas experimentações de tal técnica; porém, na literatura há alguns estudos internacionais que contém relatos de experiências positivas quando utilizado o ensino baseado em problemas, que, assim como a problematização, é classificada como uma metodologia problematizadora, o que traz indícios que tais práticas podem ser benéficas na área da fonoaudiologia (MACBEAN et al., 2013; ERICKSON; SERRY, 2016).

O avanço da tecnologia, em geral, tornou a mesma mais acessível à população e, com isso, o acesso à internet dobrou entre os anos 2008 e 2015, chegando a metade dos domicílios brasileiros (CGI-BR, 2016). Outro facilitador à tecnologia para os menos favorecidos economicamente foram as várias políticas públicas, tais como: Acessa São Paulo (GOV-SP, 2000) e o Plano Nacional de Banda Larga (BRASIL, 2010). Com isso, as tecnologias de apoio de ensino conseguiram alcançar cada vez mais brasileiros. Tais tecnologias corroboraram para a construção de um Ambiente Virtual de Aprendizagem (AVA muito utilizado tanto como apoio a cursos presenciais quanto a distância. Para a realização de um AVA, é necessário a utilização de uma ferramenta (paga ou gratuita) que proporcione a criação desse ambiente (SANTOS; SANTOS, 2015).

O Moodle é a ferramenta mais utilizada para o AVA, por ser gratuito e de código-aberto, possibilitando ao usuário personalizá-lo para suas necessidades. Além disso, ele possui uma grande comunidade de desenvolvedores, que realizam manutenção periódica e suporte ao mesmo. Portanto, o Moodle é recomendado em vários casos de AVA (SANTOS; SANTOS, 2015). 
A ferramenta Moodle permite a criação de vários cursos e cada usuário pode acessar somente seu respectivo curso. Ao criar um curso, pode-se determinar seu início, formato e duração. Essa ferramenta possui várias opções de atividades e formas de avaliação, tais como fórum de discussão, chat em tempo real, glossário de termos e definições, oficina (que permite aos alunos avaliarem os trabalhos dos colegas), fotos e vídeos, documentos diversos (PDF, PPT, DOC, XLS etc), links externos, envío de atividades, enquetes (MARTíN-BLAS; SERRANO-FERNÁNDEZ, 2009; TORI, 2010).

Durante o decorrer do curso, o professor pode visualizar o progresso dos alunos e da turma toda, por meio de relatórios automáticos, tanto por participação e notas quanto por acesso à plataforma. Além disso, essa ferramenta Moodle permite ao professor fazer uma pesquisa de avaliação do curso. Outra vantagem dessa ferramenta é que ela permite aos usuários trocarem mensagens dentro da plataforma. Enfim, apesar de todas essas características facilitadoras do ensino, mesmo os ensinos baseados em metodologias ativas de aprendizagem, é necessário um grande planejamento e trabalho para a elaboração dos conteúdos e da configuração do Moodle para que se tenha um AVA (MARTíN-BLAS; SERRANO FERNÁNDEZ, 2009; TORI, 2010).

Segundo a ASHA (2017) e o Bureau of Labor Statistics (2018), a Fonoaudiologia é uma profissão que deve aumentar em 18\% entre 2016 e 2026, mostrando um crescimento maior que a média das outras profissões nos Estados Unidos da América (EUA). Uma das maiores demandas na Fonoaudiologia está na subárea da Linguagem Infantil englobando a identificação e diagnóstico precoces de tais alterações pelas escolas e com o aumento de crianças multilíngues. Esses dados dão suporte à necessidade de que os fonoaudiólogos generalistas estarem preparados para atender essa demanda específica de linguagem infantil.

No Brasil, existe uma demanda particularmente grande por serviços de Fonoaudiologia para a população infantil. Estima-se que $52,3 \%$ dos clientes têm entre 6 e 12 anos e 67,8\% dos clientes têm distúrbios de linguagem e/ou fala da criança. Essas taxas de prevalência destacam a necessidade de garantir que os 
fonoaudiólogos têm uma base sólida em distúrbios da fala e linguagem da criança (Diniz; Bordin, 2011).

Os requisitos para a formação profissional básica de fonoaudiólogos em todo o mundo são muito heterogêneos. Por exemplo, países como Brasil, Índia, Espanha e Bolívia preparam profissionais em programas de bacharelado para a certificação dupla ("terapeutas da fala e linguagem" e "audiologistas") (Belau; Gasparianni, 2006). Por outro lado, países como EUA, Inglaterra, Canadá, Costa Rica e Portugal preparam profissionais com uma certificação única (apenas terapeutas da fala e linguagem) (Byrne, 2018).

Além disso, o requisito mínimo para a certificação clínica do fonoaudiólogo varia entre os países, por exemplo, Inglaterra, Índia, Portugal e Brasil exigem apenas diploma do curso de bacharelado. Por outro lado, os EUA e o Canadá exigem um mestrado e um exame, e os Estados Unidos também requerem 25 horas em clínica supervisionada e 375 em clínica direta.

Apesar das diferenças na preparação profissional, há informações limitadas na literatura sobre como os fonoaudiólogos se sentem sobre sua preparação para os serviços que prestam. A área da Fonoaudiologia se beneficiaria de informações que pudessem indicar quais deveriam ser os padrões curriculares mínimos para diferentes tipos de prestação de serviços. Ao comparar os padrões de preparação entre os países e as percepções dos fonoaudiólogos sobre a adequação de seu treinamento, podemos ajudar as agências de credenciamento a tomar decisões baseadas em dados sobre os requisitos mínimos de desenvolvimento curricular e profissional.

Como os fonoaudiólogos brasileiros recebem uma base generalista durante a formação a nível de graduação - bacharelado, hipotetizamos que possam ser necessários cursos de educação continuada e desenvolvimento profissional para abordar a questão da necessidade de prática clínica baseada em evidências em áreas específicas, como a intervenção na linguagem infantil. Essas informações podem ajudar a determinar se há uma necessidade percebida de cursos adicionais de 
desenvolvimento profissional para melhorar a prestação de serviços para distúrbios da linguagem infantil e, em caso afirmativo, qual deve ser a principal área de foco.

Muitos países com grandes territórios, como o Brasil, acham difícil oferecer programas de treinamento e desenvolvimento profissional de qualidade para regiões menos densamente povoadas (Copper \& Semich, 2019). O número de fonoaudiólogos brasileiros especializadas em linguagem é relativamente pequeno, como mostra a Tabela 1, e a maioria das instituições educacionais registradas nos campos de Fonoaudiologia no Brasil estão concentradas nos principais centros populacionais conforme ilustrado na Figura 1.

Tabela 1. Número de fonoaudiólogos brasileiros vs os que tem especialização em Linguagem (Conselho Federal de Fonoaudiologia, 2017a, Conselho Federal de Fonoaudiologia, 2017b).

\begin{tabular}{lll}
\hline Região & $\begin{array}{l}\text { Número de fonoaudiólogos } \\
\text { especializados } \\
\text { Linguagem }\end{array}$ & $\begin{array}{l}\text { Número } \\
\text { fonoaudiólogos } \\
\text { brasileiros }\end{array}$ \\
\hline Sudeste & 665 & 23393 \\
Centro-oeste & 118 & 3290 \\
Sul & 116 & 6036 \\
Nordeste & 59 & 7618 \\
Norte & 7 & 2083 \\
Total & 965 & 42420 \\
\hline
\end{tabular}

Figure 1 - Densidade demográfica brasileira e a concentração de instituições de ensino superior em Fonoaudiologia (Instituto Brasileiro de Geografia e Estatística, 2011) 


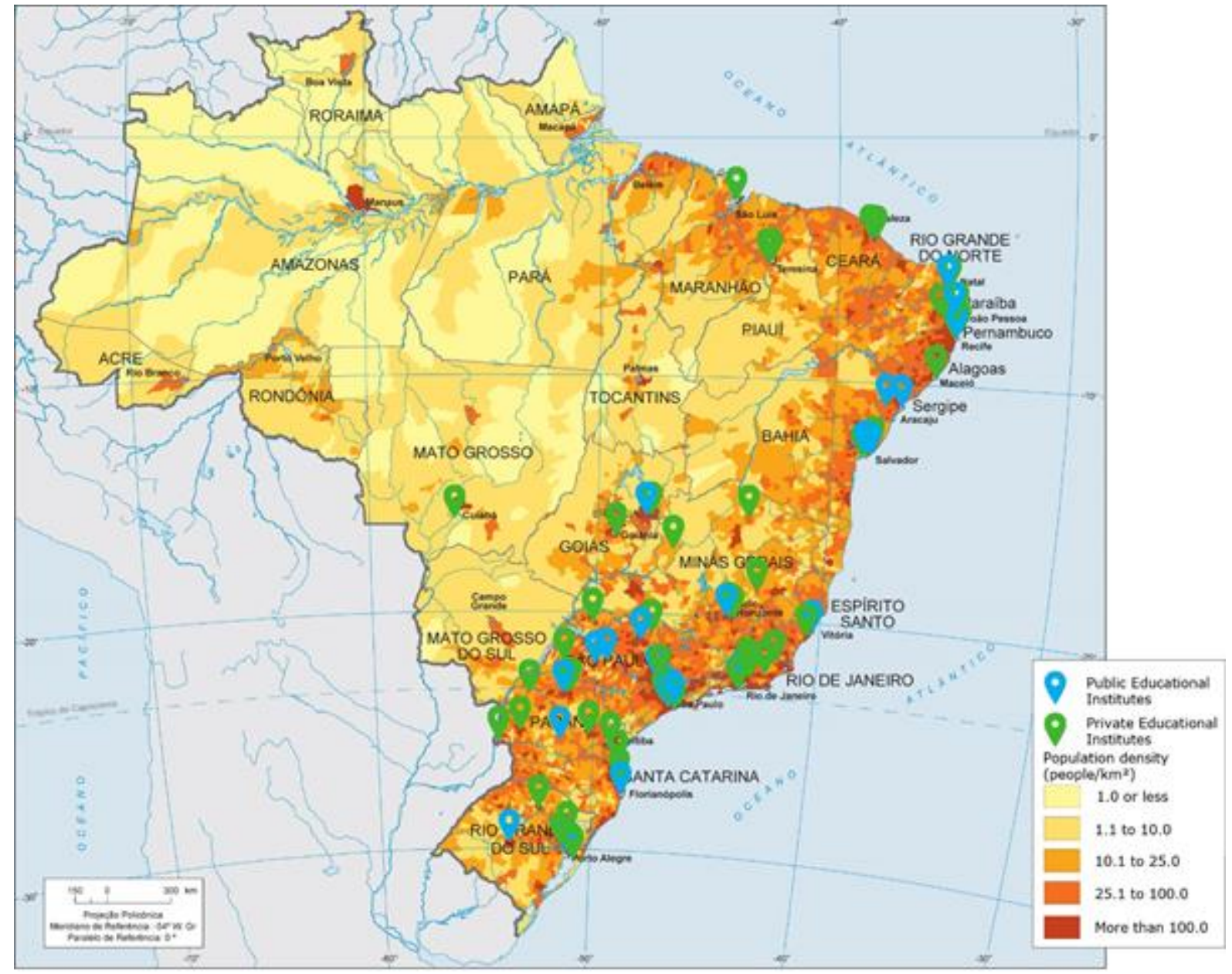

Fonte: Elaborado pelo autor

Os fatores até aqui apresentados fatores contribuem para a escassez de fonoaudiólogos altamente treinados no Brasil, embora as dificuldades educacionais decorrentes de barreiras geográficas não sejam um problema exclusivo da Fonoaudiologia Brasileira. Situações semelhantes podem ser observadas em outros campos no Brasil (Celeste et al., 2017), bem como em países com características semelhantes (Jamil; Hamre, 2018; Powell; Bodur,, 2019).

Assim, levantamos a hipótese de que o sistema de distribuição da educação brasileira na Fonoaudiologia como um todo é heterogêneo em certas regiões, sendo necessário treinamento on-line para melhorar as oportunidades de desenvolvimento educacional e profissional em países com grandes territórios e sistema educacional altamente concentrado. $\mathrm{O}$ objetivo deste projeto foi examinar se os cursos a distância podem superar as barreiras geográficas e preencher a lacuna educacional entre as diferentes regiões do país. 
Desta forma, visando minimizar as barreiras geográficas existentes no Brasil e proporcionar educação continuada a todos os fonoaudiólogos interessados, este trabalho visou a elaboração de um curso de atualização via Ensino a Distância $(\mathrm{EaD})$ com a finalidade de aprimorar e atualizar os conhecimentos dos fonoaudiólogos acerca da intervenção em Linguagem Infantil, bem como, consequentemente, melhorar os atendimentos fonoaudiológicos na referida área. 


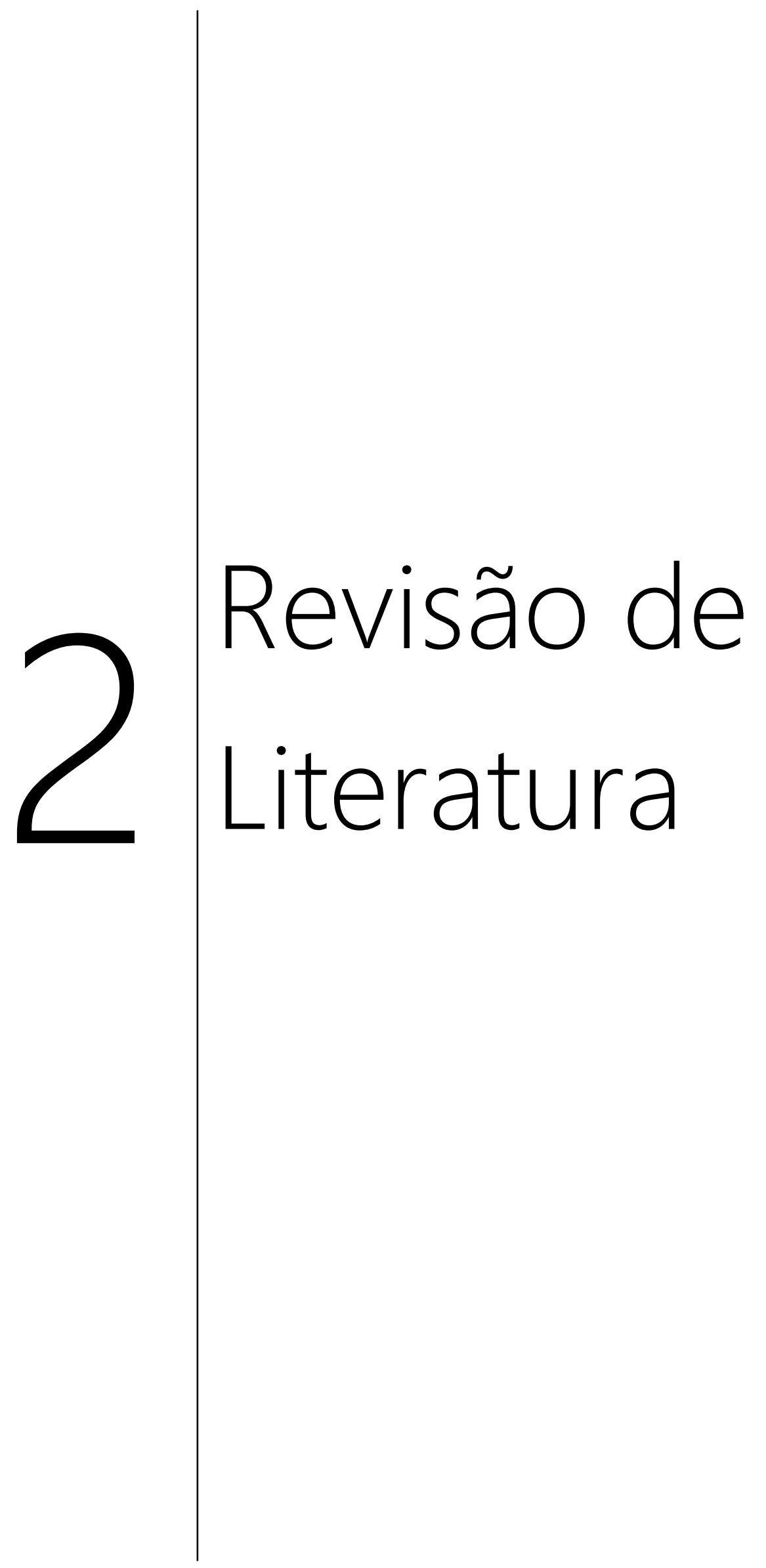





\section{2 - REVISÃO DE LITERATURA}

2.1 - Metodologia da Revisão

Para que a revisão de literatura se mantivesse imparcial foi realizado um mapeamento sistemático da literatura. Desta forma, pôde-se verificar o estado da arte com relação à educação continuada em Fonoaudiologia com um bom nível de evidência.

A educação e atualização continuada de profissionais é essencial em todas as profissões, por isso são necessárias ações e recursos efetivos para tal. Assim, pretende-se mapear cursos, recursos ou ações para educação continuada de fonoaudiólogos, sendo o enfoque na descrição, validação e avaliação deles. Além disso, também serão mapeadas as ações de educação continuada para os demais profissionais da saúde, seguindo os mesmos parâmetros para possibilitar uma comparação entre as ações, envolvendo fonoaudiólogos com outros profissionais de saúde.

O objetivo desta revisão é a descrição das ações de educação continuada, encontradas na literatura, para os profissionais fonoaudiólogos bem como comparar o estado da arte da educação continuada na Fonoaudiologia com as outras áreas da saúde.

Com o intuito de definir o escopo desta revisão, foram estabelecidos alguns critérios para garantir a viabilidade da execução (custo, esforço e tempo), acessibilidade aos dados e abrangência do mesmo. O primeiro critério foi considerar apenas as publicações escritas na língua inglesa ou portuguesa. Além disso, não houve restrição de ano na seleção dos artigos.

Já o segundo critério, foi a seleção das bases de dados, sendo que foram escolhidas as seguintes bases:

- Scopus;

- Web of Science; e 
- Biblioteca Digital Brasileira de Teses e Dissertações.

\subsection{1 - Método de Busca}

Inicialmente, foi feita uma busca automática, com base em uma expressão lógica, visando levantar um conjunto de estudos primários. Os resultados foram analisados na íntegra. Em seguida, as listas de referências dos primeiros estudos encontrados foram lidas em busca de mais estudos, em um processo também conhecido como "Snowballing" o qual se repetiu até que se chegasse a um nível de saturação, onde novos estudos não puderam mais ser identificados.

Para se chegar à expressão lógica, também chamada de string de busca, adotada nas bases de dados, foi realizado um processo de teste e refinamento da mesma, que seguiu os seguintes passos: primeiramente, foram estudados os resultados obtidos nas bases de dados e/ou referências acima descritas, utilizando as palavras-chave "educação continuada" e "fonoaudiologia" combinadas e, em seguida, "educação continuada" e "profissionais de saúde" também combinadas. Depois disso, foram analisados os artigos já citados no desenvolvimento desta tese, com o objetivo de se estabelecer as palavras-chave mais usadas. O terceiro passo, foi a adaptação dos parâmetros da busca para o protocolo Preferred Reporting Items for Systematic Reviews and Meta-Analyses (PRISMA), que traz diretrizes para revisões sistemáticas, incluindo a construção de strings de busca.

- População: Fonoaudiólogos ou profissionais da saúde.

- Intervenção: cursos, treinamentos, ações ou recursos de educação continuada, desenvolvimento profissional, atualização profissional ou aprimoramento profissional;

- Comparação: Não há comparação entre os resultados, justamente por ser um mapeamento sistemático e, não, uma revisão; e

- Saída: estudos descritivos, pesquisa-ação, estudos de produção tecnológica, pesquisas de validação de conteúdo e estudos de verificação de eficácia. 
Desta maneira, as expressões escolhidas e utilizadas foram:

- População:

("Fonoaudiologia" OR " Speech-Language Therapist" OR "Audiologist" OR "Audiologista" OR "profissional da saúde" OR "health professional")

- Intervenção:

(("cursos" OR "courses" OR " treinamentos" OR "training” OR "workshops" OR "recursos" OR "resources") AND ("educação continuada" OR "continuing education" OR "desenvolvimento profissional" OR "professional development" OR "atualização" OR "update" OR "refreshment" OR "aprimoramento" OR "specialization"))

- Saída:

("descritivo" OR "descriptive" OR "pesquisa-ação" OR "actionresearch" OR "produção tecnológica" OR "technological production" OR "technological development" OR " validação de conteúdo" OR "content validation" OR "eficácia" OR "efficacy")

Com isso, a expressão lógica foi adaptada a cada base de dados.

- Scopus:

TITLE-ABS-KEY ( ( "Fonoaudiologia" OR " Speech-Language Therapist" OR "Audiologist" OR "Audiologista" OR "profissional da saúde" OR "health professional" ) AND ( ( "cursos" OR "courses" OR " treinamentos" OR "training" OR "workshops" OR "recursos" OR "resources" ) AND ( "educação continuada" OR "continuing education" OR "desenvolvimento profissional" OR "professional development" OR "atualização" OR "update" OR "refreshment" OR "aprimoramento" OR "specialization" ) ) AND ( "descritivo" OR "descriptive" OR "pesquisa-ação" OR "actionresearch" OR "produção tecnológica" OR "technological 
production" OR "technological development" OR " validação de conteúdo" OR "content validation" OR "eficácia" OR "efficacy" )) AND ( LIMIT-TO ( SUBJAREA, "MEDI" ) )

- Web of Science:

TS=( ( "Fonoaudiologia" OR " Speech-Language Therapist" OR "Audiologist" OR "Audiologista" OR "profissional da saúde" OR "health professional" ) AND ( ( "cursos" OR "courses" OR " treinamentos" OR "training" OR "workshops" OR "recursos" OR "resources" ) AND ( "educação continuada" OR "continuing education" OR "desenvolvimento profissional" OR "professional development" OR "atualização" OR "update" OR "refreshment" OR "aprimoramento" OR "specialization" ) ) AND ("descritivo" OR "descriptive" OR "pesquisa-ação" OR "action-research" OR "produção tecnológica" OR "technological production" OR "technological development" OR " validação de conteúdo" OR "content validation" OR "eficácia" OR "efficacy" ) )

- Biblioteca Digital Brasileira de Teses e Dissertações: (Todos os campos:( ( "Fonoaudiologia" OR " Speech-Language Therapist" OR "Audiologist" OR "Audiologista" OR "profissional da saúde" OR "health professional" ) AND ( ( "cursos" OR "courses" OR " treinamentos" OR "training" OR "workshops" OR "recursos" OR "resources" ) AND ( "educação continuada" OR "continuing education" OR "desenvolvimento profissional" OR "professional development" OR "atualização" OR "update" OR "refreshment" OR "aprimoramento" OR "specialization" ) ) AND ( "descritivo" OR "descriptive" OR "pesquisa-ação" OR "action-research" OR "produção tecnológica" OR "technological production" OR "technological development" OR " validação de conteúdo" OR "content validation" OR "eficácia" OR "efficacy" ) ))

\subsection{2 - Procedimentos de Seleção e Critérios}


Os procedimentos de seleção dos artigos seguiram quatro etapas:

2.1.2.1 - 1ํㅡㄹ Etapa: Seleção e Catalogação Preliminar:

Esta etapa foi realizada a partir da utilização da expressão lógica nas bases de dados selecionadas. Todas as publicações retornadas pelas bases foram catalogadas para análise posterior e aplicação dos filtros de exclusão.

2.1.2.2 $-2^{\mathrm{a}}$ Etapa: Remoção das publicações duplicadas:

Com o uso de diversas bases de dados, pode ocorrer duplicações das publicações, pois revistas, jornais e conferências podem indexar suas publicações em diversas bases. Logo, é necessário verificar a existência de duplicações nas publicações encontradas.

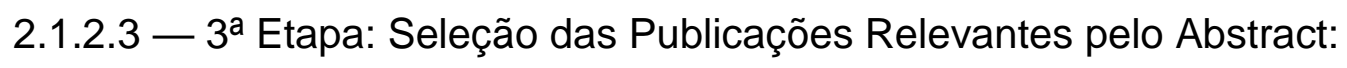

A seleção das publicações através de expressões lógicas, não garantem que todas as publicações sejam relevantes para este contexto, pois a aplicação dos critérios é restrita ao aspecto sintático da string de busca. Sendo assim, todos os resumos foram lidos e analisados de acordo com os seguintes critérios de inclusão:

- Critério de Inclusão 1: Publicações que tratavam da descrição, validação ou avaliação de cursos, recursos ou ações de educação continuada;

- Critério de Inclusão 2: Publicações escritas em língua inglesa ou portuguesa; e

- Critério de Inclusão 3: Publicações que tenham seu manuscrito completo disponível para download.

Cada publicação foi selecionada para a próxima etapa apenas se cumprisse com todos os critérios de inclusão descritos. Para diminuir o risco de que uma publicação fosse excluída prematuramente, em caso de dúvida ou não existência de abstract, ela foi considerada como válida. 
2.1.2.4 - 4⿳亠丷厂 Etapa: Seleção das Publicações Relevantes pelo Texto Completo:

Apesar de toda a verificação da $2^{\text {a }}$ etapa, pode ocorrer que algumas publicações não tenham sido excluídas na referida etapa; portanto, após a leitura completa do texto, foram aplicados todos os critérios de inclusão apresentados na referida etapa. Para facilitar a organização do mapeamento sistemático, a seleção dos artigos e a detecção dos artigos duplicados, foi usada a ferramenta StArt, que é um apoio a revisões e mapeamentos sistemáticos. Essa ferramenta segue as etapas de seleção descritas anteriormente e detecta automaticamente os artigos duplicados. Além disso, a ela permite a importação dos resultados das bases de dados e, também, a classificação da prioridade de leitura dos artigos (ZAMBONI et al., 2010).

\section{2 - RESULTADOS DA PESQUISA}

Após a definição de todos os critérios da Pesquisa, este estudo foi executado entre setembro e dezembro de 2019 com a utilização da expressão lógica apresentada e executada nas bases de dados Scopus, Web of Science e a Biblioteca Digital Brasileira de Teses e Dissertações. Inicialmente, foram retornadas 180 publicações, sendo 91, encontradas na Scopus; 13, Web of Science; e, 76, na Biblioteca Brasileira de Teses e Dissertações.

Após a execução da $2^{\text {a }}$ etapa, que compreendeu a remoção das duplicações existentes, restaram 177 publicações, pois três foram removidas devido à duplicação. Com a execução da $3^{\text {a }}$ etapa dos procedimentos de seleção, que envolvia a leitura do título e do abstract de todas as publicações, seguindo os critérios de inclusão, foram selecionadas 46 publicações, sendo 27, encontradas na Scopus; quatro, Web of Science; e, 15, na Biblioteca Digital Brasileira de Teses e Dissertações. Durante $4^{a}$ etapa de seleção, que envolvia a leitura completa de todas as publicações, foram selecionadas 10 publicações, segundo os critérios de inclusão prédeterminados. Dessas dez publicações nenhuma era relacionada à educação 
continuada de fonoaudiólogos e todas as publicações são estudos relacionados à educação continuada de outros profissionais de saúde.

Chambers, Stodart e Sullivan (1983) descrevem um workshop voltado aos profissionais de saúde e de administração em instituições de saúde para que aprendessem a consumir criticamente pesquisas sobre atenção à saúde no Canadá. Foram realizados 11 workshops com duração entre um e dois dias cada, com a referida temática onde participaram cerca de 350 profissionais ao todo. Os participantes avaliaram os workshops ao final e, também, um questionário de acompanhamento após um ano. A avaliação foi positiva e os principais achados foram de que a maioria dos profissionais não tinha o hábito de acompanhar pesquisas acadêmicas tão pouco estavam acostumados com práticas baseadas em evidências em sua educação continuada. Além disso, eles relataram que o formato de um ou dois dias de duração foi excelente, pois eles puderam participar dos workshops sem ter prejuízos grandes em sua rotina de trabalho.

Osakwe et al. (2013) foram autores de um estudo onde profissionais da saúde que participaram de um treinamento sobre farmacovigilância responderam a questionários pré e pós treinamento para verificar a efetividade do mesmo. Não há no estudo, descrição de metodologia de ensino, recursos ou demais aspectos que possam descrever o treinamento em questão. Os resultados do estudo foram que 0 treinamento foi eficaz na melhora do conhecimento e da prática dos profissionais no referente assunto, contudo o impacto geral do treinamento foi considerado mediano.

Masters et al. (2017) publicaram um relatório referente a melhora na qualidade do serviço oferecido por profissionais de saúde da Austrália decorrentes de uma ação educativa. Tal ação tinha como público-alvo estudantes de graduação e profissionais já graduados atuantes em regiões remotas da Austrália, uma vez que os mesmos tinham pouco acesso a treinamentos e atualização profissional. As ações aconteceram presencialmente na região onde os profissionais atuavam por meio de educadores/moderadores que foram treinados especificamente para realizar as ações no formato de simulação de habilidades clínicas, onde os envolvidos revezavam entre os papéis de profissional da saúde e pacientes. A ação superou as expectativas dos proponentes, pois as horas de simulação foram maiores que o planejado justamente 
pelo interesse dos estudantes e profissionais envolvidos; o custo-benefício foi alto, pois houve o deslocamento apenas do educador/moderador para o treino inicial (o mesmo já residia na área-alvo) e esse custo de deslocamento ocorreu uma única vez, porque no futuro esse educador já estará apto a treinar novos estudantes e profissionais. Por fim, os autores notaram que o treinamento de profissionais em áreas remotas é extremamente significativo para esses profissionais, além de que a ação de envolver profissionais-centrais, que atuarão como educadores/moderadores continuamente nessas áreas remotas, trouxe motivação e sustentabilidade para essa ação, pois o custo para a implementação da mesma é relativamente baixo.

Ainda sobre a simulação para treinamento de profissionais de saúde, Thomsen et al. (2015) realizaram uma revisão sistemática da literatura sobre as simulações utilizadas nas áreas cirúrgicas e de avaliação na oftalmologia. Não foram encontrados estudos quantitativos o suficiente para que uma metanálise fosse performada, contudo foram encontrados 118 publicações que puderam ser utilizadas numa análise descritiva. Destes 118 estudos, a maioria (45\%) era relacionada à realidade virtual, seguido do uso de animais para o treinamento (28\%), uso de peças inanimadas (14\%) e, por fim, o uso de cadáveres (13\%). O estudo concluiu que as pesquisas utilizadas na revisão, de forma geral, possuem baixa evidência de efetividade nos métodos de simulação utilizados o que impactou para que o estudo não pudesse trazer conclusões para que um método de simulação pudesse ser apontado como mais efetivo ou, ainda, utilizado como método de educação continuada, ou avaliação de habilidades profissionais.

Devido à necessidade do uso de recursos tecnológicos, incluindo o uso de e-health, para a educação continuada de profissionais da saúde, Lam, Nguyer e Campbell (2013) conduziram um estudo do tipo survey para verificar se os profissionais de saúde da Austrália conseguiriam utilizar o recurso de forma efetiva. $O$ questionário foi aplicado antes deles terem acesso às ferramentas de e-health, dentro de um curso de extensão sobre tecnologias aplicadas à saúde pública e após a realização do curso, de forma a verificar se o uso de e-health seria suficiente para a atualização profissional ou se os mesmos necessitariam de treinamento explícito para tal. Como resultado, foi observado uma melhora estatisticamente significante em 
conhecimentos sobre e-health, base de dados, planilhas e manipulação de dados (que foram considerados pré-requisito para o uso do e-health). Sendo assim, os autores concluíram que além de tendência, o e-health é passível de ser utilizado como recurso de educação continuada na área da saúde, pois não há necessidade de treinos explícitos para que esses profissionais sejam capazes de utilizar o recurso em sua totalidade.

Para avaliar a eficácia de um curso online para nutricionistas, nutrólogos e outros profissionais de saúde que trabalham com a nutrição sobre a temática "Prevenção da Obesidade Infantil" Stark et al. (2011) conduziram um estudo quasiexperimental onde 105 profissionais participaram do referido curso e outros 37 tiveram sua participação atrasada para que os mesmos pudessem compor o grupo controle. Foram oferecidas seis turmas entre os anos de 2006 e 2008. O curso de aprimoramento teve um estudo piloto prévio para que pudessem ser realizados os ajustes necessários antes da aplicação geral. Cada edição do curso durou seis semanas e foi utilizada a plataforma eCornell com diversos recursos, sendo videoaulas com base em slideshow a mais frequente. Por mais que houvesse data de início e data de término, o curso seguia como um MOOC (Massive Open Online Course) onde cada aluno avançava no curso em seu próprio ritmo. Havia um tutor (mediador) que acompanhava todas as turmas e agia como um facilitador de aprendizagem, inclusive auxiliando os alunos a encontrarem seu próprio ritmo. $O$ curso teve resultados estatisticamente significantes mostrando melhora no conhecimento teórico, na avaliação de auto-eficácia e na elaboração de planos de ação dos profissionais que realizaram o curso. Como conclusão, o estudo mostrou que curso online como uma ferramenta de aprimoramento de profissionais atuantes em ações de saúde pública relacionada à área de nutrição infantil se mostrou eficaz, o que traz indícios que em outras situações onde profissionais da saúde que trabalham com saúde pública também podem se beneficiar desse tipo de treinamento.

Trhukal et al. (2012) conduziram um estudo para a avaliação de um curso online na área de "Orientações pré-natal" na Índia. O estudo teve foco na aplicação de cursos online como ferramenta de educação continuada em países em desenvolvimento, aplicado em sete diferentes sites, sendo seis na Índia e um nas Maldivas entre maio e junho de 2011. Cada um dos sites teve sua turma no curso e 
para cada turma havia dois tutores/moderadores especializados que mediaram todo o processo de aprendizagem dos alunos. O curso contou com dez núcleos temáticos e utilizou os seguintes recursos: videoaulas, materiais para leitura, vídeos demonstrativos e estudos de caso, além de links externos com materiais como os manuais da Organização Mundial de Saúde, por exemplo. O curso durou cinco semanas, onde em cada semana apresentaram-se dois núcleos temáticos. Comparando algumas habilidades como conhecimento teórico e aprimoramento de habilidades práticas pré e pós curso, houve uma melhora estatisticamente significante, indicando que o curso teve eficácia na situação em questão. Os autores concluíram que cursos online podem ser uma ferramenta valiosa de educação continuada em países em desenvolvimento devido ao baixo custo e, também, à necessidade de melhorar os serviços de saúde prestados à comunidade.

Outro curso online para profissionais da saúde foi o descrito em 2001 por Farel, Amble e Polhamus, cujo foco foi o treinamento de habilidades analíticas para aqueles que trabalhavam com saúde da criança. Não foram encontradas informações suficientes sobre a estrutura do curso. Participaram do curso 28 profissionais durante três a seis meses e, apenas, cinco completaram na íntegra os seis módulos do curso. Eles tiveram uma melhora estatisticamente significante nas três dimensões avaliadas no estudo: auto-eficiência, conhecimentos teóricos e paradigmas. Seis meses depois foi aplicado um questionário de acompanhamento, onde 23 deles responderam 0 mesmo, e que tiveram um aumento significante nas habilidades, mostrando que 0 curso serviu de base para que os profissionais continuassem atualizando e aprimorando a sua prática no trabalho. Os profissionais também relataram estarem satisfeitos com o curso e que o mesmo teve melhora em sua prática profissional, mas que ainda não foram capazes de utilizar todas as habilidades aprendidas no curso. Além disso, 18 profissionais reportaram que, após o referido curso, o interesse deles em cursos a distância aumentou.

Maloney et al. (2015) conduziram um estudo com metodologia híbrida para verificar se as mídias sociais poderiam ser uma ferramenta efetiva na associação das evidências científicas e da prática profissional. Foi elaborado um curso de curtaduração disponibilizado no Facebook e no Twitter, onde foram abordados oito temas 
ao longo de duas semanas. Foram utilizadas instruções em vídeos, onde cada uma das legendas continha ao menos um link para publicação de acesso aberto sobre o tema. Além disso, os participantes também eram incentivados a usar as opções comentários e resposta para discutir pontos e compartilhar experiências com os demais participantes. Os pesquisadores obtiveram bons resultados com 0 experimento que indicou que as mídias sociais podem ser utilizadas como uma ferramenta de educação continuada em alguns tópicos, principalmente pela facilidade de acesso e potencial de alcance, contudo, ainda existem algumas restrições de recursos e nível de segurança que dificultam a utilização das mesmas para todas as temáticas envolvendo os profissionais da saúde.

Souza (2013), em sua tese de doutorado, fez uma descrição integrativa de um sistema de educação continuada baseada nas publicações da Revista Brasileira de Cirurgia Cardiovascular (RBCC). Os médicos associados à Associação Brasileira de Cirurgia Cardiovascular precisam, para fins de atualização, uma determinada carga-horária em cursos de educação continuada ao ano. Pensando nisso, a autora em conjunto com a RBCC criou um sistema que fica integrado ao site da revista onde diversos artigos têm a função/botão "educação médica continuada". Ao clicar neste botão, os assinantes da revista podem visualizar outros artigos com a mesma temática e, também, responder a um questionário que analisa a interpretação do artigo. Sendo assim, caso o leitor tenha nota suficiente no questionário (mostrando que ele realmente entendeu o artigo) o mesmo recebe um certificado de "educação médica continuada" com carga-horária correspondente a horas de estudo dirigido para leitura do artigo, facilitando então o acesso aos médicos a tais recursos. O estudo não traz resultados de eficácia do sistema desenvolvido, mas indica que houve satisfação por meio dos médicos que utilizaram o sistema, mostrando que esse é um recurso que tem adesão da população-alvo e que houve aumento no número de acessos aos artigos da revista, que indica que o sistema pode auxiliar no hábito de leitura de artigos acadêmicos pelos profissionais clínicos.

\section{3 - CONSIDERAÇÕES FINAIS}

Analisando o mapeamento sistemático da literatura aqui apresentado, podemos notar que as publicações acerca da educação continuada de profissionais 
da saúde que tragam informações detalhadas sobre as ações realizadas ou então, estudos de eficácia, ainda são escassos, mesmo tendo diversas associações ou conselhos profissionais que requerem tal prática. Contudo, notamos também que este não é um tema recente, e que a primeira publicação deste mapeamento e do ano de 1983. Muitos dos estudos encontrados sugeriam que mais estudos fossem realizados para verificação de eficácia dos cursos ou recursos utilizados, porém não foram encontrados tais estudos de continuidade desses trabalhos.

Com relação à área da Fonoaudiologia, nenhuma publicação com a temática foi encontrada. Nota-se então a necessidade da elaboração de estudos nesse sentido para que a educação continuada dos fonoaudiólogos possa ser baseada em evidências científicas e para que tenhamos dados que sirvam de suporte para a legislação, fiscalização e implementação de tais ações. 


$$
3 \text { objetivo }
$$





\section{3 - OBJETIVO}

\section{1 - OBJETIVO GERAL}

O objetivo principal deste trabalho foi desenvolver, aplicar e avaliar um curso online para o treinamento de fonoaudiólogos em intervenção na Linguagem Infantil.

\section{2 - OBJETIVOS ESPECÍFICOS}

- Investigar a percepção dos fonoaudiólogos em sua formação, durante a graduação em Fonoaudiologia, no tocante à intervenção em linguagem oral infantil, bem com suas experiências, expectativas e necessidades clínicas acerca do referido tema.

- Desenvolver colaborativamente e aplicar um curso online para o treinamento de fonoaudiólogos em intervenção na Linguagem Infantil.

- Avaliar o desempenho e a satisfação de fonoaudiólogos com um curso online sobre intervenção em linguagem infantil, realizado em um ambiente virtual de aprendizagem, no formato a distância. 



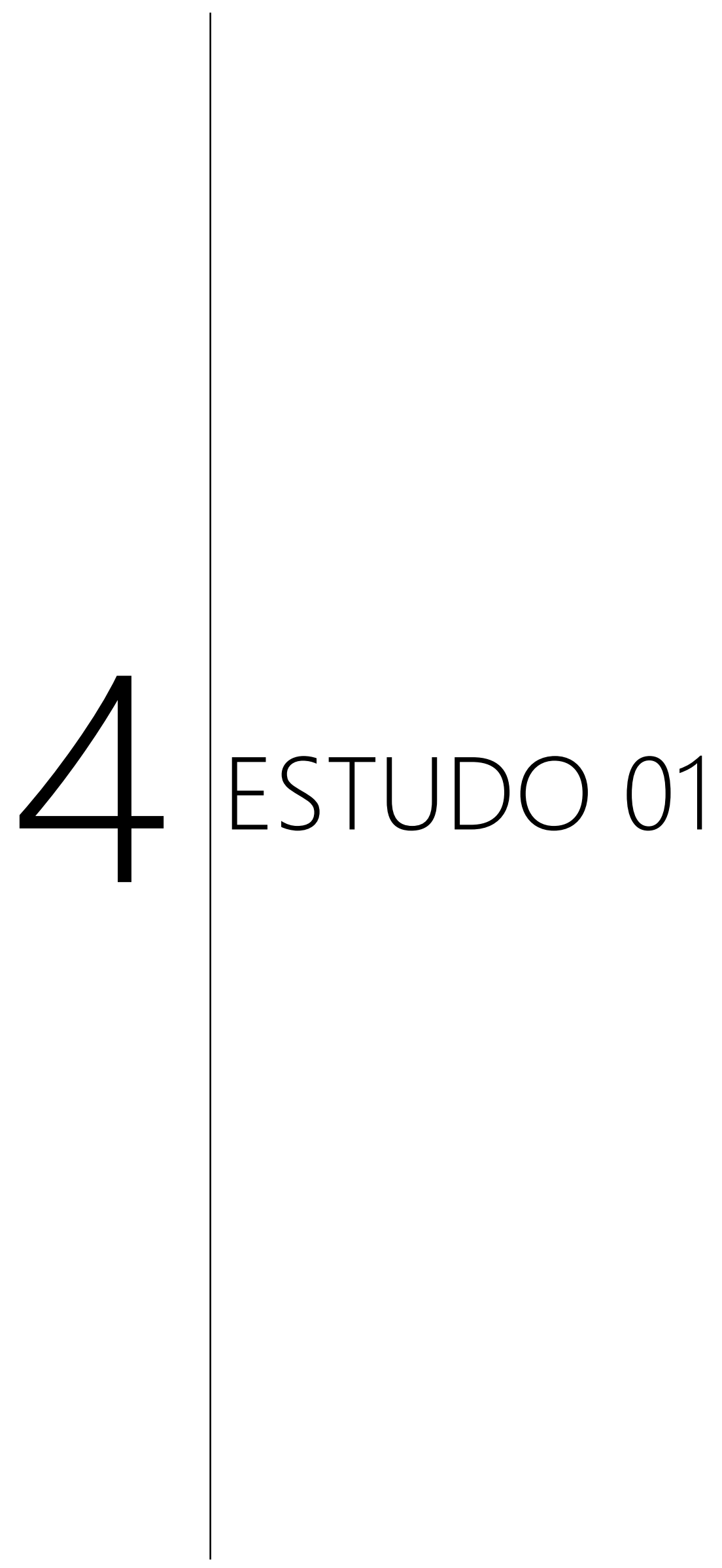





\section{4 - ESTUDO 01: EXPERIÊNCIAS E PERSPECTIVAS DE FONOAUDIÓLOGOS QUANTO À FORMAÇÃO E PRATICA PROFISSIONAL NA INTERVENÇÃO DAS ALTERAÇÕES DE LINGUAGEM INFANTIL}

\section{1 - METODOLOGIA}

\subsection{1 - Ética na Pesquisa}

O estudo foi aprovado (Anexo A) pelo Comitê de Ética em pesquisa com Seres Humanos da Faculdade de Odontologia de Bauru (FOB) - USP, sob o número do parecer 2.062.999. Nenhuma etapa de coleta foi iniciada antes da aprovação do mesmo. Os participantes da pesquisa assinaram o Termo de Consentimento Livre e Esclarecido (Apêndice A). O projeto foi elaborado de forma a respeitar a Resolução 466/12 do Conselho Nacional de Saúde.

\subsection{2 - Objetivo}

O presente estudo teve como objetivo investigar a percepção dos fonoaudiólogos em sua formação, durante a graduação em Fonoaudiologia, no tocante à intervenção em linguagem oral infantil, bem como suas experiências, expectativas e necessidades clínicas acerca do referido tema.

\subsection{3 - Desenho do Estudo}

Foi realizado um estudo indutivo analítico com entrevistas semiestruturadas para compreender a realidade do desenvolvimento profissional dos fonoaudiólogos no campo da intervenção em linguagem infantil, bem como suas necessidades e expectativas. Este foi o primeiro passo utilizado nesta tese para desenvolver um curso de treinamento profissional on-line baseado em um design colaborativo, ou seja, que foi construído levando em consideração as necessidades do público-alvo (FILATRO, 2008; ISO, 2010).

\subsection{4 - Entrevistadora}


As entrevistas foram realizadas pela própria pesquisadora, fonoaudióloga com mestrado em Linguagem Infantil. Anteriormente à entrevista, eram apresentados os objetivos e métodos da pesquisa, bem como a trajetória acadêmica da entrevistadora. Em seguida, apresentavam-se as questões éticas envolvidas neste estudo e esclarecimentos às dúvidas que poderiam surgir ${ }^{1}$.

\subsection{5 - Critérios de Seleção}

O estudo seguiu os seguintes critérios para a seleção da amostra:

- ter anuência para a participação do estudo que será comprovado pelo Termo de Consentimento Livre e Esclarecido devidamente assinado pelos mesmos;

- para os Fonoaudiólogos: ter disponibilidade e interesse em participar do curso de atualização;

- para os Docentes: serem doutores em Linguagem e terem experiência em Estimulação de Linguagem Oral e docência na graduação;

- para os designers: atuação na área e curso superior na área de design, imagem e som ou outras correlatas.

Por sua vez, o critério de exclusão consistiu em:

- não apresentar o Termo de Consentimento Livre e Esclarecido assinado.

O recrutamento foi realizado por meio de mídias sociais (Facebook, Instagram e Linkedin). Porém, alguns participantes foram contatados pessoalmente e selecionados por indicação profissional e interesse em participar da pesquisa. Nenhum participante desistiu. 


\subsection{6 - Local}

Todos os procedimentos foram realizados na FOB - USP.

Contudo, cada participante do estudo escolheu o local de sua preferência para realizar a entrevista. Sendo assim, três participantes foram entrevistados (online) de suas residências via videoconferência por Skype; dois entrevistados também por meio de Skype, em sua clínica e, três entrevistas presenciais no laboratório de pesquisa.

No momento da entrevista, apenas a pesquisadora que realizou a entrevista e o participante estavam presentes. A tabela a seguir mostra as características dos participantes.

\subsection{7 - Participantes}

Participaram deste estudo 8 fonoaudiólogos que trabalham em clínica com intervenção na linguagem infantil. A amostragem foi orientada pela técnica de saturação (GUEST; BUNCE; JOHNSON, 2006). A entrevista foi gravada, transcrita e codificada. Contudo, a pesquisadora continuou a realizar novas entrevistas (aumentando a amostragem do estudo) até que novas informações relevantes (descritas em categorias ou nós) não fossem mais encontradas.

Inicialmente, os participantes responderam a um formulário on-line com informações básicas (nome, e-mail, telefone e região do Brasil onde trabalham) e foram separados por região e contatados aleatoriamente, respeitando a proporção de estratificação. Os dados para a construção do perfil dos participantes foram organizados na Tabela 2.

Características dos participantes. 
Tabela 2.

\begin{tabular}{|c|c|c|c|c|c|c|c|c|}
\hline Participa & Ida & Tempo de & Instituiçã & Cursos & Especializa & Mestrad & Doutora & Área de \\
\hline nte & de & $\begin{array}{l}\text { Atuação } \\
\text { na } \\
\text { Fonoaudiol } \\
\text { ogia }\end{array}$ & $\begin{array}{l}0 \quad \text { de } \\
\text { Graduaçã } \\
\text { O* }^{*}\end{array}$ & $\begin{array}{l}\text { de } \\
\text { atualiza } \\
\text { ção em } \\
\text { Linguag } \\
\text { em } \\
\text { Infantil }\end{array}$ & $\begin{array}{l}\text { ção em } \\
\text { Linguagem } \\
\text { Infantil }\end{array}$ & $\begin{array}{l}\text { o em } \\
\text { Linguag } \\
\text { em } \\
\text { Infantil }\end{array}$ & $\begin{array}{l}\text { do em } \\
\text { Linguag } \\
\text { em } \\
\text { Infantil }\end{array}$ & atuação \\
\hline 1 & 38 & 4 & Unifesp & $\begin{array}{l}\text { Complet } \\
\text { o }\end{array}$ & Nenhum & $\begin{array}{l}\text { Nenhu } \\
\mathrm{m}\end{array}$ & $\begin{array}{l}\text { Nenhu } \\
\mathrm{m}\end{array}$ & Clínica \\
\hline 2 & 52 & 12 & Unorp & $\begin{array}{l}\text { Complet } \\
\text { o }\end{array}$ & Em curso & $\begin{array}{l}\text { Nenhu } \\
\mathrm{m}\end{array}$ & $\begin{array}{l}\text { Nenhu } \\
\mathrm{m}\end{array}$ & $\begin{array}{l}\text { Clínica, } \\
\text { Escola } \\
\text { e } \\
\text { Hospita } \\
\text { I }\end{array}$ \\
\hline 3 & 47 & 16 & $\begin{array}{l}\text { UNIP } \\
\text { São José } \\
\text { do Rio } \\
\text { Preto - } \\
\text { SP }\end{array}$ & $\begin{array}{l}\text { Complet } \\
\text { o }\end{array}$ & Completo & $\begin{array}{l}\text { Nenhu } \\
\mathrm{m}\end{array}$ & $\begin{array}{l}\text { Nenhu } \\
\mathrm{m}\end{array}$ & Clínica \\
\hline 4 & 23 & 0 & $\begin{array}{l}\text { USP- } \\
\text { Bauru }\end{array}$ & Nenhum & Nenhum & $\begin{array}{l}\text { Nenhu } \\
\mathrm{m}\end{array}$ & $\begin{array}{l}\text { Nenhu } \\
\mathrm{m}\end{array}$ & Clínica \\
\hline 5 & 40 & 18 & $\begin{array}{l}\text { PUC - } \\
\text { Goiás }\end{array}$ & $\begin{array}{l}\text { Em } \\
\text { curso }\end{array}$ & Nenhum & $\begin{array}{l}\text { Nenhu } \\
\mathrm{m}\end{array}$ & $\begin{array}{l}\text { Nenhu } \\
\mathrm{m}\end{array}$ & Clínica \\
\hline 6 & 40 & 17 & $\begin{array}{l}\text { Universid } \\
\text { ade Tuiuti } \\
\text { do } \\
\text { Paraná }\end{array}$ & Nenhum & Nenhum & $\begin{array}{l}\text { Nenhu } \\
\mathrm{m}\end{array}$ & $\begin{array}{l}\text { Nenhu } \\
\mathrm{m}\end{array}$ & Clínica \\
\hline 7 & 37 & 17 & UNIP & Nenhum & Nenhum & $\begin{array}{l}\text { Nenhu } \\
\mathrm{m}\end{array}$ & $\begin{array}{l}\text { Nenhu } \\
\mathrm{m}\end{array}$ & $\begin{array}{l}\text { Acade } \\
\text { mia, } \\
\text { Clínica, } \\
\text { Escola }\end{array}$ \\
\hline 8 & 26 & 4 & $\begin{array}{l}\text { UNESP - } \\
\text { Marília }\end{array}$ & $\begin{array}{l}\text { Complet } \\
\text { o }\end{array}$ & Nenhum & $\begin{array}{l}\text { Em } \\
\text { curso }\end{array}$ & $\begin{array}{l}\text { Nenhu } \\
\mathrm{m}\end{array}$ & $\begin{array}{l}\text { Clínica, } \\
\text { Hospita }\end{array}$ \\
\hline
\end{tabular}

*Siglas das instituições: Unifesp: Universidade Federal de São Paulo; Unorp: Centro Universitário do Norte Paulista; UNIP: Universidade Paulista; USP: Universidade de São Paulo; PUC: Pontifícia Universidade Católica; UNESP: Universidade Estadual Paulista. 


\subsection{8 - Coleta de Dados}

Todas as entrevistas seguiram um roteiro semiestruturado (Apêndice B), previamente analisado por um comitê de três juízes (três pesquisadores, sendo dois fonoaudiólogos e um não fonoaudiólogo com experiência em pesquisa qualitativa). A entrevistadora realizou algumas anotações qualitativas durante a realização das entrevistas que tiveram a duração entre 13 e 41 minutos.

\subsection{9 - Transcrição das Entrevistas}

Foram realizadas 8 entrevistas, entre $00 \mathrm{~h}: 13 \mathrm{~m}: 50 \mathrm{~s}$ e $00 \mathrm{~h}: 41 \mathrm{~m}: 47 \mathrm{~s}$, com duração média de 00h: 25m: 06s. As entrevistas transcritas resultaram em um documento de 33 páginas (papel de tamanho padrão com margens de 1" em todos os lados, fonte Times New Roman de 12 pontos com espaçamento simples), com cada entrevista gerando uma média de 4 páginas (variando de pelo menos 3 a um máximo de 6 páginas).

\section{2 - TRATAMENTO DOS DADOS}

Os dados foram codificados por dois codificadores independentes. Quando não havia concordância quanto à classificação dos trechos indivisíveis da entrevista, discutiam a análise até que houvesse uma concordância entre eles. Um terceiro pesquisador verificou toda a codificação final. Todos os dados foram codificados usando a análise de conteúdo descrita por Elo e Kyngas (2008) no software NVivo 12 (que é específico para análises qualitativas).

A amostra foi dividida em três categorias principais e 10 subcategorias, que foram levantadas seguindo a análise conteúdo-categorial descrita por Elo e Kyngas (2008) e Bardin (2002), que são apresentadas no Tabela 3.

Tabela 3. Categorias e subcategorias.

Experiência no Curso de Bacharelado 


Suporte Teórico
Prática Clínica
Preparação para o Mercado de Trabalho
Seguranças e inseguranças na prática clínica
Visão geral
Atraso de Linguagem
Distúrbio Específico de Linguagem
Transtorno do Espectro Autista
Desenvolvimento profissional
Interesse
Experiências
Expectativas

No total, 246 referências foram classificadas nas três principais categorias. Cada referência indica o número de ocorrências, ou seja, quantos fragmentos de documento foram codificados nessa categoria específica enquanto a fonte se refere à quantos participantes mencionaram o tema em suas entrevistas. Por fim, os 'nós' tem uma função trivial durante a análise de conteúdo pelo software, pois nos 'nós' são organizadas as pastas estabelecendo uma hierarquização dos elementos da análise que funcionam como variáveis que armazenam informações descritivas das entrevistas.

A seguir são apresentados os 'nós' de cada uma das três principais categorias bem como a sua respectiva fonte e referência (Tabela 4).

Tabela 4. Ocorrências de cada categoria.

\begin{tabular}{lll}
\hline Nó & Fonte & Referência \\
\hline Experiência no Curso de Bacharelado & 8 & 83 \\
Suporte Teórico & 8 & 31 \\
Descrição de aulas teóricas & 1 & 1 \\
Boas oportunidades de aprendizado & 3 & 5 \\
Bons professores & 3 & 4 \\
Número insuficiente de aulas teóricas & 3 & 6
\end{tabular}


Fonte Referência

Falta de aulas de intervenção

$1 \quad 1$

Falta de maturidade 1

Falta de atualização das aulas teóricas

1

Falta de teoria aplicada a prática 2

Linguagem não era o foco do curso de graduação

Mais aulas teóricas seriam benéficas

1

Excesso de aulas teóricas

Acredita na falta de experiência

Quantidade suficiente de aulas teóricas

Prática Clínica

Desafios na prática clínica

8

8

(T)

Falha na supervisão clínica

1

Falta de supervisão em TEA

Falta de supervisão em Anomalias Craniofaciais

Falta de supervisão em Atraso de Linguagem

Falta de supervisão em DEL

Foco no interesse de pesquisa do professor

Falta de prática clínica

Questão de disciplinas optativas

Falta de supervisão

Falta de professores preparados

Experiência de maternidade como suporte

Necessidade de atividades extracurriculares

Excesso de carga-horária clínica

Carga-horária clínica suficiente

Preparação para o Mercado de Trabalho

Adequada preparação para o Mercado de Trabalho

Falsa primeira impressão de estar preparado 2

Inadequada preparação para 0 Mercado de 2

33

22

Trabalho

Falta de preparo para Comunicação Alternativa $\quad 1 \quad 1$

Falta de preparo para TEA 
Falta de preparo para Avaliar Linguagem

Falta de Maturidade

$1 \quad 1$

Falta de recursos para os cursos de atualização

Limitação da demanda da clínica-escola

23

Necessidade de supervisão clínica

11

Necessidade de cursos de atualização

11

Fonoaudiologia é um campo amplo

23

Incerteza sobre a preparação provida da 1

Universidade

Seguranças e inseguranças na prática clínica

896

Visão Geral

Insegurança pela falta de prática

Insegurança pois linguagem não era seu foco

23

Insegurança em casos mais complexos

22

Cursos de atualização ajudaram na segurança

Falta de materiais com evidência científica

Precisava de mais preparo na Universidade

Incerteza sobre os motivos da insegurança

44

Supervisão ajuda a diminuir insegurança

22

Atraso de Linguagem

\section{ABA}

Modelo Denver de Intervenção Precoce

Erro no diagnóstico

Insegurança por não estar atualizado

Segurança pela boa preparação na Universidade

Segurança pelos cursos de atualização

11

Segurança pela experiência clínica

23

Hanen

22

Houve boa evolução nos casos de Atraso de 5 
ESTUDO 01: Experiências e Perspectivas de Fonoaudiólogos quanto à formação e pratica profissional na intervenção das alterações de Linguagem Infantil

Nó

Fonte Referência

Método dos dedinhos

12

Multigestos

1

Não consegue nomear uma intervenção

4

Não tem certeza sobre a evolução de um paciente 2

com Atraso de Linguagem

Prompt

1

1

Distúrbio Específico de Linguagem $8 \quad 16$

Insegurança por precisar de mais experiência ou 2 treinamento

Segurança por ser mais simples que TEA $\quad 1 \quad 1$

Segurança pela experiência clínica $\quad 1 \quad 2$

Hanen 11

Boa experiência com casos anteriores de DEL $\quad 2 \quad 2$

Falta de experiência com DEL $\quad 3 \quad 3$

Mais insegurança com DEL do que Atraso de 1 1 Linguagem por causa da complexidade

Não consegue nomear uma intervenção $\quad 1 \quad 1$

Não sabe se tem segurança pois linguagem não é 2 seu foco

Não tem certeza sobre a evolução de um paciente 1 com DEL

Transtorno do Espectro Autista

$$
8
$$

$A B A$

4

TEA necessita de mais suporte

22

Modelo Denver de Intervenção Precoce

1

Segurança pela boa preparação na Universidade

Segurança pelos cursos de atualização 3

Segurança pela experiência clínica

33

Hanen

1

Boa experiência com casos anteriores de TEA

$5 \quad 5$

Falta de experiência no atendimento de casos de 2

TEA 
Método dos dedinhos

$1 \quad 1$

Não consegue nomear uma intervenção

$1 \quad 1$

PECS

24

Ensino estruturado com suporte visual

22

Desenvolvimento profissional

$8 \quad 67$

Interesse

$8 \quad 8$

Tem interesse

$7 \quad 7$

Não tem interesse

11

Experiências

$8 \quad 38$

Experiência ruim com outros colegas

58

Desafio de selecionar informações de qualidade 2 2

nas redes sociais

Dificuldade de acompanhar o avanço da ciência 11

Boa prática clínica vai além de só fazer cursos de $1 \quad 1$ atualização

Boa experiência com cursos de atualização $\quad 3 \quad 5$

Boa experiência com redes sociais $\quad 1 \quad 3$

Tem experiências passadas $\quad 4 \quad 4$

Alto custo de deslocamento para fazer os cursos de 1 atualização

Falta de material clínico $\quad 1 \quad 1$

Falta de disponibilidade dos professores após o $1 \quad 3$ curso de atualização

Menos materiais comercializados na área de $1 \quad 1$ linguagem do que as demais áreas

Necessidade de mais cursos de atualização com $1 \quad 1$ foco na prática

Não teve experiência com cursos de atualização $\begin{array}{lll}2 & 3\end{array}$

Cursos anteriores foram insuficientes para sua 24 prática 
Fonte Referência

Formas dinâmicas de apresentar o conteúdo do 11

curso

Importância de um curso de atualização bem $1 \quad 1$ estruturado

Necessidade de conteúdo atualizado

Necessidade de foco na intervenção $1 \quad 1$

Necessidade de conteúdo mais prático 12

Necessidade de mais informação sobre os $3 \quad 5$ protocolos de avaliação

Necessidade de mais informação sobre $\begin{array}{llll}0 & 1 & 1\end{array}$ diagnóstico diferenciado

Necessidade de mais informação de como atua $2 \quad 2$ com a família

Necessidade de mais informação sobre $\begin{array}{llll}0 & 1 & 2\end{array}$ desenvolvimento típico

Necessidade de uma área de expertise 12

Foram encontradas 83 referências na categoria "Experiência no Curso de Bacharelado", sendo a maioria em "Suporte Teórico" de um total de 31 referências organizadas na Tabela 5.

Tabela 5. Categoria Experiência no Curso de Bacharelado.

\begin{tabular}{lll}
\hline Nó & Fonte & Referência \\
\hline Experiência no Curso de Bacharelado & 8 & 83 \\
Suporte Teórico & 8 & 31 \\
Descrição de aulas teóricas & 1 & 1 \\
Boas oportunidades de aprendizado & 3 & 5 \\
Bons professores & 3 & 4 \\
Número insuficiente de aulas teóricas & 3 & 6 \\
Falta de aulas de intervenção & 1 & 1 \\
Falta de maturidade & 1 & 1 \\
Falta de atualização das aulas teóricas & 1 & 1
\end{tabular}


Falta de teoria aplicada à prática

22

Linguagem não era o foco do curso de graduação $1 \quad 3$

Mais aulas teóricas seriam benéficas $\quad 1 \quad 1$

Excesso de aulas teóricas $\quad 1 \quad 1$

Acredita na falta de experiência $\quad 1 \quad 1$

Quantidade suficiente de aulas teóricas $\quad 3 \quad 4$

Prática Clínica

Desafios na prática clínica $\quad 1 \quad 1$

Falha na supervisão clínica $\quad 2 \quad 4$

Falta de supervisão em TEA $\quad 111$

Falta de supervisão em Anomalias Craniofaciais 11

Falta de supervisão em Atraso de Linguagem $\quad 1 \quad 1$

Falta de supervisão em DEL $\quad 111$

Foco no interesse de pesquisa do professor $\quad \begin{array}{lll}1 & 2\end{array}$

Falta de prática clínica $\quad 1 \quad 1$

Questões de disciplinas optativas $\quad 1 \quad 4$

Falta de supervisão $\quad 2 \quad 3$

Falta de professores preparados $\quad 1 \quad 1$

Experiência de maternidade como suporte $\quad 1 \quad 3$

Necessidade de atividades extracurriculares $\quad 1 \quad 1$

Excesso de carga-horária clínica $\quad 1 \quad 2$

Carga-horária clínica suficiente $\quad 5 \quad 6$

$\begin{array}{lll}\text { Preparação para o Mercado de Trabalho } & 8 & 24\end{array}$

Adequada preparação para o Mercado de Trabalho $3 \quad 3$

Falsa primeira impressão de estar preparado $\quad 2 \quad 2$

Inadequada preparação para o Mercado de $2 \quad 3$

Trabalho

Falta de preparo para Comunicação Alternativa $\quad 1 \quad 1$

Falta de preparo para TEA $\quad 1 \quad 1$

Falta de preparo para Avaliar Linguagem $\quad 1 \quad 1$

Falta de Maturidade $\quad 1 \quad 2$ 
ESTUDO 01: Experiências e Perspectivas de Fonoaudiólogos quanto à formação e pratica profissional na intervenção das alterações de Linguagem Infantil

Nó

Fonte Referência

$\begin{array}{lll}\text { Falta de recursos para os cursos de atualização } & 2 & 3 \\ \text { Limitação da demanda da clínica-escola } & 1 & 1 \\ \text { Necessidade de supervisão clínica } & 1 & 1 \\ \text { Necessidade de cursos de atualização } & 2 & 3 \\ \text { Fonoaudiologia é um campo amplo } & 1 & 1 \\ \text { Incerteza sobre a preparação provida da } & 1 & 2 \\ \text { ade } & \end{array}$

As nuvens de palavras são a representação gráfica das frequências de palavras/termos que aparecem na análise de conteúdo. Foram elaboradas as seguintes nuvens de palavras mais relacionadas à categoria principal "Experiência no curso de bacharelado" e na subcategoria "Suporte teórico". Para que a palavra fosse considerada nesta análise, ela deveria aparecer pelo menos cinco vezes na categoria em questão; a mesma regra de corte se aplica a todas as nuvens de palavras apresentadas neste estudo.

Figura 2- Nuvem de Palavras da categoria Experiência no curso de bacharelado em Fonoaudiologia.

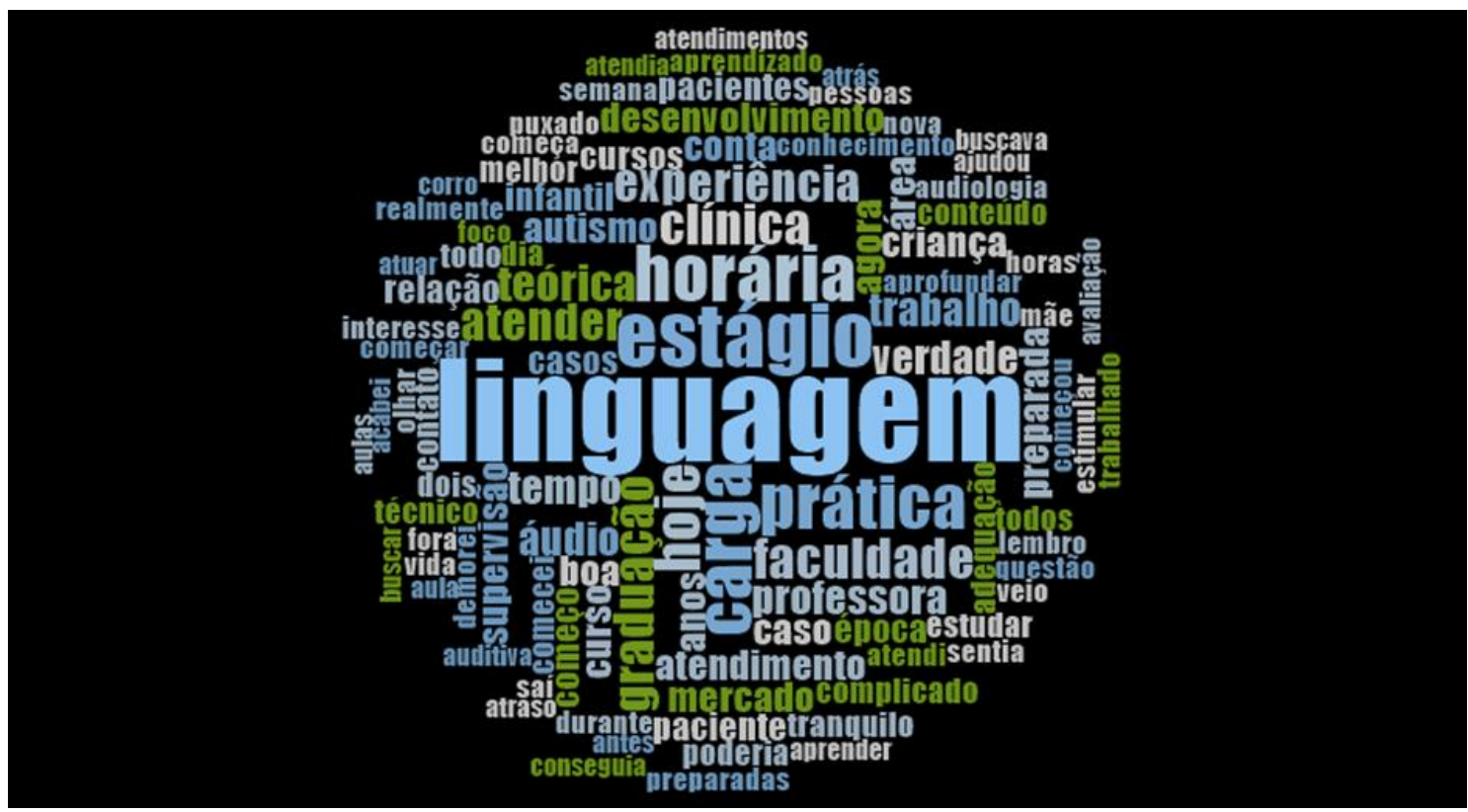

Fonte: Elaborado pela autora.

Figura 3 - Nuvem de Palavras da subcategoria Suporte teórico. 


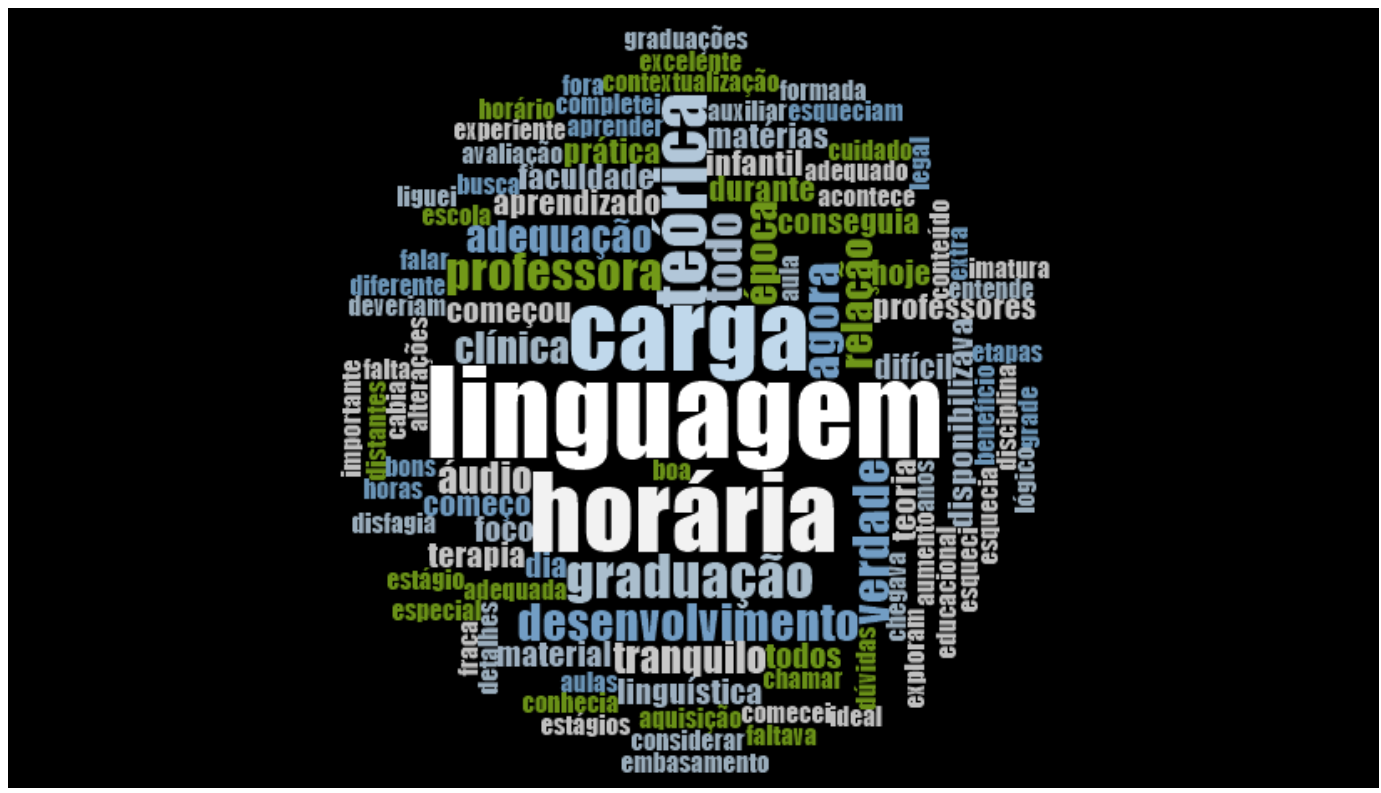

Fonte: Elaborado pela autora.

A Tabela 6 mostra as 96 referências feitas na categoria "Seguranças e inseguranças na prática clínica", com a maioria das referências (32) em "Atraso de Linguagem".

Tabela 6. Categoria Seguranças e inseguranças na prática clínica.

\begin{tabular}{lll}
\hline Nó & Fonte & Referência \\
\hline Seguranças e inseguranças na prática clínica & 8 & 96 \\
Visão Geral & 7 & 17 \\
Insegurança pela falta de prática & 3 & 3 \\
Insegurança, pois linguagem não era seu foco & 2 & 3 \\
Insegurança em casos mais complexos & 2 & 2 \\
Cursos de atualização ajudaram na segurança & 1 & 1 \\
Falta de materiais com evidência científica & 1 & 1 \\
Precisava de mais preparo na Universidade & 1 & 1 \\
Incerteza sobre os motivos da insegurança & 4 & 4 \\
Supervisão ajuda a diminuir insegurança & 2 & 2 \\
Atraso de Linguagem & 8 & 32 \\
ABA & 1 & 1 \\
Modelo Denver de Intervenção Precoce & 1 & 1
\end{tabular}



profissional na intervenção das alterações de Linguagem Infantil

Nó

Fonte Referência

$\begin{array}{lll}\text { Erro no diagnóstico } & 1 & 1 \\ \text { Insegurança por não estar atualizado } & 1 & 1 \\ \text { Segurança pela boa preparação na Universidade } & 2 & 3 \\ \text { Segurança pelos cursos de atualização } & 2 & 2 \\ \text { Segurança pela experiência clínica } & 5 & 6 \\ \text { Hanen } & 1 & 1 \\ \text { Teve boa evolução nos casos de Atraso de } & 5 & 5\end{array}$
Linguagem

Falta de prática clínica com Atraso de Linguagem $\quad 1 \quad 1$

Método dos dedinhos $\quad 1 \quad 2$

Multigestos $1 \frac{1}{1}$

Não consegue nomear uma intervenção $\quad 4 \quad 4$

Não tem certeza sobre a evolução de um paciente $2 \quad 2$ com Atraso de Linguagem

Prompt 111

$\begin{array}{lll}\text { Distúrbio Específico de Linguagem } & 8 & 16\end{array}$

Insegurança por precisar de mais experiência ou $2 \quad 2$ treinamento

Segurança por ser mais simples que TEA $\quad 1 \quad 1$

Segurança pela experiência clínica $\quad 1 \quad 2$

Hanen $\quad 1 \quad 1$

Boa experiência com casos anteriores de DEL $\quad 2 \quad 2$

Falta de experiência com DEL 33

Mais insegurança com DEL do que Atraso de $1 \quad 1$ Linguagem por causa da complexidade

Não consegue nomear uma intervenção $\quad 1 \quad 1$

Não sabe se tem segurança pois linguagem não é 2 seu foco

Não tem certeza sobre a evolução de um paciente 1 com DEL

Transtorno do Espectro Autista 
58

ESTUDO 01: Experiências e Perspectivas de Fonoaudiólogos quanto à formação e pratica profissional na intervenção das alterações de Linguagem Infantil

Nó

Fonte Referência

TEA necessita de mais suporte

Modelo Denver de Intervenção Precoce

2

Segurança pela boa preparação pela Universidade

Segurança pelos cursos de atualização

2

$1 \quad 1$

Segurança pela experiência clínica

33

Hanen

33

Boa experiência com casos anteriores de TEA

11

Falta de experiência no atendimento de casos de $2 \quad 2$

TEA

Método dos dedinhos

Não consegue nomear uma intervenção

PECS

Ensino estruturado com suporte visual

$\begin{array}{ll}1 & 1 \\ 1 & 1 \\ 2 & 4 \\ 2 & 2\end{array}$

As figuras 4 e 5 mostram as nuvens de palavras com as mais citadas nas referências feitas na categoria principal "Seguranças e inseguranças na prática clínica" e na subcategoria "Atraso de linguagem".

Figura 4 - Nuvem de Palavras da categoria Seguranças e inseguranças na prática clínica.

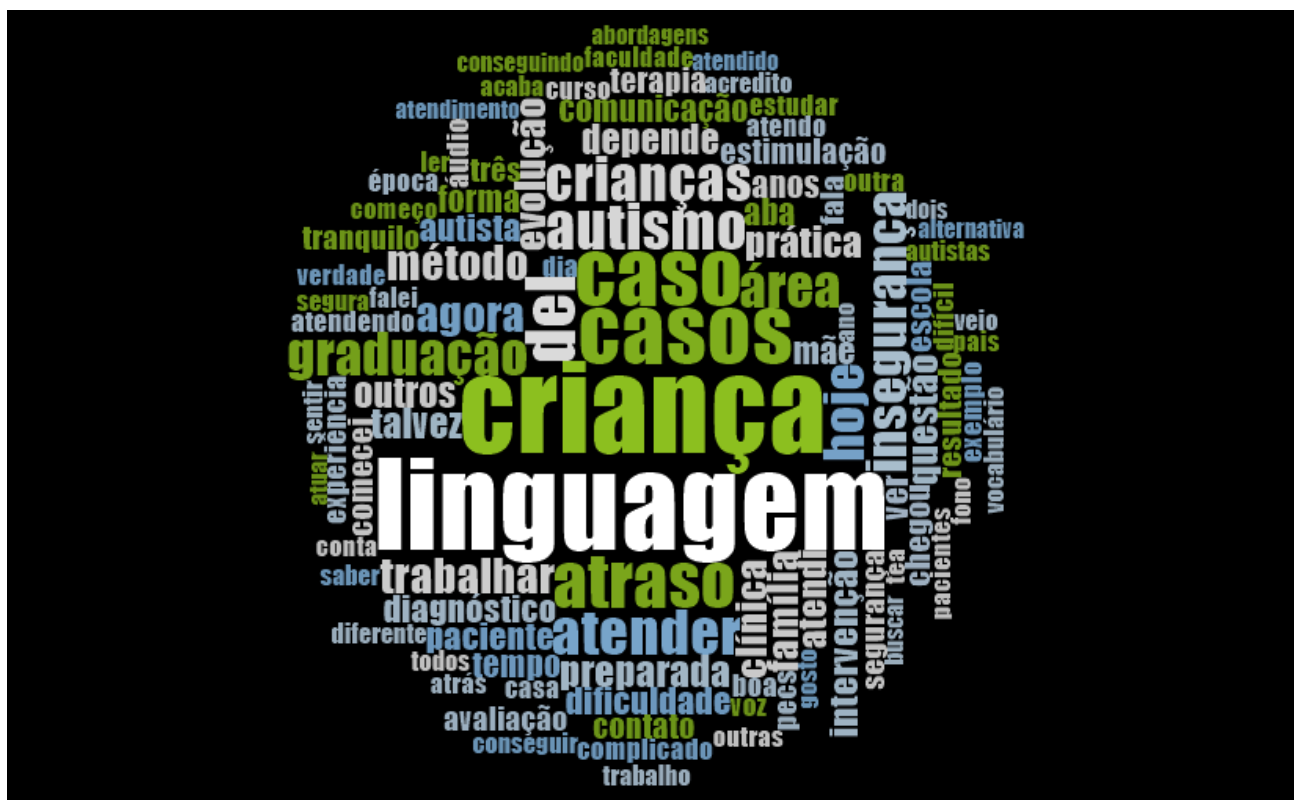

Fonte: Elaborado pela autora. 

profissional na intervenção das alterações de Linguagem Infantil

Figura 5 - Nuvem de Palavras da subcategoria Atraso de linguagem.

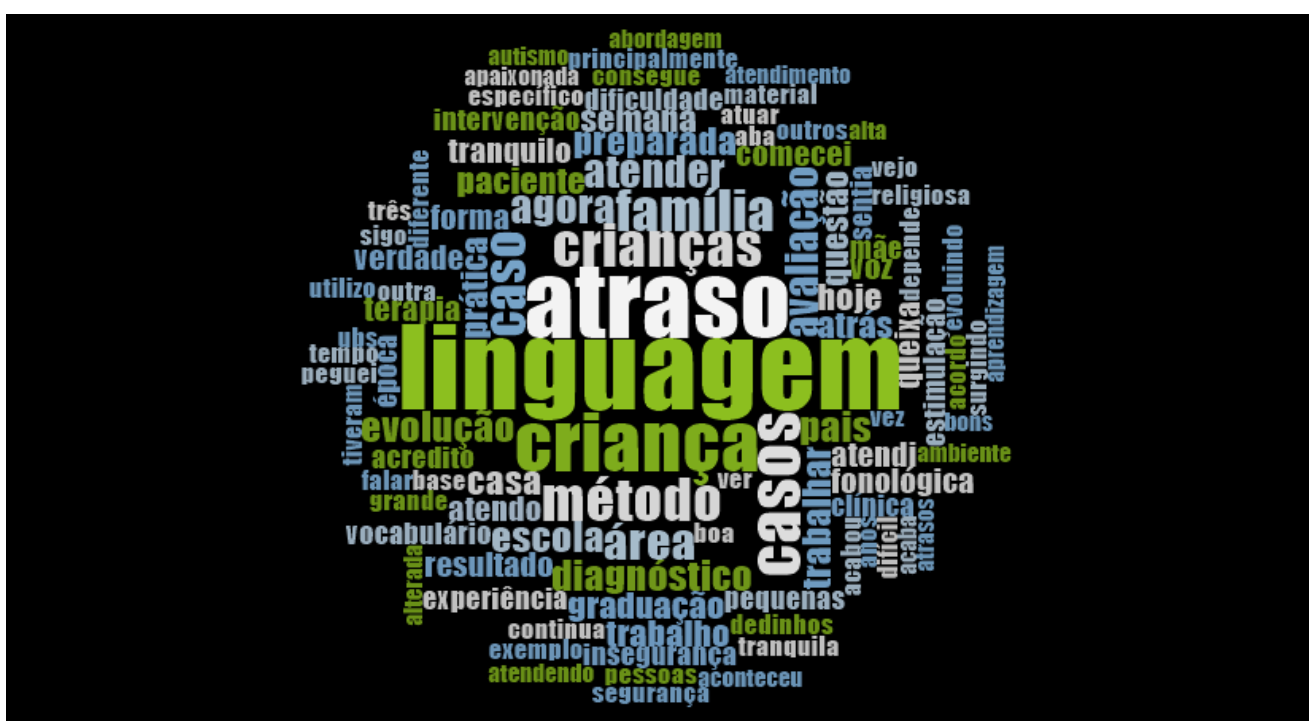

Fonte: Elaborado pela autora.

Quanto à categoria principal, "Desenvolvimento profissional", foram encontradas 67 referências organizadas na Tabela 7, com a maioria em "Experiências", sendo 38 ocorrências.

Tabela 7. Categoria Desenvolvimento profissional.

\begin{tabular}{lll}
\hline Nó & Fonte & Referência \\
\hline $\begin{array}{l}\text { Desenvolvimento profissional } \\
\text { Interesse }\end{array}$ & 8 & 67 \\
Tem interesse & 8 & 8 \\
Não tem interesse & 7 & 7 \\
Experiências & 1 & 1 \\
$\quad$ Experiência ruim com outros colegas & 8 & 38 \\
$\quad$ Desafio de selecionar informações de qualidade & 2 & 2 \\
nas redes sociais & 5 & \\
Dificuldade de acompanhar o avanço da ciência & 1 & 1 \\
Boa prática clínica vai além de só fazer cursos de & 1 & 1 \\
Boa experiência com cursos de atualização & 3 & 5 \\
Boa experiência com redes sociais & 1 & 3 \\
Tem experiências passadas & 4 & 4
\end{tabular}


60

ESTUDO 01: Experiências e Perspectivas de Fonoaudiólogos quanto à formação e pratica profissional na intervenção das alterações de Linguagem Infantil

Nó

\section{Fonte Referência}

Alto custo de deslocamento para fazer os cursos de $1 \quad 1$ atualização

Falta de material clínico 1

Falta de disponibilidade dos professores após $0 \begin{array}{lll} & 1 & 3\end{array}$ curso de atualização

Menos materiais comercializados na área de $1 \quad 1$ linguagem do que as demais áreas

Necessidade de mais cursos de atualização com 1 foco na prática

Não teve experiência com cursos de atualização $2 \begin{array}{lll}2 & 3\end{array}$

Cursos anteriores foram insuficientes para sua 24

prática

Expectativas

Formas dinâmicas de apresentar o conteúdo do 11

curso

Importância de um curso de atualização bem 1 1 estruturado

Necessidade de conteúdo atualizado 1

Necessidade de foco na intervenção $\quad 1 \quad 2$

$\begin{array}{lll}\text { Necessidade de conteúdo mais prático } & 3 & 4\end{array}$

Necessidade de mais informação sobre os $3 \quad 5$

protocolos de avaliação

Necessidade de mais informação sobre $\begin{array}{llll}0 & 1 & & 1\end{array}$ diagnóstico diferenciado

Necessidade de mais informação de como atua $2 \quad 2$ com a família

Necessidade de mais informação sobre 0 o $1 \quad 32$ desenvolvimento típico

Necessidade de uma área de expertise $\quad 1 \quad 2$ 
ESTUDO 01: Experiências e Perspectivas de Fonoaudiólogos quanto à formação e pratica profissional na intervenção das alterações de Linguagem Infantil

Em relação à categoria principal, "Desenvolvimento profissional", elaborouse a Figura 6 da nuvem de palavras através das palavras relacionadas nas referências mais utilizadas nesta categoria e a Figura 7 na subcategoria "Experiências".

Figura 6 - Nuvem de Palavras da categoria Desenvolvimento profissional.

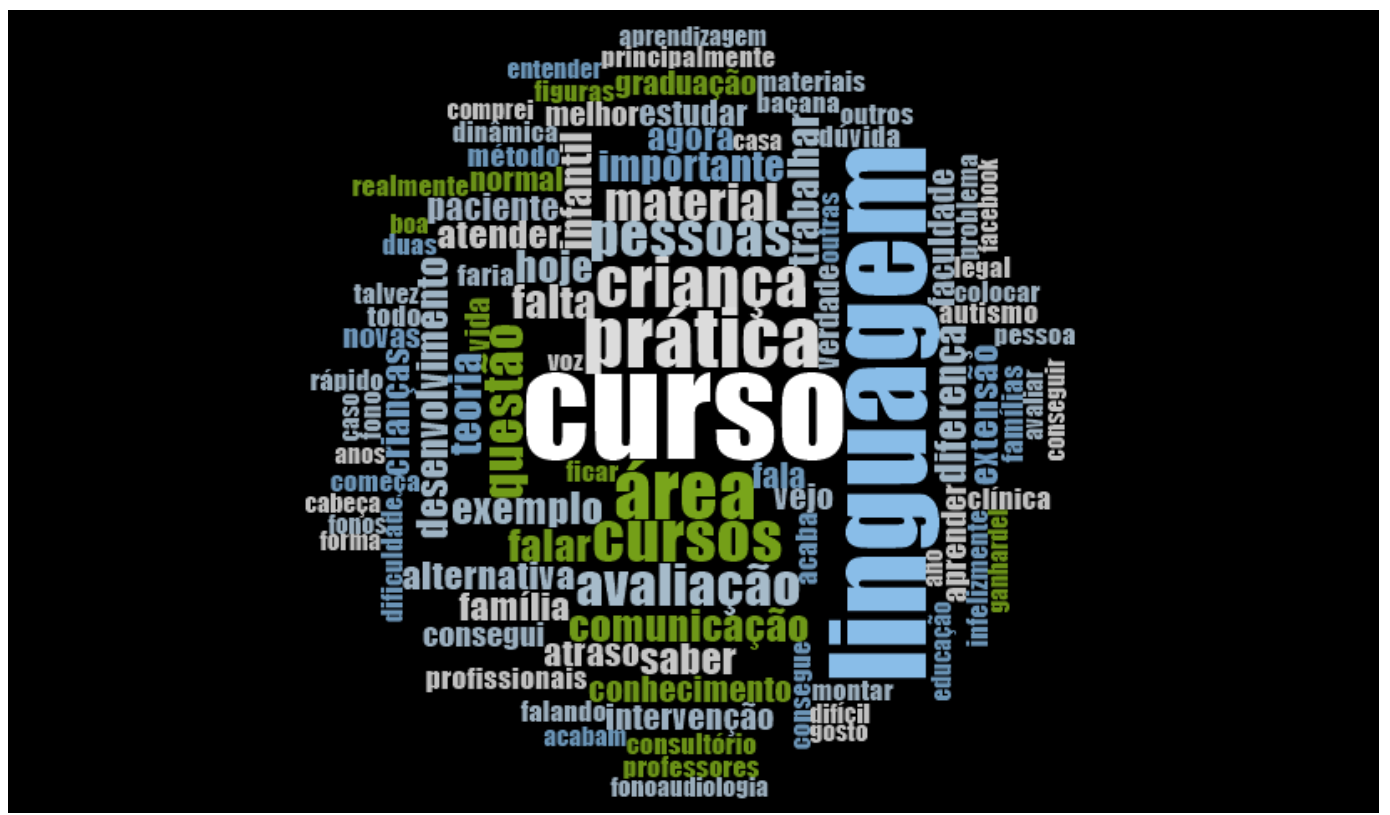

Fonte: Elaborado pela autora.

Figura 7 - Nuvem de Palavras da subcategoria Experiências.

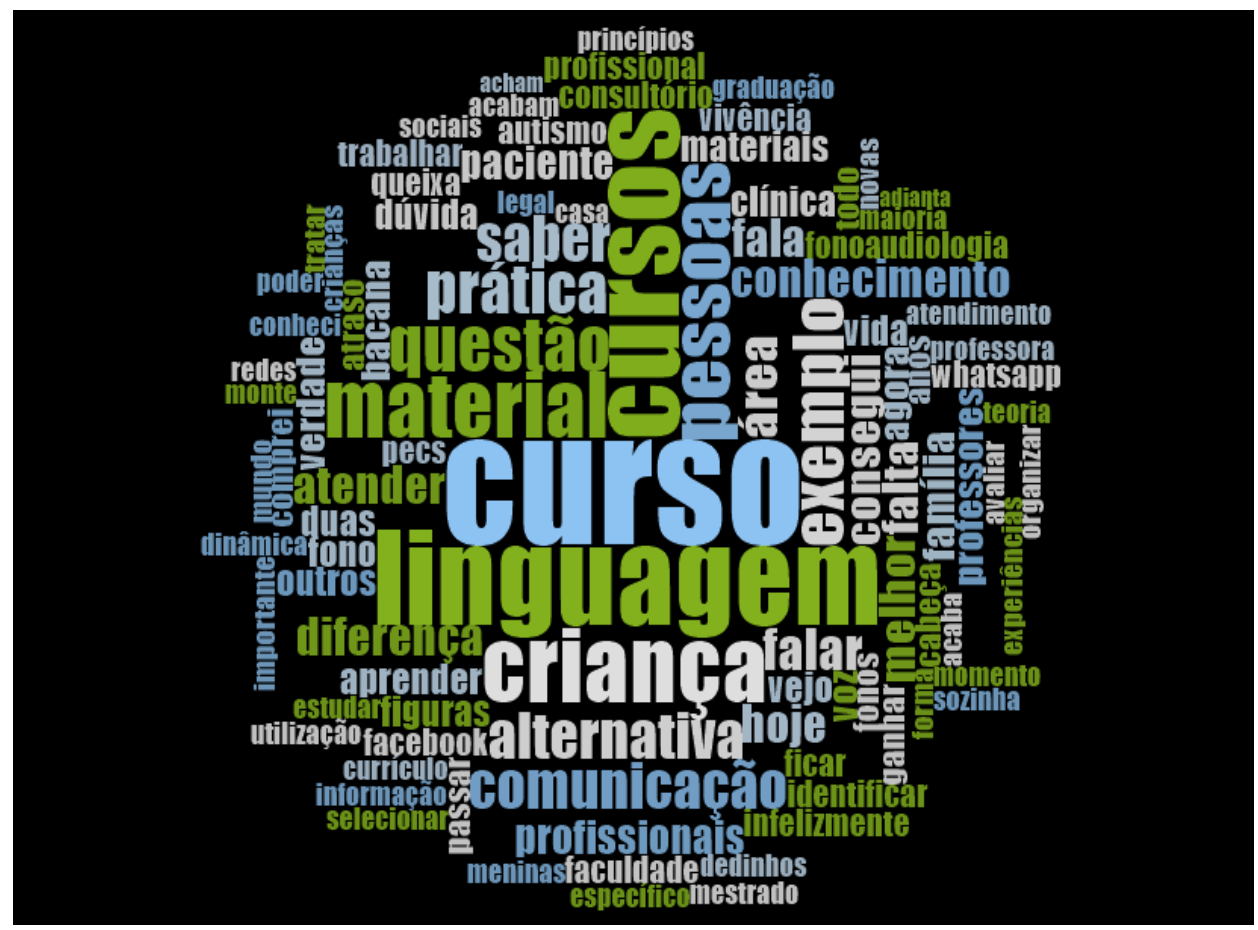

Fonte: Elaborado pela autora. 
As tabelas e figuras apresentadas até o momento fizeram parte da amostra da análise realizada pelo pesquisador, para a seleção dos depoimentos a serem expostos nos seguintes resultados, apresentados por categorias e subcategorias como ilustram as principais referências feitas pelos entrevistados.

\section{3 - ANÁLISE}

\subsection{1 - Experiência no Curso de Bacharelado}

\subsubsection{1 - Suporte Teórico}

Sobre esse tópico, pode-se observar que, no primeiro momento, quase metade das fonoaudiólogas que participou deste estudo acredita que a quantidade de crédito teórico na graduação é suficiente para a certificação clínica. No entanto, à medida que a entrevista flui, aparecem relatos que ilustram a "falta de apoio para associar a teoria à prática".

(...) assim é eu só acha penso que a parte que a gente começou a ter terapia foi um pouco distantes da nossa clínica, então foi algo que quando chegava na clínica a gente meio que esquecia alguns se esqueciam eu esqueci algumas coisas muitos detalhes mas depois a gente retomava e conseguia pegar. (p. 7)

Embora os entrevistados reconheçam que os créditos teóricos se constituem como uma boa oportunidade de aprender, os participantes relataram um aspecto positivo do curso de bacharelado para fornecer a qualidade da formação, a alta qualidade dos professores.

(...) a gente tinha uns ótimos professores e de linguagem em especial era experiente, que era a XXXX na área de linguagem (...) (p. 2) 
A maioria dos fonoaudiólogos acredita que possui prática clínica suficiente durante a graduação. Contudo, algumas fraquezas clínicas foram levantadas, como limitações na variedade de casos.

(...) Agora, por exemplo, eu não tive contato com autismo, eu não tive contato com.. Eu não tive contato com fissura (...) (p. 1)

Na prática mesmo, eu não vi nada de atraso de linguagem, de DEL, eu não atendi (...) (p. 8)

Em alguns relatos, os fonoaudiólogos falaram sobre a falta de supervisão clínica durante o curso de graduação.

Não [sobre se a parte prática foi suficiente], não, porque a gente só tinha um estágio na área de linguagem e, se não me engano, era dez vagas. Então, eu fui fazer estágio em voz, porque eu não consegui estágio no... não conseguir vaga no estágio de linguagem. (p. 5)

\subsubsection{3 - Preparação para o Mercado de Trabalho}

Alguns relatos apontaram preparação adequada para o mercado de trabalho durante a graduação. Outra resposta frequente foi sobre a falsa primeira impressão de estar preparado para o mercado de trabalho.

Ah... a gente sempre, assim, acha que está preparada [pro mercado de trabalho], né? Mas, daí quando a gente vai para a clínica, é... surgem muitos desafios e aí a gente, assim, fica alguns momentos inseguros. (p. 4)

Alguns fonoaudiólogos pensam que, quando terminam a graduação, não estão preparados para o mercado de trabalho e precisam de cursos complementares (desenvolvimento profissional). Pode-se inferir que para alguns é um desafio porque há relatos de falta de recursos para isso. 
(...) não era só não vai ter uma experiência pela equipe que eu faço parte hoje que me ensinou muito tempo inteiro é todos os cursos que eu venho agregando nesses 20 anos (...) mas hoje eu corro atrás não é que eu tô mais velhinha né? eu deixo para trás estou estudando direto acabei de voltar de um seminário está tendo aqui em XXXX que está o doutor XXXX de autismo que é a área que a gente atua na clínica então a gente tá sempre, esse mês não tenho grana, eu tô dura de tanto curso que eu fiz mas eu acho que é assim tem que ser né? uma parte que eu poderia ter aproveitado antes quando estava mais nova e hoje eu corro atrás do prejuízo. (p. 4)

\subsection{2 - Seguranças e Inseguranças na Prática Clínica}

\subsubsection{1 - Visão Geral}

Três dos fonoaudiólogos participantes relataram apresentar insegurança durante a prática clínica, principalmente, no início de sua carreira profissional, devido à falta de prática anterior, como se pode observar nas citações a seguir:

Olha, no começo me faltava um pouco da prática, né? A gente teve teoria, a gente teve toda a prática na clínica-escola, mas no dia-a-dia é muito diferente, então no começo eu senti isso, né? (p. 4)

Sim, é mais insegurança, sabe? De dificuldade assim de ter acesso a material que já não estava mais entre universidade e a insegurança estar sozinha mesmo de não ter ninguém para dizer se tá certo tá... tá errada é por aí ou dar alguma orientação a mais é mais nesse sentido. (p. 8)

Mesmo para os fonoaudiólogos que não associaram a insegurança à falta de prática clínica, todos relataram este sentimento. Algumas hipóteses: a linguagem infantil não ser seu foco clínico (2 participantes); por não terem escolhido a linguagem como seu campo de atuação nem realizaram muitos cursos de atualização nesta área; 
e, de que forma relacionar a complexidade do caso da criança (2 participantes). Além disso, metade dos participantes não tem ideia do motivo pelo qual se sente assim:

Eu atendo muito bem, eu faço um bom trabalho, eu estudo muito, eu leio muito, mas eu acho que o fato de eu estudar muito, de ler muito a respeito de linguagem, eu acho que isso pode ser uma questão de eu não me sentir segura. (p. 3)

Então, não sei [com relação ao motivo das inseguranças], talvez, nunca parei para pensar nisso, nunca parei para pensar nisso porque é que demora depois de formado para a gente ter mais segurança, não. (...) (p. 2)

\subsubsection{2 - Atraso de Linguagem}

Cinco dos fonoaudiólogos que participaram do estudo relataram uma boa evolução nos indivíduos com atrasos na linguagem. As citações a seguir ilustram as expressões de crescente competência clínica:

Eu acho que é só um atraso de linguagem, eu acho que estou com uns 3 ou 4 casos de atraso de linguagem e super evoluindo. (p. 6)

Sim, tiveram [boa evolução dos casos atendidos por ela]. (...) Então, é isso que eu te falei, eu não tive casos muito complicados, eu tive casos... essa garota foi mais complicada e realmente ela saiu, quando ela parou o atendimento comigo ela entrou numa escola especializada, não foi na $\mathrm{XXXX}$, mas numa escola assim para crianças especiais e tal, e ela foi para essa escola especial. Agora tem crianças que às vezes eu vou atrás de saber como estão ainda e tal, de vez em quando eu pego agendas, tento ligar para os pais e perguntar, passar um e-mail: "Oi, como é que está o XXXX e tal?". Então tem crianças que os pais falam que é outra criança, que cresceu, desenvolveu, adequou, então a maioria delas foi bem-sucedido mesmo (...) (p. 2) 
A maioria dos participantes não soube nomear método interventivo para os casos de Atraso de Linguagem:

Eu não lembro direito qual era abordagem [interventiva] usada. Mas também não era muito diferente do que eu vi XXXX. A gente fazia a avaliação com os protocolos, de acordo com a idade e com a necessidade da criança, e a gente via qual era a prioridade de trabalhar, a princípio, escolhia qual era a prioridade e fazia as terapias da mesma forma que eu vi $X X X X$, com jogos, figuras... era mais ou menos isso. ( $p$. 1)

\subsubsection{3 - Distúrbio Específico de Linguagem}

O assunto mais abordado neste tópico foi a falta de prática clínica, mostrando que uma grande quantidade de fonoaudiólogos que trabalham com linguagem infantil não está familiarizada com os casos de Distúrbio Específico de Linguagem (DEL):

Não, não tive [sobre ter experiência em atender DEL]. A minha demanda maior mesmo tem sido aprendizagem. (...) então, a literatura que mais, aliás que eu mais não foi o da XXXX mesmo, o livro dela, aquele XXXX e foi mais me ajudou, porque todos os outros, eu simplesmente não me ajudaram muito. (p. 5)

Não chegou a vir para mim casos de DEL precisamente, mas eu acredito que eu não sei se eu estaria bem preparada para atender, acho que eu teria que estudar um pouco mais para saber tudo certinho como abordar em terapia como avaliar saber se ele vai evoluir ou não eu acho que eu teria que estudar um pouco mais se for um caso de DEL, eu nunca atendi um caso de DEL na clínica. (p. 7) 
Além disso, foi observado que alguns fonoaudiólogos se sentiam inseguros para atender um caso de DEL pela falta de prática clínica:

Na verdade isso para mim é uma dúvida que eu tenho é que é o do $D E L$, eu não sei diagnosticar um DEL para mim é bem complicado eu até tenho um livro ali que eu comecei a ler 200 vezes e até agora não terminei né? Esse Distúrbio Específico de Linguagem me dá um nó, eu não consigo diferenciar um do outro Transtorno Específico de Linguagem, ah... é uma confusão na minha cabeça eu preciso estudar muito sobre isso. Mas, já chegou algum caso pra você que já veio com o diagnóstico de DEL? Não, nunca... Queria ver um médico encaminhar assim porque eu não vi até hoje o único que veio diferentão, assim foi o do Transtorno da Comunicação Pragmática que eu não sei se entra como DEL. Caso de autismo é o seu foco, né? Sim aqui na clínica é muito autista, eu gosto mais do que atraso de linguagem. (p. 6)

\subsubsection{4 - Transtorno do Espectro Autístico (TEA)}

Cinco fonoaudiólogos relataram observar boa evolução nos casos de TEA. Nesse tema, diferentemente do atraso de linguagem e do DEL, os fonoaudiólogos estão mais familiarizados com as técnicas de intervenção, sendo o ABA (Applied Behavioural Analysis, Análise do Comportamento Aplicada em portugues) o mais citado. As citações a seguir ilustram os relatórios de boa evolução:

Olha eu acho que tá super legal porque assim eu tenho uma equipe muito boa e autismo não funciona só com fono, isso a gente nunca vai conseguir porque o comportamento influencia, bom não tem nem o que falar né? Eu acho que tendo uma equipe boa, a gente tem muito a ganhar agora quando sozinha não faz milagre dentro do espectro, mas nem em nome do Senhor. (p. 6)

(...) Enquanto eu estava atendendo ele... eu atendi pouco tempo, mas ele teve [boa evolução]... Eu atendi ele, acho que deu uns três meses, 
porque depois que terminou $\mathrm{o}$ atendimento $\mathrm{XXXX}$, eu continuei atendendo ele algumas semanas. Acho que deu uns três meses. É pouco tempo, não é, para atender um autista? Mas eu acredito que sim. Principalmente, porque ele era pequenininho, foi descoberto novinho, a mãe mesmo me dava o feedback de que ele já estava... mas aí, quando teve... não sei se foi feriado, eu viajei para fazer um curso e fiquei umas três semanas sem atender ele, a mãe disse que ele deu uma regredida. Isso a mãe me falando. (..) (p. 1)

Além disso, observou-se que alguns fonoaudiólogos se sentem mais preparados para atender os TEA devido a cursos de atualização:

Logo no início eu peguei um caso de uma garotinha complicada que era autismo com deficiência intelectual, aí foi bem complicado, mas eu recorria muito ao material da linguagem da graduação, livros também que a gente tinha, eram indicados na graduação e comecei a ler de novo, a ler outros que eu não tinha lido. E aí foi resolvendo, fazendo cursos também, fiz vários cursos aqui nos cursinhos assim de aprimoramento em linguagem, isso vai dando mais segurança. (p. 2)

No autismo é o que eu te falei, eu tô em atualização. Eu tenho alguns casos de autismo e o que está sendo bem interessante, é que está aparecendo muitos casos de autismo e aí eu estou utilizando a minha prática em comunicação alternativa para trabalhar esses casos e eu estou tendo alguns bons resultados, então assim, de uma certa forma, eu estou me sentindo preparada para atuar, pois estou utilizando esse tipo de intervenção que eu já usava com outros casos e estou tendo bons resultados, mas o autismo para mim é sempre desafiador, porque a gente tem muita variedade, né? dentro do espectro do autismo a gente tem uma grande variedade de alterações, então cada caso que vem para mim é um desafio, dentro da comunicação alternativa que eu utilizo, eu tenho que criar caminhos e estratégias diferentes para cada paciente, 
mas de uma certa forma eu me sinto preparada sim para atuar nesses casos. (p. 4)

\subsection{3 - Desenvolvimento Profissional}

\subsubsection{1 - Interesse}

Sete dos fonoaudiólogos que foram entrevistados mostraram interesse em realizar um curso de atualização na intervenção na linguagem infantil:

Sim [sobre fazer um curso de educação continuada na área de linguagem infantil], amo fazer curso de extensão. (p. 2)

Apenas um participante não demonstrou interesse em realizar um curso de atualização em intervenção na linguagem infantil:

Mas, hoje eu tenho eu tenho atuado mais com aprendizagem, acho que eu não [sobre fazer um curso de extensão na área de linguagem infantil], só por uma questão de demanda mesmo, acho que eu continuaria onde eu tô, buscando a área de aprendizagem. (p. 5)

\subsubsection{2 - Experiências}

A maioria dos participantes relatou ter más experiências com outros colegas:

A impressão que eu tenho é que as pessoas acabam fazendo um pouco nas "coxas". Se fosse para eu atender, hoje, se fosse para eu montar um consultório e atender, eu não iria atender da forma que eu acho que as pessoas atendem, desse jeito, nas "coxas", sabe? Deixa o tempo passar, passar os 40 minutos, principalmente quem atende convênio. A gente entende que é difícil, porque, senão você não paga as suas contas. Mas eu sou um pouco exigente comigo, eu acho que, se fosse para eu 
atender, eu atenderia de forma que eu fosse ver, realmente, a evolução. Eu não iria me sentir satisfeita se eu não visse a evolução. E a impressão que eu tenho é que as pessoas não se importam muito com isso, então por isso elas são generalistas, elas atendem de tudo. Não estou falando de todo mundo, algumas pessoas que eu já ouvi, que eu tive contato, que eu já ouvi falar. (..) (p. 1)

Eu acho que sim [sobre a necessidade dos profissionais se atualizarem], pois muitos profissionais ficam estagnados com aquilo que aprenderam lá na graduação, né? Como eu te disse, a gente não pode parar, pois surgem novas pesquisas, novas descobertas, então a gente não pode parar. Então, o que eu percebo, puxando sardinha pro meu lado, é que eu vejo muitos colegas da fonoaudiologia que não trabalham com a comunicação alternativa, não conhecem e não buscam aprender e acabam muitas vezes falando que a comunicação alternativa vai fazer a criança deixar de falar, vai só ficar utilizando figuras e infelizmente a gente escuta isso dos profissionais da área né? O que eu acho que é um absurdo, já que o conhecimento não pode parar, por exemplo, na graduação eu tive nada de comunicação alternativa, né? E eu fui me atualizando, fazendo cursos para aprender. (p. 4)

Quatro dos fonoaudiólogos tiveram experiências anteriores com cursos de atualização no campo da linguagem infantil e três deles relataram boas experiências:
Ai... pra mim foi um divisor de águas nessa área, porque como falei na minha época de graduação nenhum desses testes, nenhum desses norteadores, eles existiam, então é.. eu me organizei no assunto pra falar então eu tenho eu tenho pra usar isso e isso e isso né? Porque eu, por exemplo o XXXX, eu comprei e li sozinha né? Não tinha com quem trocar, o XXXX comprei ele sozinha, não tinha né? então foi o é foi um divisor de águas, assim porque eu consegui me localizar no espaço, falar olha.. é isso... eu tenho isso para usar. (p. 5) 
Então aqui em $X X X X$ tá bem bacana com isso, sabe? Depois que a XXXX entrou e trouxe cursos para cá, num preço que não é um rim, está super dando certo e a gente está viajando bastante, né? Já fui pra XXXX fazer o introdutório do Denver e a gente viaja (p. 6)

\subsubsection{3 - Expectativas}

Sobre a expectativa nos cursos de atualização, três fonoaudiólogos informaram que tinham a expectativa que esses cursos tivessem treinamento mais prático:

Mas, eu acho assim, eu não sei... eu gosto muito da parte prática, sabe... então, é uma coisa que pra mim, pra mim eu acho que falta um pouco. (p. 3)

(...) é além da exposição teórica, tem que colocar muita prática, porque teoria lógico que é super importante colocar, não existe é prática boa sem uma teoria, mas eu acho que se tivesse mais uma prática nesses cursos, ia ser super fantástico. (p. 6)

Outra expectativa frequente foi a necessidade de obter mais informações sobre protocolos de avaliação durante os cursos de atualização:

(...) Sabe por quê? Porque o que vai nortear a sua intervenção é uma avaliação bem-feita porque eu só vou saber como intervir se eu sei o que eu avaliei o que eu tenho na minha frente. Eu acho que o mais difícil é você fazer uma avaliação e uma avaliação bem-feita. Eu não acho que a intervenção seja a maior dificuldade. Eu acho que a avaliação é a maior dificuldade. (p. 5)

Eu acho que é assim eles precisam conhecer muito profundo muitas mesmo à parte da questão de avaliação da criança pra partir da avaliação saber o método terapêutico programar, então acho que assim 
tenha fim da mesma parte de de avaliação e quais objetivos que você pode trabalhar, porque existem objetivos que a princípio pode não ser o objetivo principal que é o que você deseja e a criança vai a passos lentos e é às vezes tem um objetivo que se você trabalhar a criança consegue deslanchar mais rápido. (p. 7)

\subsection{4 - Considerações Finais}

O estudo evidencia pontos mais frequentemente abordados pelos fonoaudiólogos que participaram das entrevistas. O primeiro deles está relacionado à graduação em Fonoaudiologia, pois foi possível detectar que as grades curriculares são díspares, ou seja, há diferenças do foco principal entre as instituições de ensino. Em função disso, especificamente na área de intervenção em linguagem infantil, notase que existe diferença perceptível com relação à formação básica desses profissionais. Aliás, por mais que a graduação tenha um ótimo suporte teórico ainda faltam para esses profissionais a prática clínica, atividade mais próxima da realidade e também associação da teoria com a prática.

O segundo ponto é que - para os fonoaudiólogos clínicos - existe a necessidade da educação continuada, seja ela formal ou não. Nesse processo de desenvolvimento profissional a prática clínica deve ser o ponto principal, sempre associada à teoria. Para a temática de intervenção em linguagem infantil há também a necessidade de abordar aspectos do desenvolvimento típico e também da avaliação de linguagem. Outro aspecto importante é o fato de que ao se graduar nem todo fonoaudiólogo tem consciência da sua necessidade de atualização.

Para finalizar, o último ponto que deve ser ressaltado são as referências à conduta profissional não adequada por parte de outros fonoaudiólogos, o que traz indicativos de que ética profissional, bem como os caminhos de fiscalização e denúncias dos conselhos profissionais também precisam ser abordados durante 0 processo de educação continuada. 


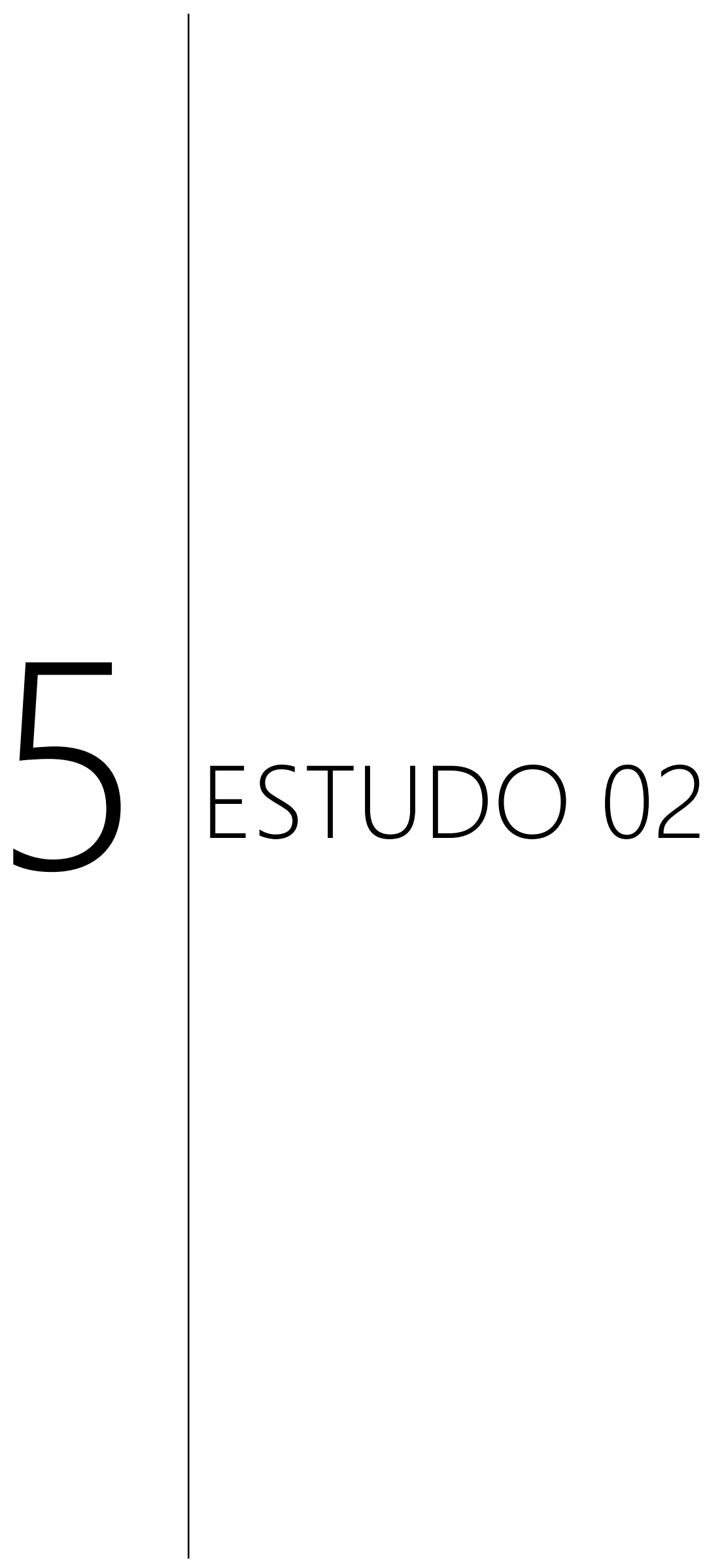





\section{5 - ESTUDO 02: DESENVOLVIMENTO DE UM CURSO ONLINE PARA EDUCAÇÃO CONTINUADA DE FONOAUDIÓLOGOS SOBRE INTERVENÇÃO EM LINGUAGEM ORAL INFANTIL}

\section{1 - METODOLOGIA}

\subsection{1 - Desenho do estudo}

Pesquisa metodológica, de produção tecnológica, referente ao desenvolvimento de curso on-line para fonoaudiólogos sobre intervenção em linguagem infantil. Foi realizada de agosto de 2017 a fevereiro de 2018, na Universidade de São Paulo (modalidade a distância). O estudo seguiu três etapas:

- Etapa 1 - Planejamento;

- Etapa 2 - Construção/Transformação dos Conteúdos;

- Etapa 3 - Desenvolvimento da Dinâmica do Workshop.

A seguir, veremos a descrição sobre como cada uma dessas etapas foi executada para o cumprimento dos objetivos.

\subsubsection{1 - Etapa 1 - Planejamento}

Nesta etapa, foi construído o plano de ação, que incluía os seguintes aspectos:

- Definição do escopo do projeto, constituindo na escolha do AVA a ser utilizado, da população-alvo do curso, dos conteúdos a serem trabalhados etc. Também foram verificados os aspectos éticos e a definição do cronograma do projeto e do curso;

- Definição de estratégias para oferta do conteúdo, com a escolha das ferramentas que serão utilizadas nas aulas, atividades e conteúdo disponibilizado;

- Métodos de registro das etapas de construção e disponibilização; 
- Métodos de avaliação dos resultados, definindo a quantidade, temas abordados, ferramentas utilizadas e peso; e

- Etapas de construção do roteiro com diretrizes técnicas, com a definição dos padrões de layout, fontes e cores que serão utilizados durante este projeto, bem como o tempo máximo de aula.

Nesta fase também foram planejadas as estratégias pedagógicas e tecnológicas, as regras e a organização do curso. Ações também foram tomadas, como a escolha de ferramentas, serviços e recursos; a definição da equipe para trabalhar no curso; o modelo para formatar os módulos; o modelo e questionário de avaliação dos módulos; e a definição do layout - identidade do produto. Para aproveitar o potencial das novas tecnologias de comunicação e promover uma mudança efetiva no sistema educacional, faz-se necessário reorganizar a educação em um sistema baseado no uso de uma tecnologia que considere os sistemas de design e uma equipe especializada em aprendizado. Portanto, para criar um curso online, foi importante ter o trabalho integrado de uma equipe multidisciplinar, pois o desenvolvimento do curso exige atenção em diferentes áreas que precisam de pessoal especializado. Por exemplo, a área de tecnologia foi composta por desenvolvedores e designers instrucionais e a área pedagógica foi composta por professores, coordenadores, conteudistas e tutores/moderadores.

\subsubsection{2 - Etapa 2 - Construção e Transformação dos Conteúdos}

Nesta etapa, toda a equipe trabalhou na construção dos conteúdos do curso, bem como no processo de transformação dos conteúdos e na inserção deles no AVA (Ambiente Virtual de Aprendizagem). Também foi realizada a criação do curso no AVA/Moodle e sua customização. Ao final desta etapa, os professores e tutores/moderadores foram inseridos no AVA/Moodle, e ele foi testado até que não houvesse mais correções de erros ou melhorias a serem implementadas. Este trabalho foi gravado e descrito, identificando os processos e atores envolvidos.

\subsubsection{3 - Etapa 3 - Desenvolvimento da Dinâmica do curso}


A oferta do curso on-line é entendida como o estágio dinâmico em que todos os participantes devem interagir com o AVA. Os objetivos educacionais foram desenvolvidos com base na taxonomia de Bloom (1956). Os princípios educacionais que orientaram a estruturação do curso, a produção de mídia e materiais didáticos foram baseados em Knowles (1970), sobre os pressupostos andragógicos, relacionados à aprendizagem de adultos e à Teoria da Aprendizagem Significativa de Ausubel (1977). A construção de storyboards, usando o PowerPoint ${ }^{\circledR}$ e o Word®, favoreceu a definição após o conteúdo e a sua implementação no ambiente virtual de aprendizagem.

No desenvolvimento, foram produzidos os materiais do curso como conteúdos e objetos de aprendizagem (imagens e exercícios interativos) que compõem as estratégias de avaliação, bem como o tutorial e a rota de navegação. $O$ conteúdo da mídia e do material didático foi preparado pela pesquisadora e revisado por outros dois fonoaudiólogos, professores da área em questão, com experiência em intervenção na linguagem, educação permanente e ensino a distância.

A fase de implementação incluiu a configuração e personalização de ferramentas e recursos no ambiente virtual de aprendizagem Moodle $\AA 3.1$ para acesso através de diferentes navegadores e dispositivos tecnológicos. Login e senha foram fornecidos aos alunos participantes da pesquisa. O processo de avaliação da aprendizagem foi delineado nas seguintes dimensões:

- Diagnóstica: realizada no início do curso, com perguntas específicas de cada unidade de aprendizagem;

- Formativa: através de exercícios com feedback e atividades digitais ao longo do curso;

- Somativa: com teste final.

A pesquisa foi realizada com a aprovação do Comitê de Ética em Pesquisa da Faculdade de Odontologia de Bauru, Universidade de São Paulo, em Parecer consubstanciado n. 1.667.269/2016 e identificador CAAE 54831516.5.0000.5392. Após a assinatura do Termo de Consentimento Livre e Esclarecido (Apêndice A), 
enviado em formato digital, os dados de acesso e desempenho foram coletados no curso.

Durante todas as etapas deste estudo, a pesquisadora manteve um registro das ações que foram realizadas. Os resultados deste estudo serão apresentados de forma descritiva.

\section{2 - RESULTADOS}

Para desenvolver a pesquisa, tentamos experimentar e descrever todas as ações envolvidas na preparação de um curso no AVA/Moodle. Foi utilizado como tema: "intervenção fonoaudiológica na linguagem oral infantil".

Embora as características do curso sejam distintas de um curso regular, os processos estão presentes nos dois formatos, englobando todas as etapas do desenvolvimento, desde o planejamento das atividades de ensino até o fechamento com o processo de avaliação, à semelhança do que ocorre em uma disciplina tida como regular.

As atividades realizadas pela equipe de trabalho incluíram as etapas de preparação, oferecendo dinâmica e conclusão apresentadas nas Tabelas 8, 9 e 10. Já a Figura 8 apresenta as etapas e os processos executados neste estudo.

Tabela 8. Ações desenvolvidas na etapa de planejamento

\begin{tabular}{llll}
\hline Processo & $\begin{array}{l}\text { Ações } \\
\text { desenvolvidas }\end{array}$ & $\begin{array}{l}\text { Informações } \\
\text { requeridas }\end{array}$ & Atores e funções \\
\hline Planejamento & Título, Agenda, & Datas, conteúdos & Professores: \\
& Ementa, & programáticos, & Construção e \\
& Programas, & conhecimentos & planejamento \\
& Requisitos & e prévios & Técnicos: \\
público-alvo & necessários & participação \\
& & & Tutores: \\
& & & participação \\
\hline
\end{tabular}


Estudo 02: Desenvolvimento de um Curso Online para Educação Continuada de Fonoaudiólogos sobre Intervenção em Linguagem Oral Infantil

\begin{tabular}{|c|c|c|c|}
\hline Processo & $\begin{array}{l}\text { Ações } \\
\text { desenvolvidas }\end{array}$ & $\begin{array}{l}\text { Informações } \\
\text { requeridas }\end{array}$ & Atores e funções \\
\hline $\begin{array}{l}\text { Desenvolvimento } \\
\text { dos conteúdos }\end{array}$ & $\begin{array}{l}\text { Aulas expositivas, } \\
\text { textos obrigatórios, } \\
\text { textos } \\
\text { complementares, } \\
\text { exercícios, textos } \\
\text { de orientação e } \\
\text { bibliografia }\end{array}$ & $\begin{array}{l}\text { Conteúdos das } \\
\text { aulas expositivas, } \\
\text { lista de textos, } \\
\text { fontes de } \\
\text { referência }\end{array}$ & $\begin{array}{l}\text { Professores: } \\
\text { produção } \\
\text { pesquisa-ação } \\
\text { Técnicos: } \\
\text { orientação } \\
\text { Tutores: } \\
\text { participação }\end{array}$ \\
\hline $\begin{array}{l}\text { Desenvolvimento } \\
\text { das avaliações }\end{array}$ & $\begin{array}{l}\text { Atividades, } \\
\text { Avaliações por } \\
\text { módulo, } \\
\text { Avaliações gerais }\end{array}$ & $\begin{array}{l}\text { Conteúdos das } \\
\text { aulas, } \\
\text { conhecimentos a } \\
\text { serem avaliados, } \\
\text { fontes de } \\
\text { referência }\end{array}$ & $\begin{array}{l}\text { Professores: } \\
\text { produção } \\
\text { pesquisa-ação } \\
\text { Técnicos: } \\
\text { orientação } \\
\text { Tutores: } \\
\text { participação }\end{array}$ \\
\hline
\end{tabular}

Tabela 9. Ações desenvolvidas durante a etapa de construção e transformação dos conteúdos

\begin{tabular}{|c|c|c|c|}
\hline Processo & $\begin{array}{l}\text { Ações } \\
\text { desenvolvidas }\end{array}$ & $\begin{array}{l}\text { Informações } \\
\text { requeridas }\end{array}$ & Atores e funções \\
\hline $\begin{array}{l}\text { Criação do curso } \\
\text { no AVA/Moodle }\end{array}$ & $\begin{array}{l}\text { Inserção do curso } \\
\text { no AVA com } \\
\text { informações dos } \\
\text { professores }\end{array}$ & $\begin{array}{l}\text { Título, descrição, } \\
\text { logo, cronograma e } \\
\text { conteúdo } \\
\text { programático do } \\
\text { curso }\end{array}$ & $\begin{array}{l}\text { Professores: } \\
\text { orientação } \\
\text { Técnicos: } \\
\text { produção } \\
\text { Tutores: } \\
\text { orientação }\end{array}$ \\
\hline $\begin{array}{l}\text { Transformação } \\
\text { dos conteúdos }\end{array}$ & $\begin{array}{l}\text { Elaboração do } \\
\text { conteúdo no } \\
\text { formato adequado } \\
\text { ao AVA }\end{array}$ & $\begin{array}{l}\text { Arquivos com os } \\
\text { conteúdos } \\
\text { elaborados pelos } \\
\text { professores } \\
\text { tutores }\end{array}$ & $\begin{array}{l}\text { Professores: } \\
\text { orientação } \\
\text { verificação } \\
\text { Técnicos: } \\
\text { produção }\end{array}$ \\
\hline
\end{tabular}




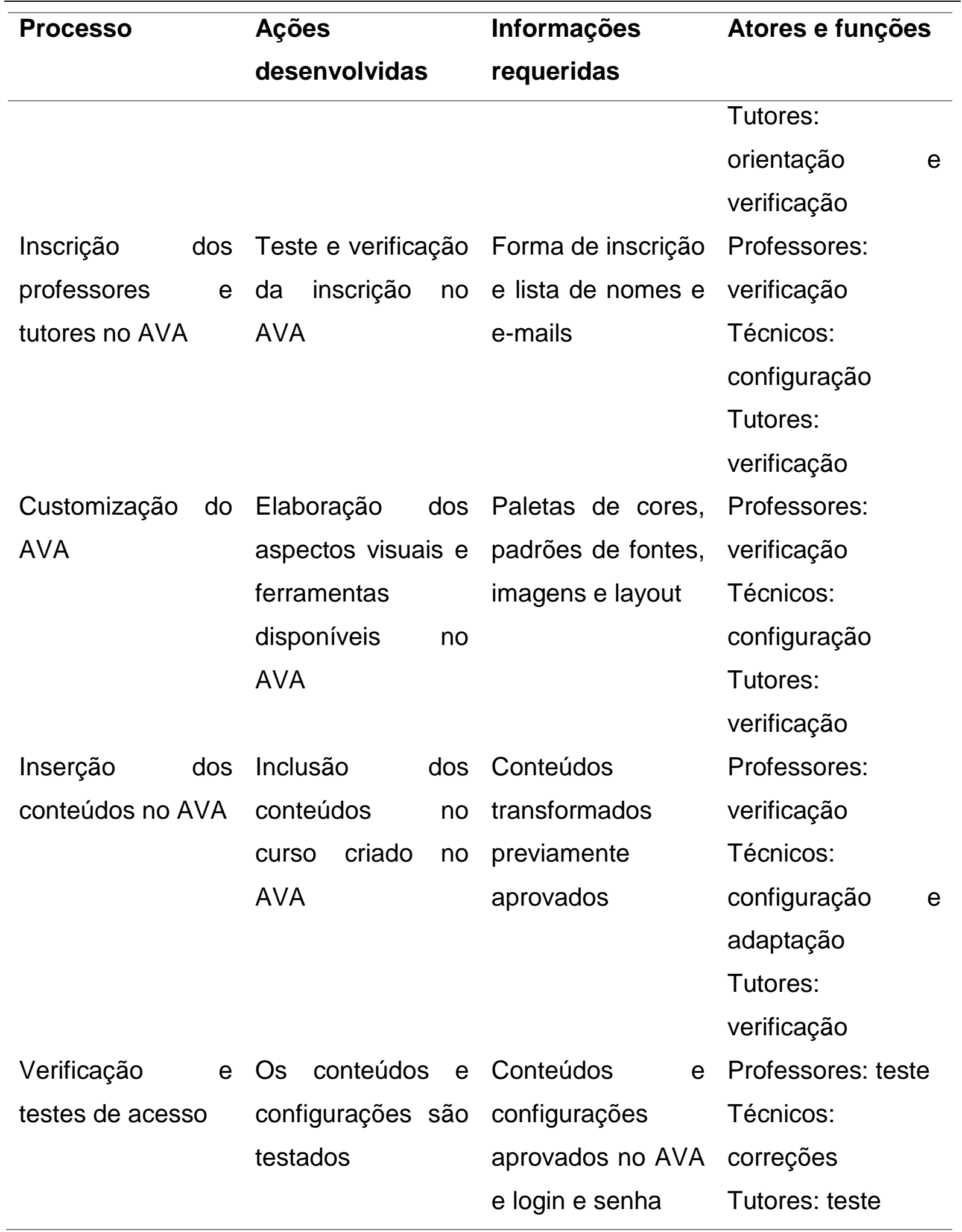

Tabela 10. Ações desenvolvidas na etapa de dinâmica do curso 
Estudo 02: Desenvolvimento de um Curso Online para Educação Continuada de Fonoaudiólogos sobre Intervenção em Linguagem Oral Infantil

\begin{tabular}{|c|c|c|c|c|}
\hline Processo & $\begin{array}{l}\text { Ações } \\
\text { desenvolvidas }\end{array}$ & & $\begin{array}{l}\text { Informações } \\
\text { requeridas }\end{array}$ & Atores e funções \\
\hline $\begin{array}{l}\text { Inscrição dos } \\
\text { estudantes }\end{array}$ & $\begin{array}{l}\text { Preparo } \\
\text { recebimento } \\
\text { inscrições } \\
\text { automatizadas }\end{array}$ & $\begin{array}{l}\text { para } \\
\text { de }\end{array}$ & $\begin{array}{l}\text { Forma de inscrição } \\
\text { e lista de nomes e } \\
\text { e-mails de } \\
\text { estudantes }\end{array}$ & $\begin{array}{l}\text { Professores: } \\
\text { verificação } \\
\text { Técnicos: } \\
\text { programação } \\
\text { Tutores: } \\
\text { verificação }\end{array}$ \\
\hline $\begin{array}{l}\text { Oferecimento do } \\
\text { curso }\end{array}$ & $\begin{array}{l}\text { Ativação } \\
\text { conteúdos, } \\
\text { notificações } \\
\text { correções } \\
\text { atividades, } \\
\text { verificação } \\
\text { acesso }\end{array}$ & $\begin{array}{l}\text { dos } \\
\text { e } \\
\text { das } \\
\text { do }\end{array}$ & $\begin{array}{l}\text { Ações dos alunos, } \\
\text { professores } \\
\text { tutores }\end{array}$ & $\begin{array}{l}\text { Professores: } \\
\text { verificação, } \\
\text { notificação, } \\
\text { correção } \\
\text { Técnicos: } \\
\text { acompanhamento } \\
\text { Tutores: } \\
\text { acompanhamento, } \\
\text { correção }\end{array}$ \\
\hline
\end{tabular}

Figura 8 - Etapas e processos executados neste estudo 


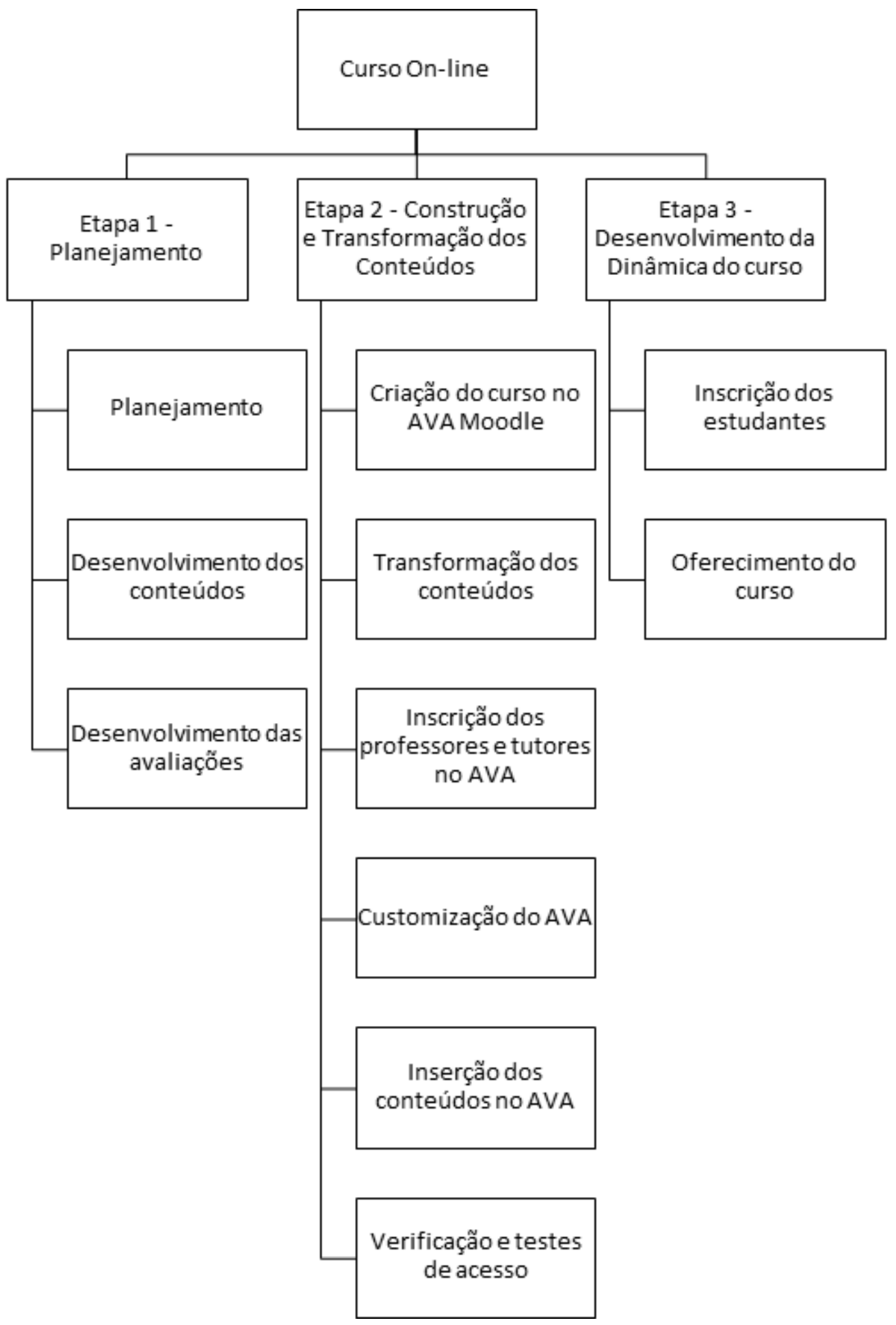

Fonte: Elaborado pelo autor

\subsection{1 - Etapa de Planejamento}

5.2.1.1 - Planejamento 
O trabalho de planejamento foi realizado em um curto período de tempo (20 dias úteis), com a participação ativa de todos os membros da equipe. Durante as reuniões, foram definidos as datas e horários para gravação das aulas e o cronograma para preparação dos materiais do curso, levando-se também em consideração o calendário acadêmico da instituição de ensino, neste caso, a USP - Campus Bauru. Além disso, durante as reuniões foi definido o cronograma e ementa do curso (Tabela 11).

Tabela 11. Cronograma do Curso

\begin{tabular}{|c|c|c|c|}
\hline Módulo & Conteúdo Programático & Início & Término \\
\hline $\begin{array}{l}\text { Alterações de } \\
\text { Linguagem Infantil }\end{array}$ & $\begin{array}{l}\text { Neste módulo, o aluno poderá } \\
\text { conhecer um pouco mais sobre os } \\
\text { quadros mais frequentes das } \\
\text { alterações de linguagem oral que } \\
\text { englobam déficits em todos os } \\
\text { níveis de linguagem (fonológico, } \\
\text { sintático, morfológico, semântico } \\
\text { e pragmático). Para isso, serão } \\
\text { abordados o Atraso de } \\
\text { Linguagem, o Distúrbio Específico } \\
\text { de Linguagem (DEL) e o } \\
\text { Transtorno do Espectro Autista } \\
\text { (TEA), trazendo informações } \\
\text { sobre definições, diagnóstico } \\
\text { diferencial e características, } \\
\text { enfocando principalmente como } \\
\text { essas diferenças nos quadros } \\
\text { influenciam durante a intervenção } \\
\text { fonoaudiológica na área da } \\
\text { Linguagem. }\end{array}$ & $20 / 09 / 2017$ & $03 / 10 / 2017$ \\
\hline $\begin{array}{l}\text { Avaliando } \\
\text { Intervir }\end{array}$ & $\begin{array}{l}\text { Neste módulo, o aluno poderá } \\
\text { conhecer um pouco mais sobre a } \\
\text { avaliação fonoaudiológica na área }\end{array}$ & 04/10/2017 & $15 / 10 / 2017$ \\
\hline
\end{tabular}




\begin{tabular}{|c|c|c|c|}
\hline Módulo & Conteúdo Programático & Início & Término \\
\hline & $\begin{array}{l}\text { de Linguagem Infantil, pensando } \\
\text { na avaliação como base e } \\
\text { indicador de progresso no } \\
\text { processo de intervenção. Para } \\
\text { isso, serão abordados a } \\
\text { importância da avaliação, } \\
\text { protocolos utilizados para a } \\
\text { avaliação da linguagem e todos } \\
\text { os seus aspectos, e como utilizar } \\
\text { estes resultados no processo } \\
\text { interventivo. }\end{array}$ & & \\
\hline Orientação Escolar & $\begin{array}{l}\text { Neste módulo, o aluno poderá } \\
\text { conhecer um pouco mais sobre } \\
\text { como incluir a escola no processo } \\
\text { interventivo. }\end{array}$ & $16 / 10 / 2017$ & $22 / 10 / 2017$ \\
\hline $\begin{array}{l}\text { Orientação } \\
\text { Familiar }\end{array}$ & $\begin{array}{l}\text { Neste módulo, o aluno poderá } \\
\text { conhecer um pouco mais sobre } \\
\text { como incluir a família no processo } \\
\text { interventivo. }\end{array}$ & $23 / 10 / 2017$ & $29 / 10 / 2017$ \\
\hline $\begin{array}{l}\text { Planejamento } \\
\text { Interventivo e } \\
\text { Comportamento } \\
\text { Infantil }\end{array}$ & $\begin{array}{l}\text { Neste módulo, o aluno poderá } \\
\text { conhecer um pouco mais sobre } \\
\text { como realizar um bom } \\
\text { planejamento interventivo. Para } \\
\text { isso, serão abordados as } \\
\text { características e aspectos que } \\
\text { precisam ser observados para o } \\
\text { bom delineamento da } \\
\text { intervenção, bem como a } \\
\text { apresentação de programas, } \\
\text { métodos e modelos interventivos } \\
\text { descritos na literatura. Além disso, } \\
\text { o aluno poderá conhecer um }\end{array}$ & $30 / 10 / 2017$ & $05 / 11 / 2017$ \\
\hline
\end{tabular}




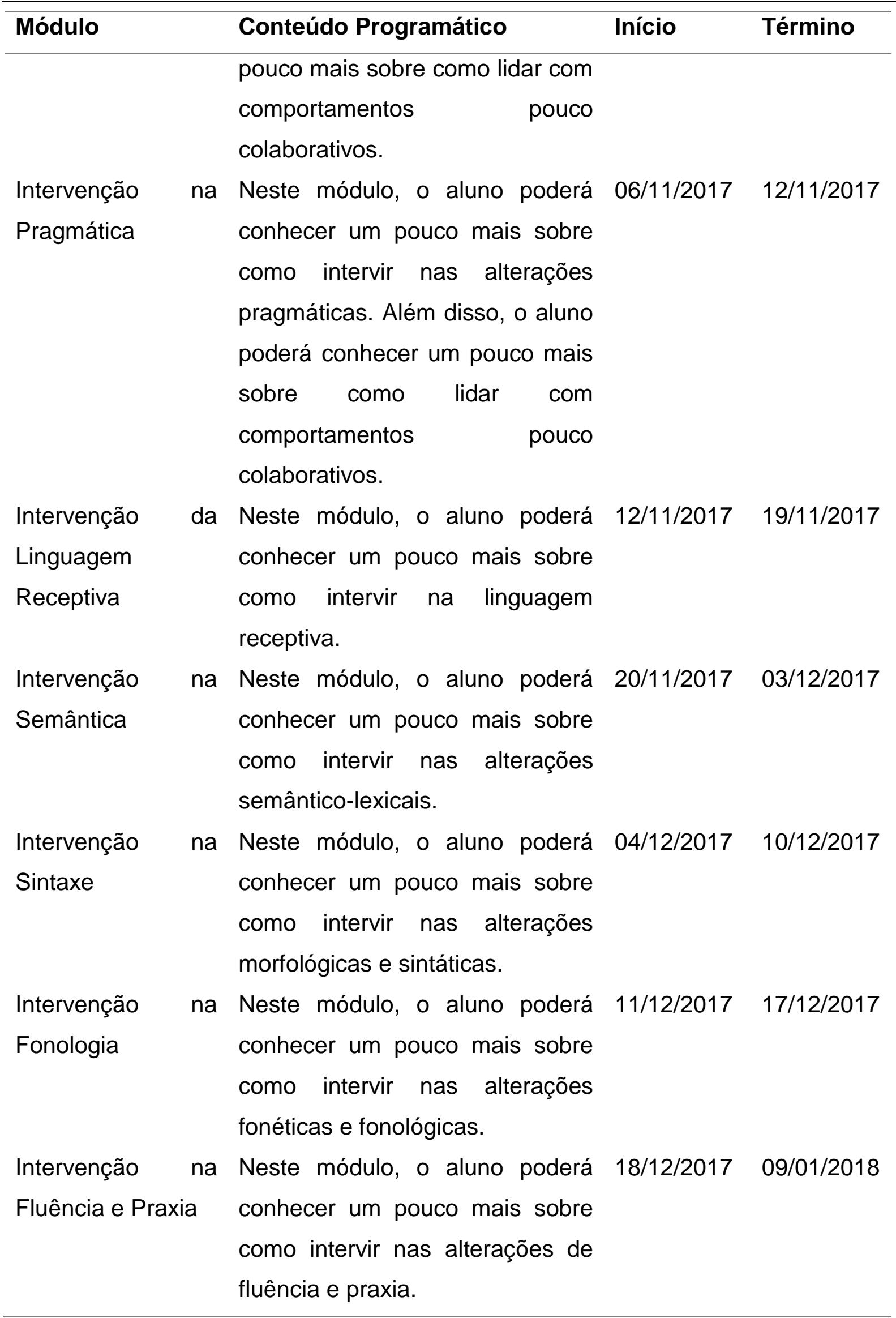




\begin{tabular}{|c|c|c|c|}
\hline Módulo & Conteúdo Programático & Início & Término \\
\hline $\begin{array}{l}\text { Intervenção nas } \\
\text { Habilidades } \\
\text { Metalinguísticas, } \\
\text { na Memória e nas } \\
\text { Funções } \\
\text { Executivas }\end{array}$ & $\begin{array}{l}\text { Neste módulo, o aluno poderá } \\
\text { conhecer um pouco mais sobre } \\
\text { como intervir nas alterações de } \\
\text { consciência sintática e fonológica. } \\
\text { Além disso, o aluno poderá } \\
\text { conhecer um pouco mais sobre } \\
\text { como intervir nas alterações de } \\
\text { memória e de funções executivas } \\
\text { associadas à Linguagem. }\end{array}$ & $10 / 01 / 2018$ & $23 / 01 / 2018$ \\
\hline $\begin{array}{l}\text { Considerações } \\
\text { Finais }\end{array}$ & Encerramento do curso. & $24 / 01 / 2018$ & $31 / 01 / 2018$ \\
\hline
\end{tabular}

O processo de planejamento foi realizado de forma satisfatória, sem apresentar dificuldades técnicas; todas as etapas e definições de planejamento foram realizadas dentro do cronograma.

\subsubsection{2 - Desenvolvimento dos Conteúdos}

O conteúdo foi desenvolvido pelo corpo docente, utilizando ferramentas de software as quais eles já estavam acostumados, eliminando a necessidade de treinamento. A equipe técnica participou ativamente para auxiliar nos casos de incompatibilidade entre versões, para que não houvesse perda de produtividade no desenvolvimento do conteúdo, bem como retrabalho.

O processo de desenvolvimento do conteúdo iniciou-se ao mesmo tempo que o processo de aprovação do decano da Reitoria de Cultura e Extensão da USP, tendo sido concluído em um período total de 90 dias. O trabalho colaborativo da equipe de ensino foi realizado por e-mail e reuniões presenciais. Os modelos e formatos das aulas expositivas e guias didáticos das atividades foram estabelecidos em conjunto com o tutor/mediador e corpo docente. O desenvolvimento ocorreu de forma rápida e natural, confirmando a estratégia de manter as ferramentas já utilizadas pelos professores. Ao final deste processo, foi elaborada uma lista com os conteúdos de cada módulo: 
- Início do Curso

- Sejam bem-vindos

- Explicação sobre o Curso de Intervenção Fonoaudiológica em Linguagem Infantil

- Cronograma do Curso

- Vídeo Interativo sobre Como utilizar o Fórum

- Módulo 1 - Alterações de Linguagem Infantil

- Aulas sobre Atraso de Linguagem

- Parte 1 - Definições e características

- Parte 2 - Etiologia e prognóstico

- Parte 3 - Princípios de intervenção

- Aulas sobre Distúrbio Específico de Linguagem

- Parte 1 - Definições e características

- Parte 2 - Etiologia e prognóstico

- Parte 3 - Princípios de intervenção

- Aulas sobre Transtorno do Espectro Autista

- Parte 1 - Definições e características

- Parte 2 - Etiologia e prognóstico

- Parte 3 - Princípios de intervenção

- Infográfico sobre as Alterações da Linguagem na Infância

- Vídeo da Internet: Lev Vigotski - Desenvolvimento da linguagem

- Vídeo da Internet: Como funciona o cérebro da pessoa com autismo?

- Vídeo da Internet: Série "Autismo", no Fantástico

- Vídeo da Internet: Filme francês "O cérebro de Hugo", sobre autismo

- Vídeo da Internet: Falando um pouco sobre o Autismo com a Prof ${ }^{a}$ Maria Elisa Fonseca

- Artigos para consulta

- Módulo 2 - Avaliando para Intervir

- Aula sobre Avaliando para Intervir 
- Aula sobre Escalas de Avaliação de Linguagem

- Aula sobre Avaliando a Forma da Linguagem: Fonologia e Sintaxe

- Aula sobre Avaliando o Conteúdo da Linguagem: Semântica

- Aula sobre Avaliando as Habilidades Psicolinguísticas

- Vídeo da Internet: CONFIART - Instrumento de avaliação da consciência fonoarticulatória

- Vídeo da Internet: ADL - Avaliação do Desenvolvimento da Linguagem - Aplicação

- Vídeo da Internet: ADL - Avaliação do Desenvolvimento da Linguagem

- Vídeo da Internet: PROLEC Provas de Avaliação dos Processos de Leitura

- Vídeo da Internet: Testes de vocabulário em crianças de 2 a 5 anos - Pesquisadora Miriam Damazio

- Vídeo da Internet: Avaliação de Conceitos Básicos

- Vídeo da Internet: Avaliando Articulação e Fonologia com o iPad

- Vídeo da Internet: Seminário Perturbações dos Sons da Fala: Avaliação e Intervenção

- Artigos para consulta

\section{- Módulo 3 - Orientação Escolar}

- Aulas sobre Orientação Escolar

- Atuação do Fonoaudiólogo no Ambiente Escolar

- Estratégias

- Vídeo da Internet: Fonoaudiologia educacional - Conexão Futura - Canal Futura

- Vídeo da Internet: Vídeo sobre a Fonoaudiologia Educacional

- Vídeo da Internet: 3x4: Contação de histórias como auxílio à aprendizagem

- Artigos para consulta 
- Módulo 4 - Orientação Familiar

- Aula sobre Orientação a Familiares de Crianças com Alteração de Linguagem

- Aula sobre Intervenção Indireta

- Artigos para consulta

- Módulo 5 - Planejamento Interventivo e Comportamento Infantil

- Aula sobre Planejamento Interventivo nas Alterações da Linguagem Infantil

- Aula sobre Planejando Intervenções em Grupo

- Artigos para consulta

- Módulo 6 - Intervenção na Pragmática

- Aulas sobre Avaliando o uso da Linguagem: Pragmática

○ Definições

- Protocolos

- Aula sobre Avaliando o uso da Linguagem: Narrativa

- Aula sobre Desenvolvimento Narrativo-Pragmático

- Aulas sobre Intervenção nas Habilidades NarrativoPragmáticas

○ Definições

- Características nas crianças com Atraso de Linguagem

- Características nas crianças com DEL

- Características nas crianças com TEA

- Princípios de Intervenção

- Sugestões de Estratégias

- Artigos para consulta

- Módulo 7 - Intervenção da Linguagem Receptiva

- Aulas sobre Intervenção na Linguagem Receptiva

○ Introdução

- Princípios de Intervenção

- Estratégias

- Artigos para consulta 
- Módulo 8 - Intervenção na Semântica

- Aulas sobre Intervenção na Semântica-Lexical

○ Introdução

- Princípios de Intervenção

- Estratégias

- Vídeo da Internet: Aplicativos para o iPad para fonoaudiologia - Aprendendo Adjetivos

- Vídeo da Internet: Aprendendo Adjetivos - Para crianças com autismo e distúrbios de linguagem

- Artigos para consulta

- Módulo 9 - Intervenção na Sintaxe

- Aulas sobre Intervenção na Morfologia e na Sintaxe

- Desenvolvimento Típico

- Características nas crianças com Atraso de Linguagem

- Características nas crianças com DEL

- Características nas crianças com TEA

- Princípios de Intervenção

- Artigos para consulta

- Módulo 10 - Intervenção na Fonologia

- Aulas sobre Intervenção na Fonologia
- Introdução
- Processos Fonológicos
- Princípios de Intervenção
○ Estratégias

- Artigos para consulta

- Módulo 11 - Intervenção na Fluência e Praxia

- Aulas Sobre Intervenção na Fluência

- Introdução

- Avaliação da Fluência

- Princípios de Intervenção

- Aulas Sobre Intervenção na Praxia

○ Introdução 
- Avaliação

- Princípios de Intervenção

- Artigos para consulta

- Módulo 12 - Intervenção nas Habilidades Metalinguísticas, na Memória e nas Funções Executivas

- Aulas sobre Intervenção nas Habilidades Metalinguísticas, na Memória e nas Funções Executivas

○ Introdução

- Habilidades Perceptivo-Auditivas

○ Metalinguagem

- Artigos para consulta

\section{- Módulo 13 - Considerações Finais}

- Encerramento

As informações transmitidas pelos professores à equipe técnica foram identificadas durante o processo de criação do curso e contribuíram para a composição do roteiro proposto nesta etapa, que foi criado rapidamente e sem erros. O administrador técnico obteve as informações necessárias dos professores e estas foram imediatamente usadas no processo de criação.

\subsubsection{3 - Desenvolvimento das Avaliações}

As avaliações foram desenvolvidas pelo corpo docente, utilizando ferramentas de software as quais eles já estavam acostumados, conforme processo anterior. Neste processo, foi determinada a quantidade de avaliações, temas abordados e ferramentas. Na escolha das ferramentas, a equipe técnica e tutores/moderadores foram consultados para que fosse possível incluir as avaliações no AVA/Moodle e que fosse de fácil utilização para os alunos.

Esta etapa ocorreu em paralelo com o processo anterior, tendo sido concluída também em um período total de 90 dias. O trabalho colaborativo foi realizado por e-mail e reuniões presenciais. O desenvolvimento ocorreu de forma rápida e natural. Ao final da elaboração das avaliações, elas foram verificadas pelos tutores/moderadores. Conforme o processo anterior, foi elaborada uma lista com as 
avaliações de cada módulo, facilitando a inclusão no AVA/Moodle e em sua conferência:

- Avaliação Inicial

- Questionário de caracterização

- Prova Diagnóstica

- Questionário Sobre Aquisição e Desenvolvimento de Linguagem Infantil

- Módulo 1 - Alterações de Linguagem Infantil

- Fórum

- Construindo Materiais Informativos

- Questionário

- Observação de características linguísticas em crianças (5 casos - Análise de vídeo)

- Módulo 2 - Avaliando para Intervir

- Fórum

- Questionário

- Classificando os processos fonológicos e semânticos

- Tarefa Aplicação e Análise de Protocolos de Avaliação

- Módulo 3 - Orientação Escolar

- Fórum

- Elaboração de propostas para atuação escolar

- Questionário

- Módulo 4 - Orientação Familiar

- Fórum

- Relato de Experiência: Refletindo sobre as práticas com a família

- Questionário

- Módulo 5 - Planejamento Interventivo e Comportamento Infantil

- Fórum

- Planejando uma Intervenção

- Pesquisa sobre os métodos/técnicas de intervenção 
- Módulo 6 - Intervenção na Pragmática

- Fórum

- Avaliando a Narrativa

- Oficina de Estratégias

- Questionário

- Módulo 7 - Intervenção da Linguagem Receptiva

- Fórum

- Oficina de Estratégias

- Questionário

- Módulo 8 - Intervenção na Semântica

- Fórum

- Oficina de Estratégias

- Questionário

- Módulo 9 - Intervenção na Sintaxe

- Fórum

- Oficina de Estratégias

- Questionário

- Módulo 10 - Intervenção na Fonologia

- Fórum

- Oficina de Estratégias

- Questionário

- Módulo 11 - Intervenção na Fluência e Praxia

- Fórum

- Oficina de Estratégias

- Questionário

- Módulo 12 - Intervenção nas Habilidades Metalinguísticas, na Memória e nas Funções Executivas

- Fórum

- Oficina de Estratégias

- Questionário

- Módulo 13 - Considerações Finais

- Prova Diagnóstica

- Avaliação do curso 
Durante o desenvolvimento do trabalho de transformação das aulas expositivas, foi pensado o formato que cumpria a função de informar plenamente o aluno e indicar claramente os conteúdos e caminhos recomendados, pois não haveria presença física do professor. Esse desafio foi solucionado por meio da inclusão de elementos de texto para orientação e adaptação da linguagem usada pelo professor, tentando traduzir os discursos das aulas por elementos contidos na própria apresentação.

O trabalho de inserção de conteúdo foi realizado principalmente pelo administrador técnico. Observou-se, durante o trabalho, a necessidade de informações adicionais para o seu pleno desenvolvimento, obtidas junto aos professores, durante o trabalho de inserção. Em alguns momentos, foi fundamental fazer o acesso e a verificação em tempo real, no AVA, com os professores, para fazer os ajustes necessários. Na inserção do conteúdo, foi imprescindível dialogar com os professores para definir informações complementares e corrigir a sequência do conteúdo disponível.

Para inserir os links de acesso para as leituras, o administrador local usou a ferramenta "adicionar etiqueta", com a opção de abrir uma nova janela do navegador para cada link de leitura disponível. A Figura 9 ilustra como os textos e leituras complementares foram apresentados durante os módulos do curso.

Figura 9 - Exemplo de exibição dos materiais complementares 
Estudo 02: Desenvolvimento de um Curso Online para Educação Continuada de Fonoaudiólogos sobre Intervenção em Linguagem Oral Infantil

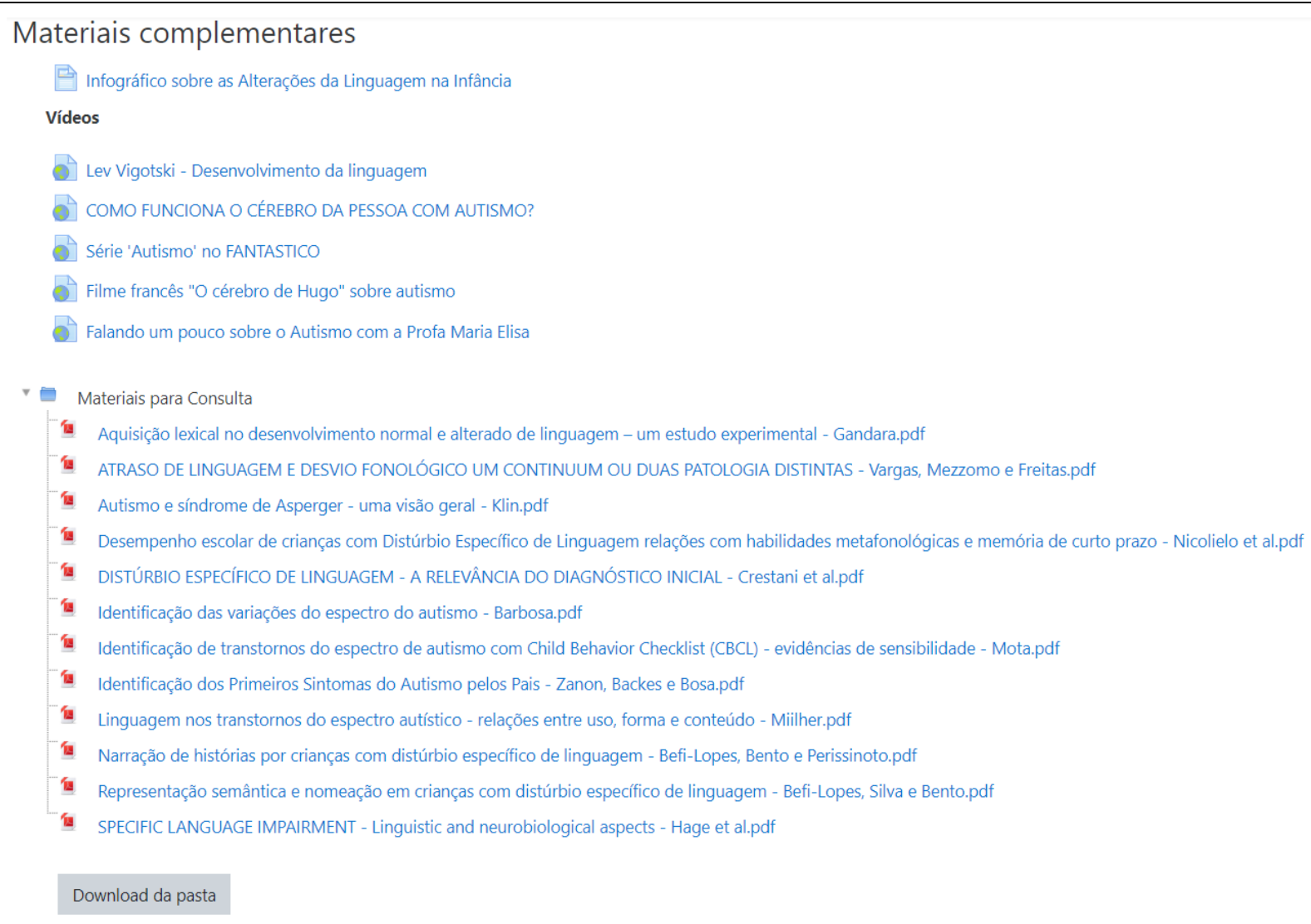

Fonte: Elaborado pelo autor

Para o desenvolvimento do curso on-line, foi seguido um modelo com princípios de design instrucional, que considera o formato da apresentação e o estilo de aprendizagem, que estimula à reflexão e inclui planos de orientação ao aluno.

Para o processo de inscrição, foi planejada a elaboração de um formulário eletrônico padrão fornecido pelo sistema de inscrição Apolo, utilizado pela USP para cursos de extensão universitária. Considerou-se que o modelo foi bem aceito, pois, os estudantes não tiveram dificuldades no acesso. A Figura 10 mostra o passo a passo de inscrição no curso. 


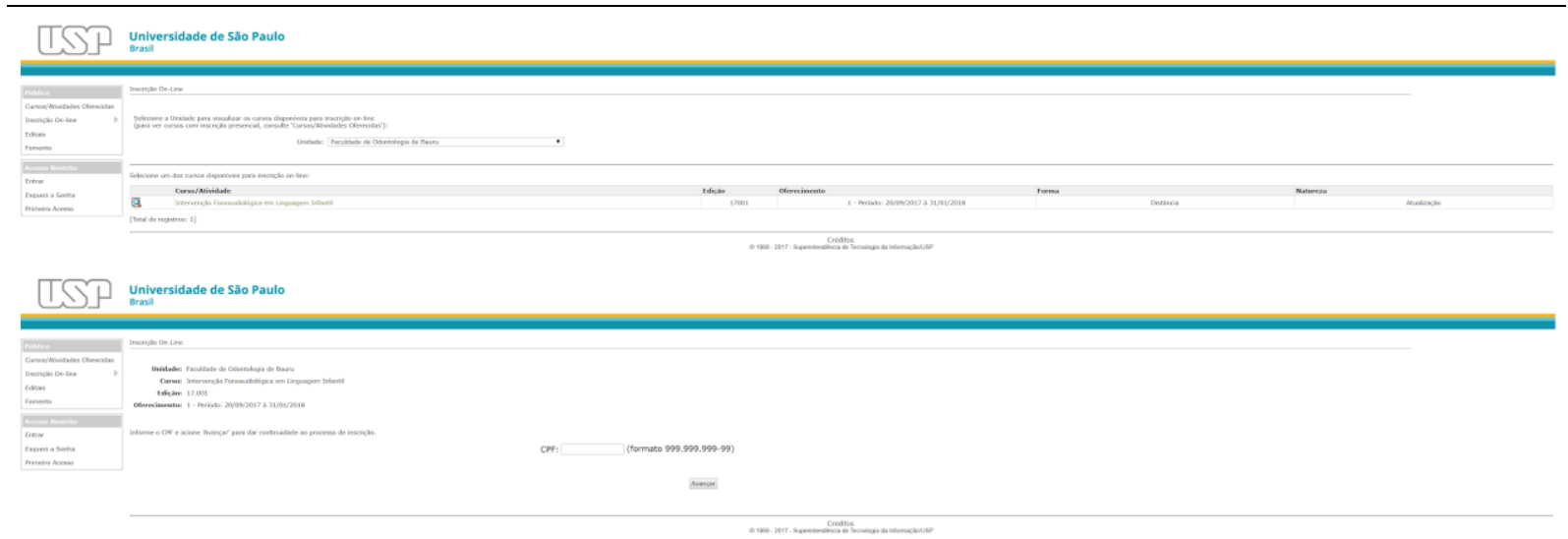

Fonte: Elaborado pelo autor

Em relação ao desenvolvimento, o curso foi configurado com uma carga horária estimada de 60 horas e disponibilizado na plataforma Moodle $\AA 3.1$, no endereço eletrônico http://cursoinfoli.com.br, com acesso por login, na tela de identificação. O desenho do curso foi delineado, com base na matriz de desenho instrucional, em doze unidades de aprendizagem definidas, incluindo objetivos educacionais específicos, conteúdo, objetos de aprendizagem, estratégias pedagógicas e critérios de avaliação. $\mathrm{Na}$ tela inicial, foram exibidos ícones para acessar o tutorial, a avaliação diagnóstica, o plano de curso, as dúvidas e o certificado, que mostravam as informações essenciais para o estudo do participante. No tutorial, foram exemplificadas as diretrizes sobre os comandos e a operação dos ícones, o objetivo educacional geral do curso, as estratégias de avaliação da aprendizagem e a rota de navegação para ilustrar os caminhos percorridos pelo participante durante 0 processo de aprendizagem pelas unidades de ensino. A Figura 11 ilustra o tutorial do curso.

Figura 11 - Exemplo de um tutorial do curso sobre o uso de fóruns de discussões 


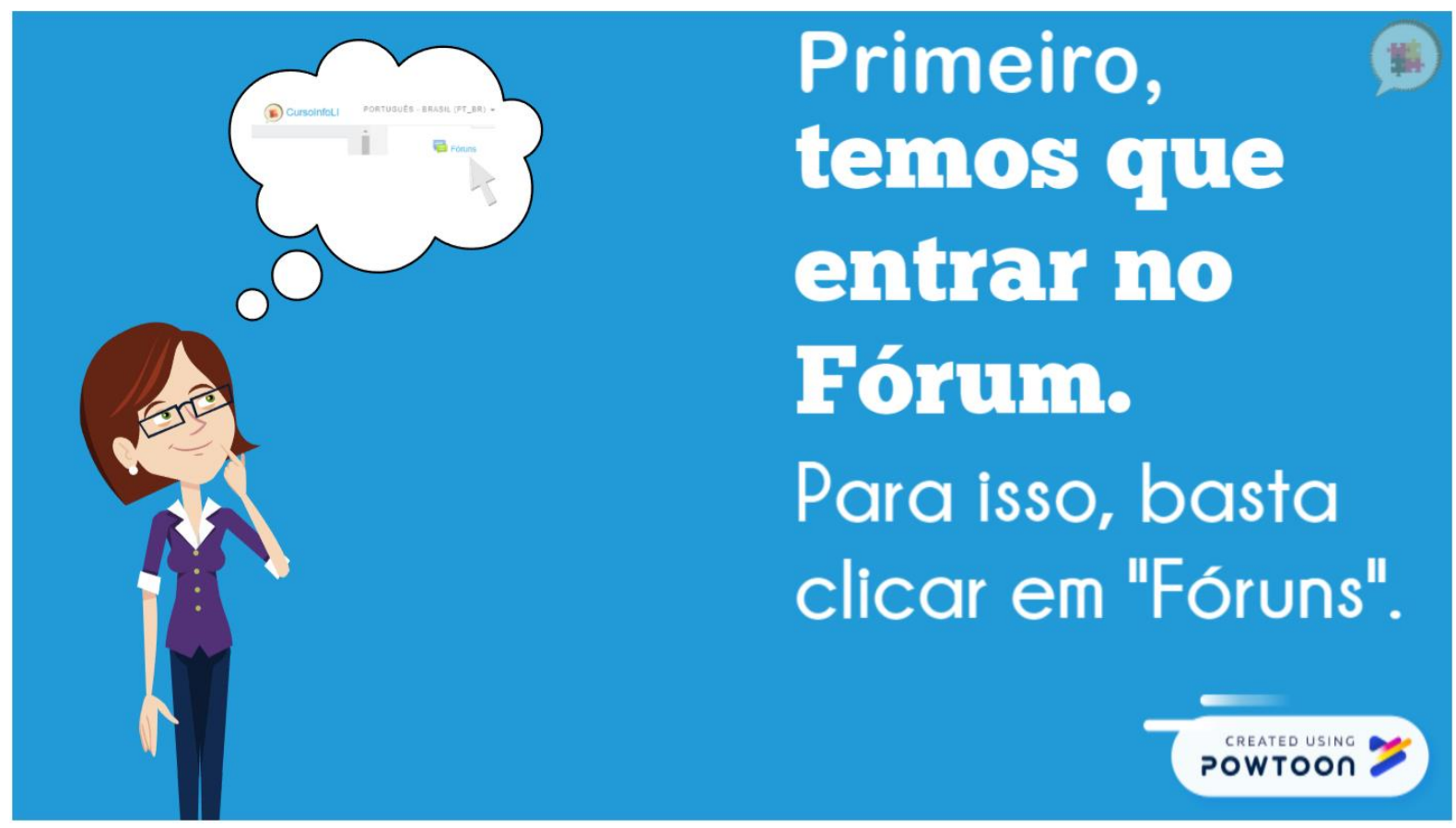

Fonte: Elaborado pelo autor

Para iniciar o curso, o participante deveria realizar a atividade denominada "avaliação diagnóstica" (Apêndice $\mathrm{C}$ ), utilizando um questionário composto por 36 perguntas, quatro para cada tema, abordadas nas doze unidades de aprendizagem com o objetivo de identificar as lacunas de conhecimento do participante e quais temas precisam revisar na íntegra ou em partes, e, dessa forma, orientar os caminhos a serem seguidos durante os estudos. Cada uma das unidades de aprendizagem continha uma pergunta de plantão na forma de um fórum de discussão, onde os alunos tinham acesso aos professores para responder às perguntas que estavam disponíveis para todos os participantes. A seção "materiais complementares" forneceu materiais didáticos complementares e de apoio para expandir o conhecimento, como diretrizes nacionais e internacionais para fonoaudiologia, artigos científicos, infográficos, links para páginas da web e vídeos, com acesso gratuito. $\mathrm{O}$ "certificado" foi disponibilizado aos estudantes por meio da Pró-Reitoria de Cultura e Extensão da USP. As unidades de aprendizagem foram estruturadas usando o recurso "lição" do Moodle $\circledast$, adotando hipertextos, vídeos, videoaulas, exercícios de aprendizagem e jogos digitais. Os hipertextos permitem o acesso a outros conteúdos, páginas ou unidades de aprendizagem de maneira flexível, dinâmica e não sequencial. 

Fonoaudiólogos sobre Intervenção em Linguagem Oral Infantil

O curso teve duração de 5 meses e meio e contou com 75 fonoaudiólogos participantes, sendo que ao total foram realizadas 535 inscrições. Durante todo 0 curso o planejamento foi executado com exatidão.

Notou-se também que o referido curso on-line não atraiu mais fonoaudiólogos de regiões menos densamente povoadas (Tabela 12); no entanto, aqueles que o fizeram tiveram maior probabilidade de concluir todo o curso do que seus colegas localizados em áreas mais densamente povoadas do país.

Tabela 12. Número de Fonoaudiólogos interessados no curso por região.

\begin{tabular}{|c|c|c|c|c|c|}
\hline Região & $\begin{array}{l}\text { Número de } \\
\text { Fonoaudiólogos } \\
\text { Interessados no } \\
\text { Curso On-line (a) }\end{array}$ & $\begin{array}{l}\text { Número de } \\
\text { Fonoaudiólog } \\
\text { os com título } \\
\text { de } \\
\text { especialista } \\
\text { em linguagem } \\
\text { pelo Conselho } \\
\text { Federal de } \\
\text { Fonoaudiolog } \\
\text { ia (b) }\end{array}$ & $\begin{array}{l}\text { Número de } \\
\text { Fonoaudiólo } \\
\text { gos com } \\
\text { registro (c) }\end{array}$ & $\mathbf{a} / \mathbf{b}$ & a / c \\
\hline Sudeste & 368 & 665 & 23393 & $55.34 \%$ & $1.57 \%$ \\
\hline Sul & 56 & 116 & 6036 & $48.28 \%$ & $0.93 \%$ \\
\hline Nordeste & 51 & 59 & 7618 & $86.44 \%$ & $0.66 \%$ \\
\hline Centro-oeste & 34 & 118 & 3290 & $28.81 \%$ & $1.03 \%$ \\
\hline Norte & 26 & 7 & 2083 & $371.43 \%$ & $1.25 \%$ \\
\hline Total & 535 & 965 & 42420 & $55.44 \%$ & $1.26 \%$ \\
\hline
\end{tabular}




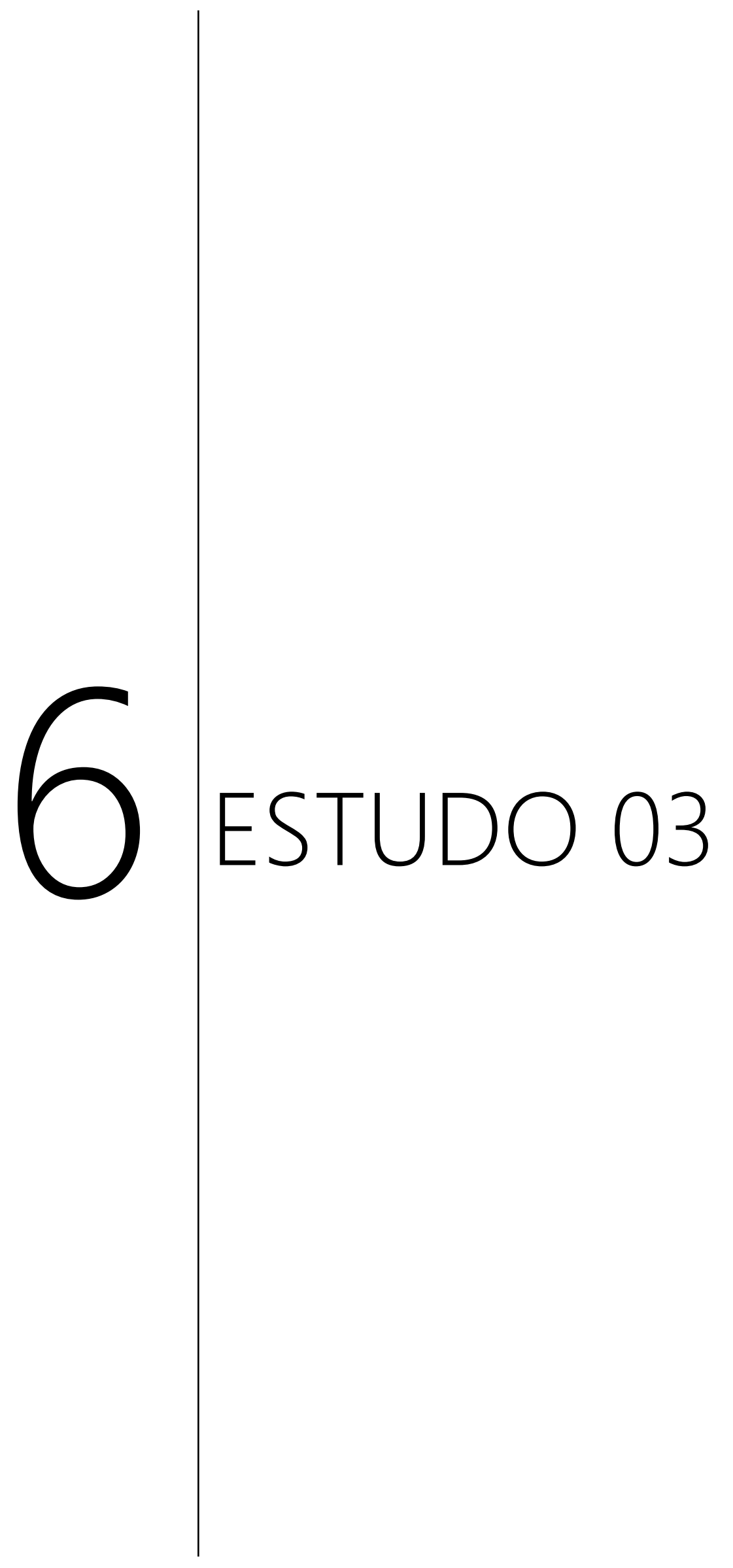





\section{6 - ESTUDO 03: AMBIENTE VIRTUAL DE APRENDIZAGEM PARA O TREINO DE FONOAUDIÓLOGOS EM LINGUAGEM INFANTIL}

\section{$6.1-$ METODOLOGIA}

\subsection{1 - Local}

Todos os procedimentos foram realizados na Faculdade de Odontologia de Bauru (FOB-USP).

\subsection{2 - Participantes}

Participaram deste estudo um total de 74 fonoaudiólogos que cursaram a referida atualização.

\subsubsection{1 - Critérios para a seleção da amostra}

Critérios de inclusão:

- Ter anuência para a participação no estudo, o que foi comprovado mediante a assinatura do Termo de Consentimento Livre e Esclarecido pelos participantes.

- Ser fonoaudiólogo ativo em seu conselho regional.

Critérios de exclusão:

- Não apresentar o Termo de Consentimento Livre e Esclarecido.

\subsubsection{2 - Seleção da amostra}

A seleção dos participantes do experimento foi realizada segundo a técnica de amostragem não probabilística por conveniência (FARMER; MILLER; LAWRENSON, 1996), de modo que os participantes selecionados foram os mais próximos e mais convenientes para realizar o experimento, o que será definido por conveniência à disponibilidade do sujeito em participar do estudo. 
A proposta do curso foi enviada para a Pró-reitoria de Cultura e Extensão da USP, sob código de processo no 2017.1.1664.25.3, e aprovada por este colegiado (Anexo B), sendo que o curso foi oferecido como extensão universitária da instituição sob código 250300008.

\subsection{3 - Ética na Pesquisa}

O estudo foi aprovado (Anexo A) pelo Comitê de Ética em pesquisa com Seres Humanos da FOB - USP, sob o número do Parecer 2.062.999. Nenhuma etapa de coleta foi iniciada antes da aprovação do referido parecer. Os participantes da pesquisa assinaram o Termo de Consentimento Livre e Esclarecido. O projeto foi elaborado de forma a respeitar a Resolução 466/12 do Conselho Nacional de Saúde.

\subsection{4 - Procedimentos De Coleta De Dados}

Foram recrutados 74 fonoaudiólogos neste estudo. Eles foram submetidos a uma avaliação pré-AVA (Ambiente Virtual de Aprendizagem), que foi composta por um questionário desenvolvido especificamente para este trabalho, a fim de verificar a retenção de informações prévias sobre o assunto. Ao final do curso, os fonoaudiólogos foram submetidos a uma avaliação pós-AVA, composta pelo mesmo questionário. Dessa forma, foi possível comparar a melhora no desempenho deles.

Já em relação à satisfação com o curso, foram utilizados os questionários Incidentes Críticos (Anexo C) e o ATTLS (Anexo D) para autoavaliação e avaliação de satisfação (respectivamente) em cada módulo. Já para a avaliação final, foi utilizado o COLLES versão "expectativas e experiência efetiva" (Anexo E). Todos os questionários são sugeridos pelo próprio Moodle para a avaliação desse tipo de curso.

\section{2 - FORMA DE ANÁLISE DOS RESULTADOS}

\subsection{1 - Análise Descritiva}


A princípio, foi realizada uma análise descritiva dos resultados para a obtenção de gráficos e tabelas de frequência, com o intuito de caracterizar os indivíduos. Para descrição dos resultados foram utilizadas a frequência absoluta e a porcentagem para as variáveis categóricas. A frequência absoluta $\left(n_{i}\right)$ é dada pelo número de vezes em que uma determinada variável assume um determinado valor/categoria em questão. A porcentagem $\left(p_{i}\right)$ é o resultado da razão entre a frequência absoluta e o tamanho da amostra, multiplicado por 100, isto é, $100 \cdot \frac{n_{i}}{n} \%$. Já para a descrição das variáveis numéricas, serão utilizadas a média aritmética, o desvio padrão, a mediana, o mínimo e o máximo. A média aritmética simples é dada por $\bar{x}=\frac{1}{n} \sum_{i=1}^{n} x_{i}$, em que $x_{1}, \ldots, x_{n}$ são os $\mathrm{n}$ valores de uma determinada variável $X \mathrm{e}$ o desvio padrão por $s=\sqrt{\frac{1}{n-1} \sum_{i=1}^{n}\left(x_{i}-\bar{x}\right)^{2}}$.

\subsection{2 - Correlação}

Uma vez que a distribuição das variáveis de interesse, avaliadas por meio do teste de Shapiro-Wilk, foge à normalidade, optou-se pela utilização do teste não paramétrico de correlação por postos de Spearman (1904), que não faz nenhuma suposição sobre a distribuição dos dados e é apropriado para variáveis com escala ao menos ordinal. De acordo com Gibbons e Chakraborti (2003), tal coeficiente é uma medida da associação entre duas variáveis, que avalia o grau de correspondência entre posições em vez dos valores reais de variáveis.

Um escore $R_{X}$ é atribuído a cada observação de $X$, referentes aos postos das observações de cada variável. Caso ocorram empates, o escore é dado pela média das ordens das observações repetidas. Do mesmo modo, um escore $R_{Y}$ é atribuído a cada observação de $Y$. Seja n o número de observações e $d_{i}=R_{X_{i}}-R_{Y_{i}}$, de acordo Sheskin (2003), a estatística $r_{S}$ dada pela fórmula abaixo:

$$
r_{S}=1-\frac{6 \sum_{i=1}^{n} d_{i}^{2}}{n\left(n^{2}-1\right)}
$$


O coeficiente $r_{S}$ varia no intervalo de $(-1,1)$. O sinal indica a direção da correlação, inversa (negativa) ou direta (positiva); enquanto que o valor indica a força da correlação. Quanto mais próximo o coeficiente estiver de -1 ou 1, mais forte é a correlação entre as variáveis. Por outro lado, se a correlação for igual a zero, não existe relação entre as variáveis em estudo.

\subsection{3 - Comparação}

Para avaliar a diferença das pontuações na prova diagnóstica pré e pós, optou-se pelo teste não paramétrico de Wilcoxon pareado, indicado na situação em que as suposições realizadas nos testes paramétricos não são verificadas, uma vez que a distribuição dos escores se mostrou assimétrica.

Realizando a ordenação dos valores absolutos das diferenças calculadas, a exceção das diferenças iguais a zero, um escore $R_{i}$ é atribuído a cada valor, $D_{i}, i=$ $1,2, \ldots, n$, caso ocorram empates o escore é dado pela média das ordens das observações repetidas. Posteriormente, é realizada a soma dos postos $R_{i}$, multiplicados pelo sinal da diferença. De acordo com Sheskin (2003), a estatística $W$ é dada pela expressão abaixo:

$$
W=\sum_{i=1}^{n}\left[\operatorname{sinal}\left(D_{i}\right) \times R_{i}\right] .
$$

\subsection{4 - Cluster}

Com o objetivo de agrupar as observações em grupos que apresentem características similares, de acordo com o resultado do questionário de aquisição e desenvolvimento de linguagem e do resultado da prova diagnóstica inicial pré-curso, foi aplicada a análise de cluster pelo método de agrupamento hierárquico, utilizando a medida de distância euclidiana. Uma vez que não se tinha o conhecimento do número de grupos entre os quais as observações iriam ser divididas, em cada estágio da aglomeração, os dois grupos foram combinados (Hair et al., 2009). 
Também foi construído um dendrograma como forma de avaliar a proximidade das observações e de selecionar o número de grupos. O dendrograma é uma representação gráfica dos resultados de um procedimento hierárquico em que cada objeto é distribuído em um eixo e o outro eixo retrata as etapas no procedimento hierárquico. Começando com cada objeto representado como um cluster separado, o dendrograma mostra graficamente como os clusters são combinados em cada etapa do procedimento até que todos estejam contidos em um único cluster (Hair et al., 2009).

Para todos os testes, foi fixado o nível de significância em $5 \%$. Todas as análises foram realizadas com o auxílio do ambiente estatístico $R$ ( $R$ Development Core Team), versão 3.6.2.

\section{3 - RESULTADOS}

\subsection{1 - Análise Descritiva}

A princípio, são descritas as características dos participantes da pesquisa a respeito do perfil, da aquisição e do desenvolvimento de linguagem e da avaliação do curso.

\subsubsection{1 - Caracterização}

Tabela 13. Distribuição de frequências das variáveis de caracterização dos participantes da pesquisa.

\begin{tabular}{lcc}
\hline Variável & $\begin{array}{c}\text { Frequência } \\
\text { absoluta }\end{array}$ & $\%$ \\
\hline Sexo & 70 & $94,59 \%$ \\
$\quad$ Feminino & 4 & $5,41 \%$ \\
$\quad$ Masculino & & \\
Estado & 37 & $50,00 \%$ \\
São Paulo & 8 & $10,81 \%$ \\
Paraná & 7 & $9,46 \%$ \\
Minas Gerais & 6 & $8,11 \%$ \\
Rio de Janeiro & 5 & $6,76 \%$ \\
Bahia & 3 & $4,05 \%$ \\
Santa Catarina & 2 & $2,70 \%$ \\
Rio Grande do Sul & 6 & $8,11 \%$ \\
Outros & & \\
\hline
\end{tabular}




\begin{tabular}{|c|c|c|}
\hline Variável & $\begin{array}{l}\text { Frequência } \\
\text { absoluta }\end{array}$ & $\%$ \\
\hline \multicolumn{3}{|l|}{ Titulação máxima } \\
\hline Graduação Completa em Fonoaudiologia & 33 & $44,59 \%$ \\
\hline Especialização em Andamento & 12 & $16,22 \%$ \\
\hline Especialização Completa & 25 & $33,78 \%$ \\
\hline Mestrado em Andamento & 1 & $1,35 \%$ \\
\hline Mestrado Completo & 2 & $2,70 \%$ \\
\hline Doutorado Completo & 1 & $1,35 \%$ \\
\hline \multicolumn{3}{|l|}{ Área de atuação* } \\
\hline Linguagem & 69 & $93,24 \%$ \\
\hline Motricidade & 53 & $71,62 \%$ \\
\hline Fonoaudiologia Educacional & 30 & $40,54 \%$ \\
\hline Voz & 22 & $29,73 \%$ \\
\hline Disfagia & 17 & $22,97 \%$ \\
\hline Fonoaudiologia Neurofuncional & 15 & $20,27 \%$ \\
\hline Audiologia & 14 & $18,92 \%$ \\
\hline Saúde Coletiva & 9 & $12,16 \%$ \\
\hline Gerontologia & 6 & $8,11 \%$ \\
\hline Fonoaudiologia do Trabalho & 3 & $4,05 \%$ \\
\hline Neuropsicologia & 1 & $1,35 \%$ \\
\hline \multicolumn{3}{|l|}{ Quantos anos atua nessa(s) área(s)? } \\
\hline Até 1 ano & 12 & $16,22 \%$ \\
\hline Mais de 1 ano até 5 anos & 23 & $31,08 \%$ \\
\hline Mais de 5 anos até 10 anos & 16 & $21,62 \%$ \\
\hline Mais de 10 anos & 23 & $31,08 \%$ \\
\hline \multicolumn{3}{|l|}{$\begin{array}{l}\text { Quantas horas você acessa a Internet por } \\
\text { semana? }\end{array}$} \\
\hline Até 5 horas & 11 & $14,86 \%$ \\
\hline Mais de 5 horas até 10 horas & 17 & $22,97 \%$ \\
\hline Mais de 10 horas até 20 horas & 27 & $36,49 \%$ \\
\hline Mais de 20 horas & 19 & $25,68 \%$ \\
\hline \multicolumn{3}{|l|}{$\begin{array}{l}\text { Quais dispositivos você utiliza para acessar a } \\
\text { internet?* }\end{array}$} \\
\hline Celular & 71 & $95,95 \%$ \\
\hline Computador & 29 & $39,19 \%$ \\
\hline Notebook & 62 & $83,78 \%$ \\
\hline Tablet & 20 & $27,03 \%$ \\
\hline \multicolumn{3}{|c|}{$\begin{array}{l}\text { Qual dispositivo você mais utiliza para acessar a } \\
\text { internet? }\end{array}$} \\
\hline Celular & 60 & $81,08 \%$ \\
\hline Computador & 5 & $6,76 \%$ \\
\hline Notebook & 8 & $10,81 \%$ \\
\hline Tablet & 1 & $1,35 \%$ \\
\hline \multicolumn{3}{|l|}{ Quais locais você acessa internet?* } \\
\hline Casa & 73 & $98,65 \%$ \\
\hline Trabalho & 62 & $83,78 \%$ \\
\hline Faculdade & 1 & $1,35 \%$ \\
\hline Outro & 12 & $16,22 \%$ \\
\hline Onde você mais acessa a internet? & & \\
\hline
\end{tabular}




\begin{tabular}{lcc}
\hline \hline Variável & $\begin{array}{c}\text { Frequência } \\
\text { absoluta }\end{array}$ & $\%$ \\
\hline Casa & 58 & $78,38 \%$ \\
Trabalho & 14 & $18,92 \%$ \\
Faculdade & 1 & $1,35 \%$ \\
Outro & 1 & $1,35 \%$ \\
Qual a velocidade da sua internet? (em mbps) & 16 & $21,62 \%$ \\
Até 5 mbps & 26 & $35,14 \%$ \\
Mais de 5 mbps até 10 mbps & 8 & $10,81 \%$ \\
Mais de 10 mbps até 20 mbps & 21 & $28,38 \%$ \\
Mais de 20 mbps & 8 & $10,81 \%$ \\
Você participa de cursos EaD? & 66 & $89,19 \%$ \\
Não & & \\
Sim & &
\end{tabular}

Observa-se na Tabela 13 que a grande maioria dos participantes da pesquisa foi do sexo feminino $(94,59 \%)$, metade $(50,00 \%)$ é do estado de São Paulo e quase metade $(44,59 \%)$ possui apenas a graduação completa em fonoaudiologia como titulação máxima $(44,59 \%)$.

Em relação à área de atuação, vê-se que a linguagem é a mais comum entre os participantes $(93,24 \%)$, seguida pela motricidade orofacial $(71,62 \%)$ e fonoaudiologia educacional $(40,54 \%)$, sendo que, no geral, quase metade atua há 5 anos ou menos na área $(47,30 \%)$.

Quanto ao uso de internet, observa-se que $36,49 \%$ acessam a rede entre 10 a 20 horas por semana, sendo que o celular é o dispositivo mais usado pela maior parte dos entrevistados $(81,08 \%)$, e o local de onde os alunos mais acessam é de casa $(78,38 \%)$. Ainda, mais da metade deles possui internet com velocidade de até 10 Mbps (56,76\%) e a grande maioria participa de cursos $\operatorname{EaD}(89,19 \%)$.

6.3.1.2 - Conhecimentos prévios sobre Aquisição e desenvolvimento de linguagem

Tabela 14. Medidas descritivas da nota dos participantes da pesquisa nas questões do questionário de aquisição e desenvolvimento de linguagem. 


\begin{tabular}{cccccc}
\hline Questão & Média & Desvio Padrão & Mediana & Mínimo & Máximo \\
\hline Q1 & 2,03 & 0,99 & 2,50 & 0,00 & 2,50 \\
Q2 & 1,01 & 1,24 & 0,00 & 0,00 & 2,50 \\
Q3 & 1,82 & 1,12 & 2,50 & 0,00 & 2,50 \\
Q4 & 2,47 & 0,29 & 2,50 & 0,00 & 2,50 \\
Q5 & 2,30 & 0,69 & 2,50 & 0,00 & 2,50 \\
Q6 & 1,35 & 1,25 & 2,50 & 0,00 & 2,50 \\
Q7 & 1,99 & 1,01 & 2,50 & 0,00 & 2,50 \\
Q8 & 0,74 & 1,15 & 0,00 & 0,00 & 2,50 \\
Q9 & 0,47 & 0,99 & 0,00 & 0,00 & 2,50 \\
Q10 & 2,17 & 0,52 & 2,50 & 0,25 & 2,50 \\
Geral & $\mathbf{1 6 , 3 6}$ & $\mathbf{3 , 5 8}$ & $\mathbf{1 7 , 2 5}$ & $\mathbf{7 , 7 5}$ & $\mathbf{2 5 , 0 0}$ \\
\hline
\end{tabular}

Pela Tabela 14, nota-se que para o questionário de aquisição e desenvolvimento de linguagem, as notas média e mediana dos participantes da pesquisa foram de 16,36 e 17,25 pontos, sendo que a pontuação pode variar entre 0 e 25 pontos. Avaliando as médias por questão (cada uma podendo variar entre $0 \mathrm{e}$ 2,5 pontos), vê-se que a maior média foi observada para a questão Q4 (2,47 pontos), enquanto que a menor refere-se a questão Q9 (0,47 pontos).

\subsubsection{3 - Avaliação do curso}

Figura 12 - Distribuição de frequências das respostas dos participantes da pesquisa ao questionário de avaliação do curso. 


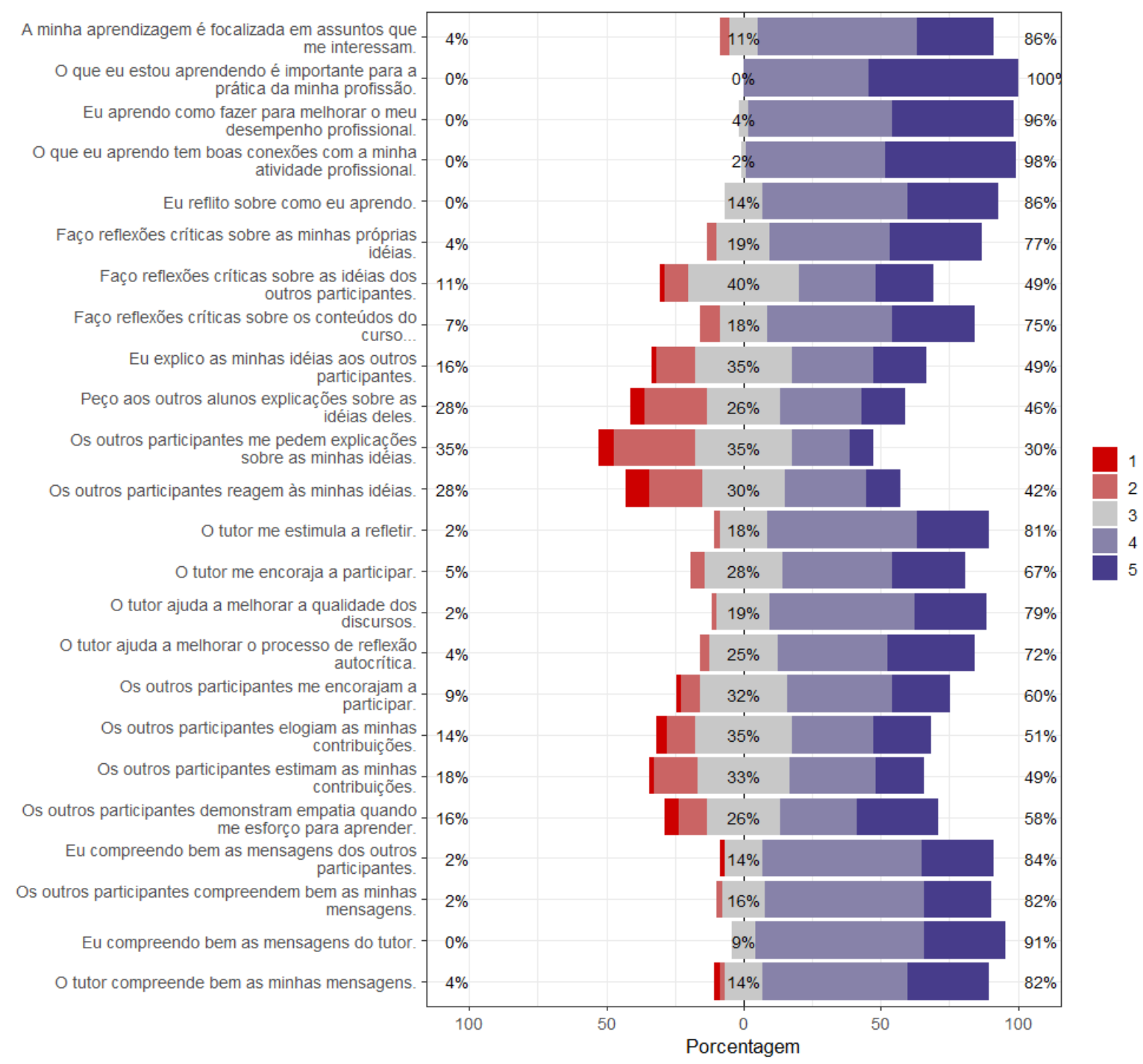

Fonte: Elaborado pelo autor

Quanto à avaliação do curso, nota-se pela Figura 12 que o único item avaliado que recebeu uma frequência maior de respostas discordantes (alternativas 1 ou 2), em relação a respostas concordantes (4 ou 5), foi o referente a "Os outros participantes me pedem explicações sobre as minhas ideias" (35\% contra $30 \%$, respectivamente), ao passo que para o item "O que eu estou aprendendo é importante para a prática da minha profissão", todos os participantes apontaram as alternativas concordantes.

\subsection{2 - Correlações}

A seguir serão apresentados os resultados dos testes de correlação entre as variáveis de interesse. 
6.3.2.1 - Nota na avaliação pré-pós treinamento x Nota por módulo

O curso de avaliação foi dividido em 12 módulos (núcleos temáticos), como pode ser verificado a seguir:

1. Alterações de Linguagem Infantil

2. Avaliando para Intervir

3. Orientação Escolar

4. Orientação Familiar

5. Planejamento Interventivo e Comportamento Infantil

6. Intervenção na Pragmática

7. Intervenção da Linguagem Receptiva

8. Intervenção na Semântica

9. Intervenção na Sintaxe

10. Intervenção na Fonologia

11. Intervenção na Fluência e Praxia

12. Intervenção nas Habilidades Metalinguísticas, na Memória e nas Funções Executivas

A tabela a seguir mostra os dados referentes à correlação entre as notas dos alunos em cada um dos módulos e as notas gerais (pré e pós curso).

Tabela 15. Resultados dos testes de correlação entre as notas dos módulos e a nota geral (pré e pós) dos participantes da pesquisa.

\begin{tabular}{ccccc}
\hline Módulo & \multicolumn{2}{c}{ Pré } & \multicolumn{2}{c}{ Pós } \\
& Correlação & Valor $\mathbf{p}$ & Correlação & Valor $\mathbf{p}$ \\
\hline Módulo 1 & 0,370 & $0,001^{*}$ & 0,307 & $0,016^{\star}$ \\
Módulo 2 & 0,320 & $0,006^{\star}$ & 0,292 & $0,022^{\star}$ \\
Módulo 3 & 0,310 & $0,007^{\star}$ & 0,352 & $0,005^{\star}$ \\
Módulo 4 & 0,309 & $0,007^{\star}$ & 0,337 & $0,008^{\star}$ \\
Módulo 5 & 0,230 & $0,048^{\star}$ & 0,336 & $0,008^{\star}$ \\
Módulo 6 & 0,241 & $0,039^{*}$ & 0,456 & $<0,001^{*}$ \\
Módulo 7 & 0,198 & 0,091 & 0,246 & 0,056 \\
Módulo 8 & 0,118 & 0,317 & 0,209 & 0,105 \\
Módulo 9 & 0,103 & 0,381 & 0,210 & 0,105 \\
Módulo 10 & 0,053 & 0,656 & 0,185 & 0,153 \\
Módulo 11 & 0,173 & 0,140 & 0,341 & $0,007^{\star}$ \\
Módulo 12 & 0,127 & 0,281 & 0,268 & $0,037^{\star}$ \\
\hline
\end{tabular}




\begin{tabular}{|c|c|c|c|c|}
\hline \multirow{2}{*}{ Módulo } & \multicolumn{2}{|c|}{ Pré } & \multicolumn{2}{|c|}{ Pós } \\
\hline & Correlação & Valor $p$ & Correlação & Valor $p$ \\
\hline Total do curso & 0,244 & $0,036^{*}$ & 0,385 & $0,002^{*}$ \\
\hline
\end{tabular}

Avaliando os resultados do teste de correlação de Spearman apresentados na Tabela 15, vê-se que o resultado geral da prova diagnóstica pré apresenta correlação positiva e significativa com as notas obtidas pelos alunos nos módulos de 1 a 6 , assim como com a nota total do curso, ao nível de $5 \%$ de significância, indicando que quanto maior a nota na prova diagnóstica pré, maior tendem a ser as notas em tais módulos. Quanto a nota da prova diagnóstica pós, além dos módulos de 1 a 6 e total, também se observou correlação positiva significativa com as notas dos módulos 11 e 12 (valores p de 0,007 e 0,037, respectivamente).

\subsubsection{2 - Nota por módulo x Acesso por módulo}

Tabela 16. Resultados dos testes de correlação entre as notas e os acessos de cada módulo dos participantes da pesquisa.

\begin{tabular}{ccc}
\hline Módulo & Correlação & Valor $\mathbf{p}$ \\
\hline Módulo 1 & 0,583 & $<0,001^{*}$ \\
Módulo 2 & 0,394 & $0,001^{*}$ \\
Módulo 3 & 0,383 & $0,001^{*}$ \\
Módulo 4 & 0,315 & $0,006^{*}$ \\
Módulo 5 & 0,565 & $<0,001^{*}$ \\
Módulo 6 & 0,576 & $<0,001^{*}$ \\
Módulo 7 & 0,564 & $<0,001^{*}$ \\
Módulo 8 & 0,507 & $<0,001^{*}$ \\
Módulo 9 & 0,638 & $<0,001^{*}$ \\
Módulo 10 & 0,629 & $<0,001^{*}$ \\
Módulo 11 & 0,663 & $<0,001^{*}$ \\
Módulo 12 & 0,610 & $<0,001^{*}$ \\
Total do curso & 0,644 & $<0,001^{*}$ \\
\hline
\end{tabular}

Nota-se na Tabela 16 que em todos os módulos avaliados, bem como de modo geral, a quantidade de acessos no curso apresenta uma correlação positiva e significativa com a nota no módulo em questão, de acordo com os resultados do teste de correlação de Spearman, ao nível de 5\% de significância, indicando que quanto maior o acesso dos alunos ao curso, maiores tendem a ser suas notas. 


\subsubsection{3 - Nota na avaliação pré-pós treinamento x Acesso geral}

Tabela 17. Resultados dos testes de correlação entre o acesso geral e a nota geral (pré e pós) dos participantes da pesquisa.

\begin{tabular}{ccccc}
\hline Acesso & \multicolumn{2}{c}{ Pré } & \multicolumn{2}{c}{ Pós } \\
\cline { 2 - 5 } & Correlação & Valor $p$ & Correlação & Valor $p$ \\
Total do curso & 0,228 & 0,051 & 0,469 & $<0,001^{*}$ \\
\hline$*:$ Valor- $p<0,05$. & & & &
\end{tabular}

Correlacionando-se o total de acessos com as notas das provas diagnósticas, observa-se na Tabela 17 que para a prova pré não houve significância, fixando o nível de significância em $5 \%$, ao passo que a correlação foi significativa com o resultado pós, indicando que a relação dos acessos é maior com o resultado pós curso, se comparado com o resultado pré.

\subsection{3 - Comparações}

Com o intuito de avaliar a relação entre os resultados da prova diagnóstica pré e pós curso, fez-se uma análise de comparação entre as notas e os resultados são dados a seguir:

Tabela 18. Resultados dos testes de comparação entre as notas dos participantes da pesquisa na prova diagnóstica pré e pós.

\begin{tabular}{cccc}
\hline Questão & \multicolumn{2}{c}{ Média (desvio padrão) } & Valor $\mathbf{p}$ \\
& Pré & Pós & \\
\hline Q1 & $0,61(0,1)$ & $0,6(0,14)$ & 0,766 \\
Q2 & $0,59(0,16)$ & $0,61(0,11)$ & 0,149 \\
Q3 & $0,49(0,26)$ & $0,56(0,2)$ & 0,208 \\
Q4 & $0,52(0,24)$ & $0,54(0,23)$ & 0,393 \\
Q5 & $0,62(0,07)$ & $0,62(0,08)$ & 1,000 \\
Q6 & $0,54(0,23)$ & $0,61(0,11)$ & $0,011^{*}$ \\
Q7 & $0,61(0,1)$ & $0,61(0,11)$ & 1,000 \\
Q8 & $0,6(0,13)$ & $0,62(0,08)$ & 0,346 \\
Q9 & $0,63(0)$ & $0,63(0)$ & 1,000 \\
Q10 & $0,62(0,07)$ & $0,61(0,11)$ & 0,773 \\
Q11 & $0,6(0,13)$ & $0,62(0,08)$ & 0,773 \\
Q12 & $0,2(0,29)$ & $0,35(0,32)$ & $0,016^{*}$ \\
Q13 & $0,58(0,17)$ & $0,54(0,23)$ & 0,530 \\
Q14 & $0,59(0,16)$ & $0,59(0,16)$ & 0,530 \\
Q15 & $0,57(0,19)$ & $0,57(0,19)$ & 0,790 \\
Q16 & $0,1(0,24)$ & $0,2(0,3)$ & $0,022^{*}$ \\
\hline
\end{tabular}




\begin{tabular}{cccc}
\hline Questão & \multicolumn{2}{c}{ Média (desvio padrão) } & Valor $\mathbf{p}$ \\
P17 & $0,35(0,19)$ & $0,37(0,22)$ & 0,054 \\
Q18 & $0,29(0,32)$ & $0,36(0,31)$ & 0,424 \\
Q19 & $0,42(0,3)$ & $0,52(0,24)$ & $0,031^{*}$ \\
Q20 & $0,37(0,31)$ & $0,44(0,29)$ & 0,132 \\
Q21 & $0,41(0,3)$ & $0,47(0,28)$ & 0,332 \\
Q22 & $0,3(0,32)$ & $0,37(0,31)$ & 0,132 \\
Q23 & $0,5(0,26)$ & $0,44(0,29)$ & 0,149 \\
Q24 & $0,18(0,28)$ & $0,25(0,31)$ & $0,041^{*}$ \\
Q25 & $0,07(0,2)$ & $0,14(0,26)$ & $0,008^{*}$ \\
Q26 & $0,1(0,23)$ & $0,25(0,31)$ & $0,001^{*}$ \\
Q27 & $0,43(0,3)$ & $0,5(0,25)$ & 0,165 \\
Q28 & $0,39(0,31)$ & $0,49(0,26)$ & 0,113 \\
Q29 & $0,4(0,3)$ & $0,48(0,27)$ & 0,132 \\
Q30 & $0,2(0,29)$ & $0,23(0,31)$ & 0,683 \\
Q31 & $0,43(0,3)$ & $0,47(0,28)$ & 0,165 \\
Q32 & $0,43(0,29)$ & $0,56(0,2)$ & $0,002^{*}$ \\
Q33 & $0,09(0,22)$ & $0,27(0,31)$ & $<0,001^{*}$ \\
Q34 & $0,34(0,17)$ & $0,42(0,19)$ & $0,014^{*}$ \\
Q35 & $1,74(0,37)$ & $1,8(0,27)$ & $0,013^{*}$ \\
Q36 & $1,1(0,43)$ & $1,71(0,41)$ & $<0,001^{*}$ \\
Geral & $16,33(2,74)$ & $18,65(3,57)$ & $<0,001^{*}$ \\
\hline$*$ *ar-p & & &
\end{tabular}

*: Valor-p $<0,05$

A prova com as questões na íntegra encontra-se no Apêndice $C$ deste estudo e os temas referentes a cada uma das questões foram:

- Q1: Planejamento Interventivo

- Q2: Planejamento Interventivo

- Q3: Planejamento Interventivo

- Q4: Planejamento Interventivo

- Q5: Avaliar para Intervir

- Q6: Planejamento Interventivo

- Q7: Planejamento Interventivo

- Q8: Planejamento Interventivo

- Q9: Orientação a Família

- Q10: Planejamento Interventivo

- Q11: Fonologia

- Q12: Características das Alterações de Linguagem Infantil

- Q13: Fonologia

- Q14: Pragmática

- Q15: Pragmática e Semântica 
- Q16: Fonologia

- Q17: Orientação aos pais

- Q18: Fluência

- Q19: Fonologia

- Q20: Avaliar para Intervir

- Q21: Características das Alterações de Linguagem Infantil

- Q22: Características das Alterações de Linguagem Infantil

- Q23: Características das Alterações de Linguagem Infantil

- Q24: Pragmática

- Q25: Características das Alterações de Linguagem Infantil

- Q26: Planejamento Interventivo

- Q27: Planejamento Interventivo

- Q28: Orientação a Escola

- Q29: Fonologia

- Q30: Fluência

- Q31: Fluência

- Q32: Pragmática

- Q33: Memória

- Q34: Memória

- Q35: Orientação aos pais e professores

- Q36: Planejamento Interventivo

A partir da Tabela 18, em que se encontram os resultados do teste de Wilcoxon pareado, vê-se que há uma diferença significativa entre as notas dos alunos pré e pós curso ao nível de $5 \%$ de significância (valor $p<0,001$ ), sendo que, em termos de média, a nota obtida pelos participantes da pesquisa no primeiro momento foi de 16,33 pontos, subindo para 18,65 pontos após o curso. Da mesma forma, vê-se que um aumento significativo nas notas também foi observado para as questões Q6, Q12, Q16, Q19, Q24, Q25, Q26, Q32, Q33, Q34, Q35 e Q36, isto é, em um terço das questões avaliadas.

\subsection{4 - Clusters}


Com o intuito de agrupar os participantes da pesquisa de acordo com o seu conhecimento prévio (nota do questionário de aquisição e desenvolvimento de linguagem e nota da prova diagnóstica pré), foi aplicada a análise de cluster, cujos resultados são apresentados a seguir.

Figura 13 - Dendograma dos participantes da pesquisa.

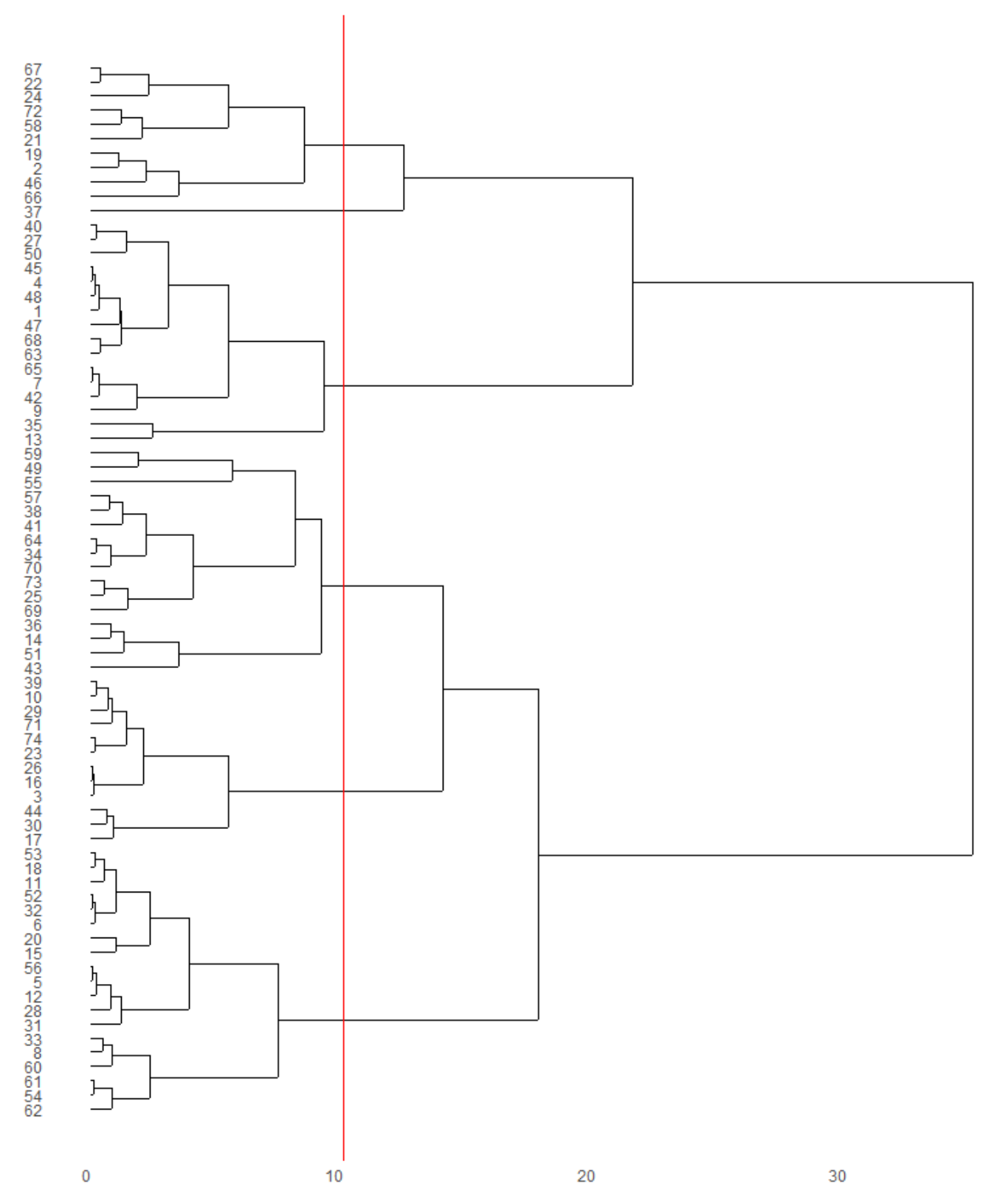

Fonte: Elaborado pelo autor

$\mathrm{Na}$ Figura 13 tem-se a resultante de um método de agrupamento hierárquico, em que se apresenta a divisão entre os grupos formados pelo método. $\mathrm{A}$ escolha do número ótimo de clusters foi baseada no método do "cotovelo" (elbow 
method), que indica a soma de quadrados total dentro dos clusters, de acordo com o número de clusters.

Figura 14 - Soma de quadrados total dentro dos clusters, de acordo com o número de clusters.

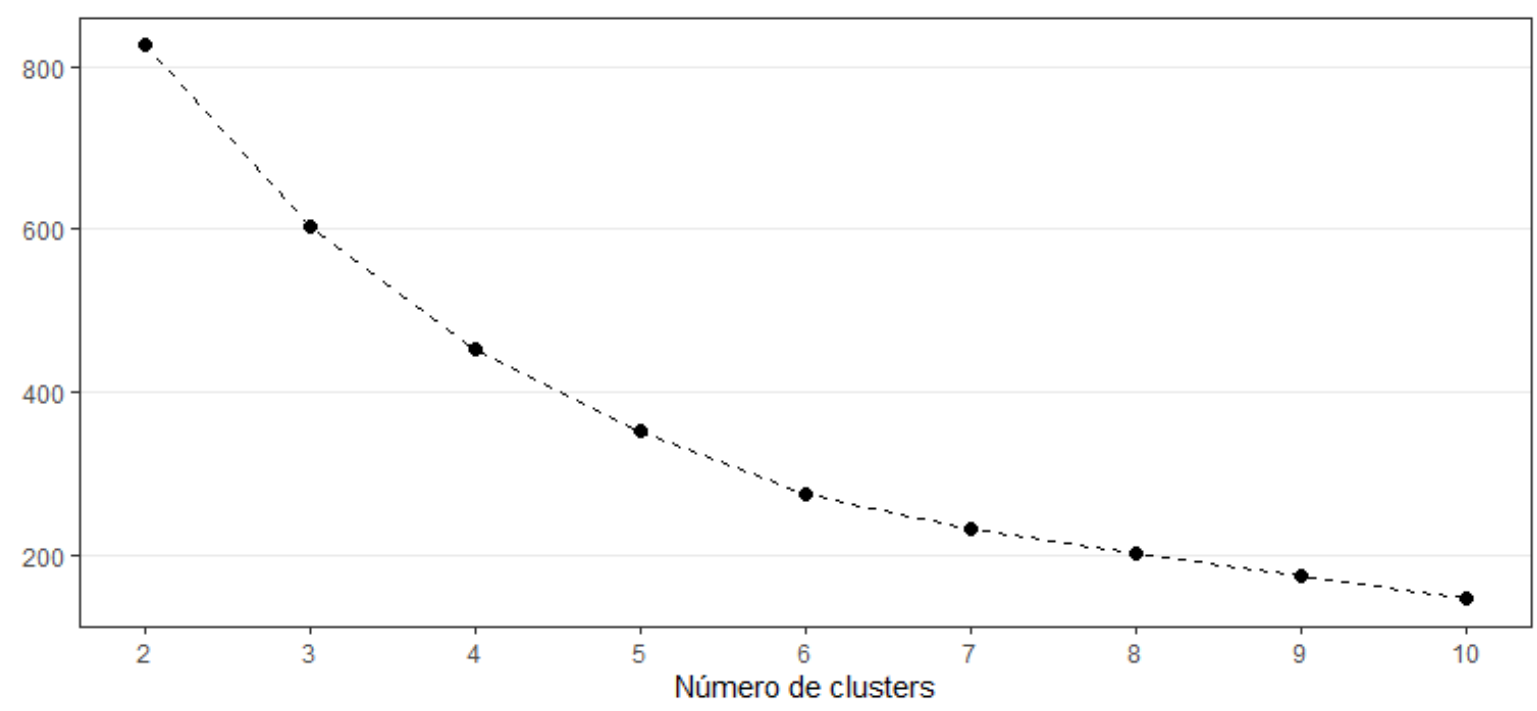

Fonte: Elaborado pelo autor

O critério de decisão do método do "cotovelo" se baseia no ponto de inflexão da curva apresentada na Figura 14, pela qual se tem a decisão do agrupamento em 6 clusters.

Tabela 19. Número de observações por cluster.

\begin{tabular}{cccccc}
\hline \multicolumn{7}{c}{ Cluster } \\
1 & 2 & 3 & 4 & 5 & 6 \\
\hline 16 & 10 & 12 & 19 & 16 & 1 \\
\hline
\end{tabular}

Pela Tabela 19 vê-se que o cluster 6 possui apenas 1 participante, enquanto os demais possuem entre 10 e 19 participantes, cada.

Figura 15 - Diagrama de dispersão entre as notas na prova diagnóstica pré e no questionário de aquisição e desenvolvimento de linguagem de acordo com o cluster. 


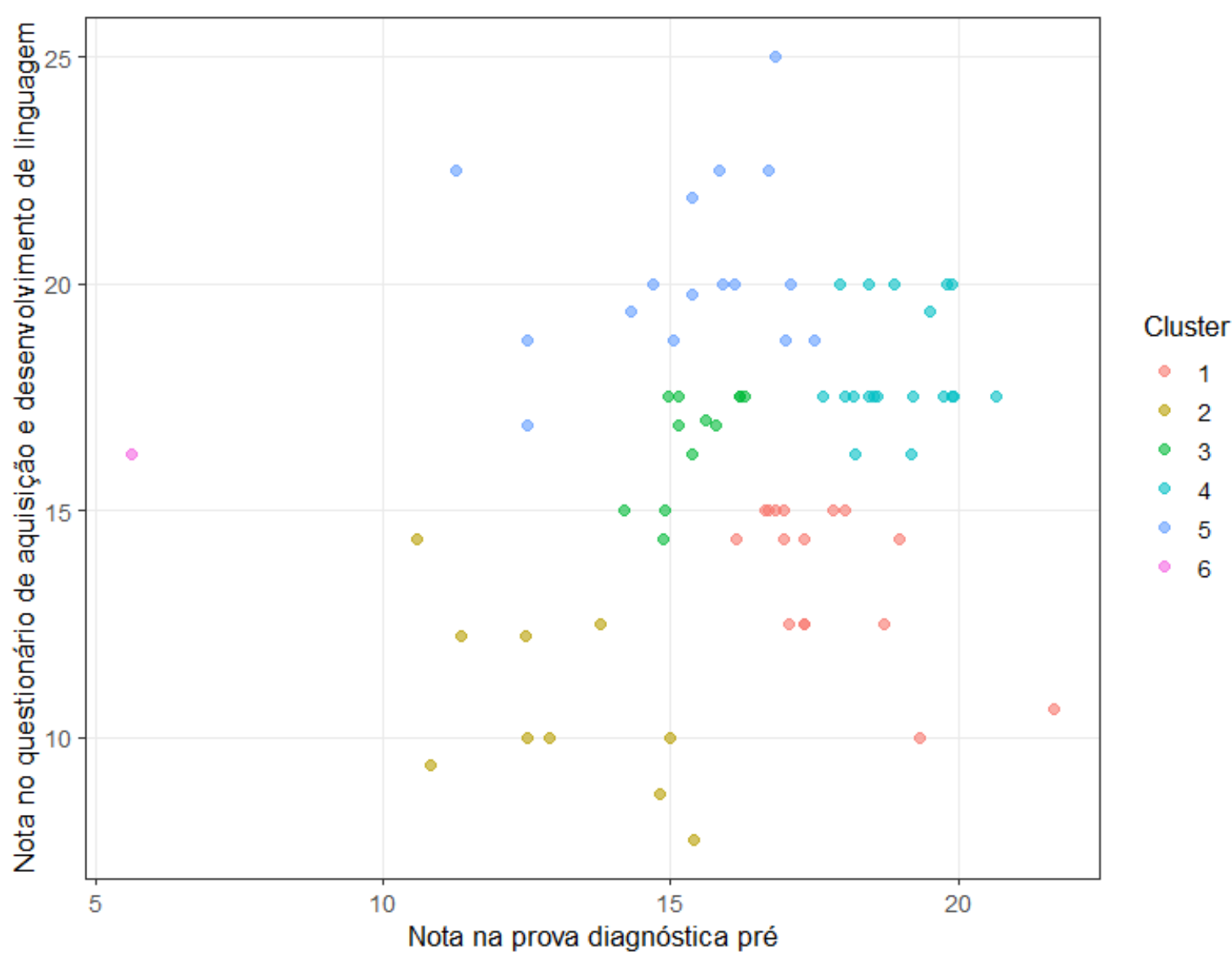

Fonte: Elaborado pelo autor

Vê-se na Figura 15 que o único aluno classificado no cluster 6 apresenta nota baixa na prova pré e nota média na aquisição, enquanto que os alunos do cluster 2 mostraram notas entre 10 e 15 no pré e baixas na aquisição. Já o cluster 3 é formado por participantes com notas razoáveis em ambos os instrumentos, ao passo que o cluster 4 apresenta notas razoáveis na aquisição e mais altas no pré, sendo que o mesmo cenário, mas com os instrumentos inversos, é observado para o cluster 5 . Por fim, os participantes do cluster 1 mostram altas notas no pré e baixas na aquisição.

Para avaliar o comportamento de cada um dos clusters formados, foram calculadas as médias dos acessos e notas dos alunos durante e após o curso.

Tabela 20. Média (desvio padrão) das variáveis, por cluster.

\begin{tabular}{cccccccc}
\hline Variável & \multicolumn{6}{c}{ Cluster } \\
& $\mathbf{1}$ & $\mathbf{2}$ & $\mathbf{3}$ & $\mathbf{4}$ & $\mathbf{5}$ & $\mathbf{6}$ \\
\hline Diagnóstico & Pós & 18,22 & 14,52 & 17,87 & 20,64 & 19,66 & 13,88 \\
& & $(3,65)$ & $(4,98)$ & $(1,11)$ & $(2,42)$ & $(2,9)$ & $(-)$ \\
\hline
\end{tabular}




\begin{tabular}{|c|c|c|c|c|c|c|c|}
\hline \multicolumn{2}{|c|}{ Variável } & \multicolumn{6}{|c|}{ Cluster } \\
\hline & & 1 & 2 & 3 & 4 & 5 & 6 \\
\hline \multirow[t]{22}{*}{ Nota } & Módulo & $\begin{array}{c}75,94 \\
(22,23)\end{array}$ & $\begin{array}{c}65,5 \\
(28.54)\end{array}$ & $\begin{array}{c}71,92 \\
(23,52)\end{array}$ & $\begin{array}{l}88,26 \\
(14,4)\end{array}$ & $\begin{array}{c}74,06 \\
(24,43)\end{array}$ & $\begin{array}{c}67,5 \\
(-)\end{array}$ \\
\hline & Módulo & 77,62 & 72,66 & 82,19 & 94,26 & 85 & $25(-)$ \\
\hline & 2 & $(32,33)$ & $(30,45)$ & $(28,11)$ & $(9,84)$ & $(13,64)$ & \\
\hline & $\begin{array}{c}\text { Módulo } \\
3\end{array}$ & $\begin{array}{c}88,75 \\
(25,53)\end{array}$ & $\begin{array}{c}71 \\
(38,43)\end{array}$ & $\begin{array}{c}88,33 \\
(29,18)\end{array}$ & $\begin{array}{c}95,79 \\
(10,71)\end{array}$ & $\begin{array}{l}88,12 \\
(18,7)\end{array}$ & $0(-)$ \\
\hline & Módulo & 88,75 & 84 & 94,17 & 98,42 & 93,75 & $40(-)$ \\
\hline & 4 & $(20,62)$ & $(17,76)$ & $(17,3)$ & $(5,01)$ & $(8,85)$ & \\
\hline & Módulo & 75,62 & 74,5 & 90 & 90,26 & 90,31 & $0(-)$ \\
\hline & 5 & $(34,49)$ & $(33,04)$ & $(28,6)$ & $(24,86)$ & $(10,87)$ & \\
\hline & Módulo & 73,44 & 65,5 & 88,33 & 85,26 & 88,12 & $0(-)$ \\
\hline & 6 & $(41,22)$ & $(37,6)$ & $(28,55)$ & $(31,69)$ & $(19,99)$ & \\
\hline & Módulo & 72,19 & 68 & 82,5 & 87,37 & 85,94 & $40(-)$ \\
\hline & 7 & $(43,93)$ & $(39,94)$ & $(38,64)$ & $(31,24)$ & $(29,39)$ & \\
\hline & Módulo & 68,12 & 69 & 89,17 & 87,37 & 88,75 & $80(-)$ \\
\hline & 8 & $(47,5)$ & $(40,67)$ & $(28,75)$ & $(31,24)$ & $(28,02)$ & \\
\hline & Módulo & 66,88 & 68 & 82,5 & 87,89 & 88,75 & $40(-)$ \\
\hline & 9 & $(46,86)$ & $(40,22)$ & $(38,64)$ & $(31,37)$ & $(28,02)$ & \\
\hline & Módulo & 63,75 & 68 & 91,67 & 87,11 & 84,38 & $40(-)$ \\
\hline & 10 & $(46,74)$ & $(40,22)$ & $(28,87)$ & $(31,15)$ & $(30,1)$ & \\
\hline & Módulo & 65,62 & 67 & 82,5 & 87,89 & 89,38 & $0(-)$ \\
\hline & 11 & $(46,04)$ & $(39,45)$ & $(38,64)$ & $(31,37)$ & $(25,16)$ & \\
\hline & Módulo & 67,5 & 73 & 81,67 & 85,79 & 90,62 & $0(-)$ \\
\hline & 12 & $(47,12)$ & $(39,45)$ & $(38,57)$ & $(33,22)$ & $(24,89)$ & \\
\hline \multirow[t]{24}{*}{ Acesso } & Módulo & 103,31 & 75,8 & 94,83 & 100,95 & 115,44 & $57(-)$ \\
\hline & 1 & $(53,74)$ & $(37,53)$ & $(55,63)$ & $(39,19)$ & $(62,65)$ & \\
\hline & Módulo & 104,56 & 80,1 & 114,08 & 116,63 & 128,44 & $40(-)$ \\
\hline & 2 & $(42,14)$ & $(51,49)$ & $(70,37)$ & $(43,98)$ & $(53,03)$ & \\
\hline & Módulo & 36 & 29,4 & 33,92 & 39,68 & 41,81 & $10(-)$ \\
\hline & 3 & $(19,39)$ & $(18,22)$ & $(18,12)$ & $(18,42)$ & $(10,84)$ & \\
\hline & Módulo & 34,81 & 24,1 & 32 & 38 & 42,12 & $14(-)$ \\
\hline & 4 & $(24,57)$ & $(13,88)$ & $(14,46)$ & $(15,86)$ & $(16,73)$ & \\
\hline & Módulo & 33,38 & 29,6 & 45,75 & 46,47 & 44,88 & $5(-)$ \\
\hline & 5 & $(18,85)$ & $(17,58)$ & $(29,95)$ & $(23,14)$ & $(27,48)$ & \\
\hline & Módulo & 59,38 & 45,7 & 66,08 & 69,16 & 83,56 & $10(-)$ \\
\hline & 6 & $(38,59)$ & $(28,3)$ & $(32,8)$ & $(39,69)$ & $(43,02)$ & \\
\hline & Módulo & 24,19 & 20,8 & 26,75 & 26,37 & 28,81 & $24(-)$ \\
\hline & 7 & $(17,06)$ & $(13,32)$ & $(17,06)$ & $(13,65)$ & $(12,37)$ & \\
\hline & Módulo & 22,25 & 24,3 & 32,75 & 29,42 & 37 & $24(-)$ \\
\hline & 8 & $(17,5)$ & (15) & $(16,65)$ & $(17,89)$ & $(21,74)$ & \\
\hline & Módulo & 19,44 & 21,3 & 26,92 & 26,47 & 30,75 & $13(-)$ \\
\hline & 9 & $(16,5)$ & $(14,05)$ & $(17,28)$ & $(14,05)$ & $(16,95)$ & \\
\hline & Módulo & 22 & 21,9 & 38,75 & 32,37 & 35,81 & $23(-)$ \\
\hline & 10 & $(16,81)$ & $(13,73)$ & $(25,84)$ & $(16,64)$ & $(24,48)$ & \\
\hline & Módulo & 20,44 & 19,4 & 28,08 & 32,79 & 33,31 & $11(-)$ \\
\hline & 11 & $(15,34)$ & $(13,68)$ & $(19,72)$ & $(18,85)$ & $(19,32)$ & \\
\hline & Módulo & 15,88 & 16,5 & 22,58 & 21,63 & 25,19 & $1(-)$ \\
\hline & 12 & $(11,5)$ & $(10,22)$ & $(14,44)$ & $(10,13)$ & $(13,69)$ & \\
\hline
\end{tabular}


Observa-se na Tabela 20 que o cluster 6, formado por um único aluno, apresenta baixo desempenho tanto na prova diagnóstica quanto nas notas e acessos aos módulos. As menores médias de acesso (exceto cluster 6 ) são referentes ao cluster 2, que também destaca-se com as menores notas médias nos primeiros módulos e na prova diagnóstica pré (exceto cluster 6), ao passo que, nos últimos módulos, as menores médias foram observadas para o cluster 1 (exceto cluster 6). Já o cluster 3 apresenta resultados razoáveis, isto é, médias nem tão altas nem tão baixas, para todas as variáveis avaliadas.

Por outro lado, o cluster 4 apresenta a maior nota média na prova diagnóstica pós e nos primeiros módulos, ao passo que o cluster 5 mostra, em geral, as maiores notas médias nos últimos módulos e maiores médias de acesso em quase todos os módulos.

\section{4 - RESUMO DOS PRINCIPAIS ACHADOS}

- Mesmo que o objetivo do curso online tenha sido atingir fonoaudiólogos de regiões remotas do Brasil, a maioria dos que realizaram o curso eram provenientes do Estado de São Paulo.

- No questionário sobre aquisição e desenvolvimento da linguagem (elaborado para profissionais não-fonoaudiólogos) a média de acerto percentual dos participantes antes de iniciar o curso foi de $65,44 \%$, sendo que a questão mais errada por eles foi referente ao desenvolvimento da narrativa.

- Os participantes afirmaram que o conteúdo do curso foi importante para a atuação profissional deles, mas que a relação entre os demais alunos teve algumas limitações.

- Os fonoaudiólogos com melhor desempenho na avaliação pré-curso também tiveram melhor desempenho nas notas finais dos módulos um a seis. 
- Os fonoaudiólogos com melhor desempenho nos modulo 1 a 6 e 11 12, tiveram também melhor desempenho na avaliação final póscurso.

- Quanto maior a frequência de acesso no curso, melhor o desempenho do fonoaudiólogo na avaliação final pós-curso.

- Houve melhora significativa no conhecimento teórico mensurado pela avaliação pré x pós curso.

- Antes de iniciar o curso, a maioria dos participantes teve uma nota média na prova sobre aquisição e desenvolvimento da linguagem e nota melhor na prova pré-curso (sobre características das alterações de linguagem e intervenção).

- Os alunos que inicialmente apresentavam maior nota na prova de aquisição e desenvolvimento de linguagem e nota média na avaliação pós-curso foram os alunos com mais frequência de acesso ao curso e também melhor evolução.

- Já os alunos que apresentaram nota baixa na prova de aquisição e desenvolvimento da linguagem e notas médias para baixas na avaliação pré-curso foram os que tiveram menor frequência de acessos no curso e também pior evolução. 


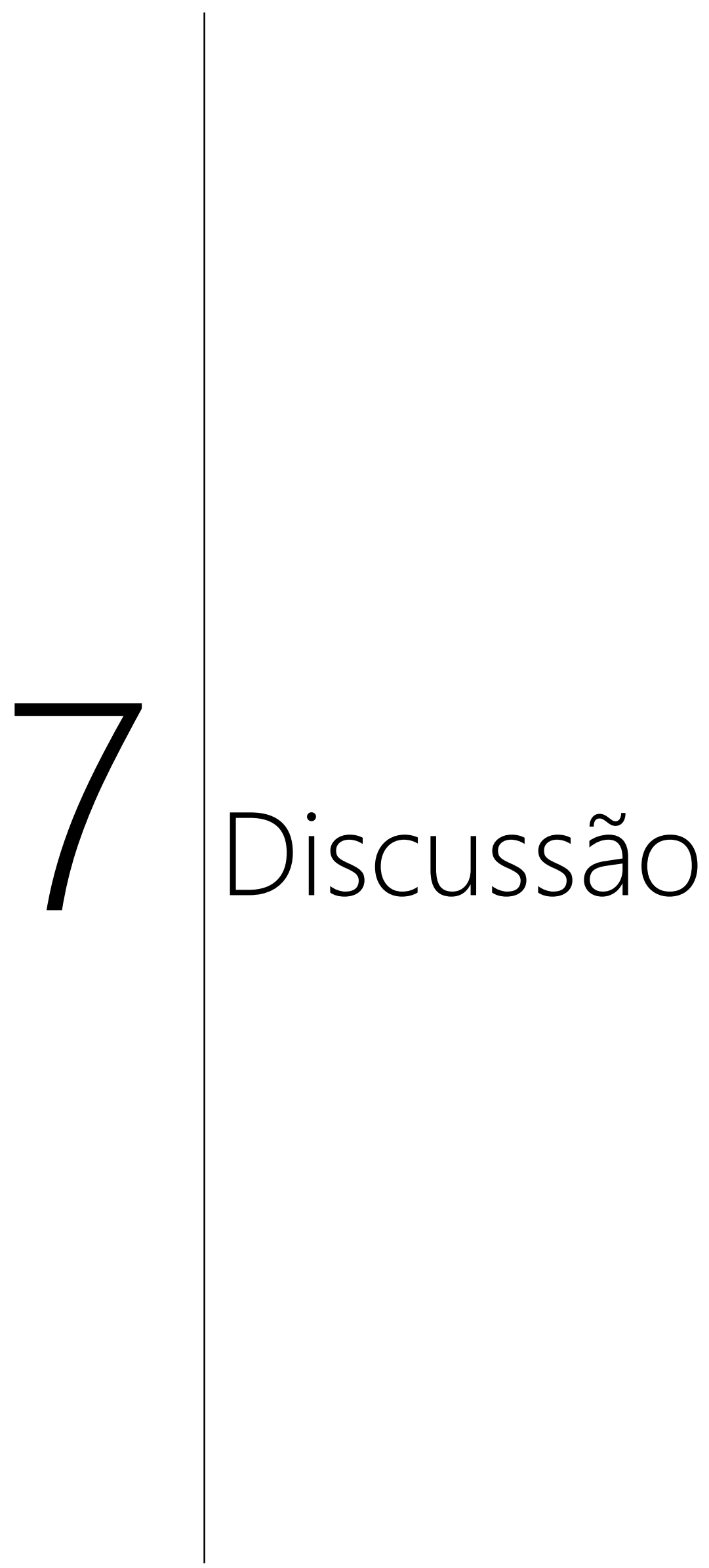





\section{7 - Discussão}

O presente estudo desenvolveu, aplicou e analisou um curso EaD para educação continuada de fonoaudiólogos na área de intervenção fonoaudiológica nas alterações de linguagem oral infantil. Para isso foram entrevistados 8 fonoaudiólogos para entender suas experiências prévias, necessidades e expectativas. Em seguida foi conduzida uma pesquisa-ação para que o curso fosse planejado, criado e executado. Durante a aplicação do curso, o mesmo foi monitorado de modo a verificar a satisfação dos alunos, se houve melhora nos conhecimentos teóricos em situação pré e pós-curso e, também, se fatores como conhecimento prévio e frequência de acessos interferiram na evolução dos alunos no curso.

Pasupathy e Bogschutz (2013) observaram que os estudantes de pósgraduação do segundo ano são estatisticamente significante mais autoconfiantes em sua prática clínica do que os alunos de pós-graduação do primeiro ano. Sendo que nesse contexto a pós-graduação que dura cerca de dois anos e um pré-requisito para a certificação clínica. Eles também encontraram uma correlação direta significativa entre autoconfiança e o número de horas clínicas praticadas com supervisão. Esses dados corroboram com o nosso estudo, pois pudemos ver que durante as entrevistas os fonoaudiólogos mostraram que são menos autoconfiantes em sua prática clínica no início de sua carreira profissional.

Mandrá et al., (2019) realizaram uma pesquisa para investigar as percepções de estágio clínico supervisionado de estudantes brasileiros de graduação em Fonoaudiologia. As principais observações foram que estágios clínicos ajudam a desenvolver uma abordagem profissional, raciocínio clínico, iniciativa e capacidade de tomada de decisão clínica, autopercepção de dificuldades e como usar a discussão de casos clínicos para construir a auto-aprendizagem. Todos os alunos que participam do estudo não têm opinião sobre se o estágio clínico reforça a base teórica. Isso mostra a importância da prática supervisionada e pode explicar as diferenças entre a autoconfiança dos fonoaudiólogos e o conhecimento prático com base em seus antecedentes de formação. 
Teixeira et al., (2013) encontraram uma relação entre as percepções de fonoaudiólogos sobre a inserção no mercado de trabalho e a qualidade da formação profissional, onde os fonoaudiólogos que relataram ter mais dificuldade durante a inserção no mercado de trabalho também classificaram a qualidade de seu curso de bacharel mais baixo.

Strömbergsson et al., (2019) repetiram o processo de reestruturação em um currículo de curso de graduação em Fonoaudiologia. Neste relatório, destacaram algumas ações, como o contato com o paciente entre o terceiro e o quarto semestre do curso. Com essa mudança, eles observaram que os alunos de Fonoaudiologia melhoraram sua associação teórico-prática, autoconfiança e acabaram tendo uma boa transição para o mercado de trabalho. Além disso, neste estudo, eles também descobriram uma maneira de aprimorar a independência profissional fazendo um curso intitulado "transição para a autonomia profissional".

Durante as entrevistas, os participantes conseguiram nomear intervenções para crianças com TEA, mas nenhum foi capaz de nomear uma intervenção para crianças com DEL ou Atraso de Linguagem. Um possível motivo disso ter ocorrido pode ser o fato de diretrizes e publicações de práticas baseadas em evidências sobre intervenções nos TEA, por exemplo, o artigo de Odom et al., (2010), ser mais frequente do que intervenções para DEL ou Atraso de Linguagem. Brackenbury, Burroughs e Hewitt (2008) também traz um estudo que embasa essa hipótese. Eles analisaram o que existe na literatura para guia de intervenção em linguagem infantil e notaram que a quantidade de publicações com alta evidência científica ainda é baixa.

Um estudo realizado por Courtney (2018) investigou o conhecimento explícito da sintaxe de estudantes de graduação em Fonoaudiologia e fonoaudiólogos clínicos. Eles notaram que o profissional teve um desempenho ligeiramente melhor do que os estudantes, embora ambos não tenham atingido os escores padrões para a escolaridade segundo os testes utilizados. $O$ conhecimento sobre linguística e regras de linguagem é muito importante para um fonoaudiólogo que trabalha com distúrbios de linguagem e mostra a necessidade de ter esse suporte teórico mais intenso durante as solicitações de certificação profissional e nos cursos de educação continuada. 
Outro achado no estudo de Pasupathy e Bogschutz (2013) foi o fato de os estudantes de Fonoaudiologia terem mais autoconfiança para intervir nos distúrbios da comunicação do que diagnosticar e avaliar esses casos. Essa informação também aparece em nosso estudo quando vemos que os fonoaudiólogos pensam que protocolos de avaliação são uma parte importante do curso de intervenção em linguagem infantil.

Murray e Bicford (2019), escreveram um relato de experiência de um evento científico que aconteceu na Austrália. Durante o texto eles ressaltaram que três pilares são fundamentais para que a prática profissional de fonoaudiologia seja sempre aprimorada e atualizada: inovação, base em evidências científicas e engajamento. A elaboração e aplicação do curso online também seguiu tais pilares, pois trouxe informações atualizadas e baseadas em pesquisas acadêmicas; mostrou inovações nos recursos utilizados no curso e também no conteúdo do mesmo; e propiciou o engajamento dos fonoaudiólogos tanto na elaboração quanto na aplicação do curso, de forma que o mesmo fosse significativo para a prática clínica desses fonoaudiólogos.

Kimbarow (2019) discutiu em sua publicação que há três diferentes fases do profissional:

- Fonoaudiólogo em sua carreira profissional que pode impactar em sua educação continuada: etapa inicial, que engloba os cinco primeiros anos de atuação, onde na excitação pela nova profissão 0 fonoaudiólogo, muitas vezes, não tem foco para aprimoramento específico e/ou foca apenas nas demandas imediatas de seu trabalho.

- Fonoaudiólogo em etapa intermediária, onde o fonoaudiólogo já tem mais experiência e sabe filtrar melhor como e onde realizar sua educação continuada. É uma fase de muito aprimoramento e afunilamento para sua área de expertise.

- Fonoaudiólogo em etapa avançada, onde com o avanço do conhecimento científico na área, o profissional precisa de atualizações para sua prática clínica não ficar defasada. 
Por isso, o autor sugere que, ao oferecer ações de educação continuada, as mesmas possam se encaixar no perfil de cada um desses profissionais em seus diferentes estágios de carreira e que, durante a ação, os fonoaudiólogos tenham condições de entender seus pontos fortes, seus pontos fracos e as oportunidades ao seu redor de forma a aprimorar a sua prática profissional. No estudo referente à esta tese também foi levado em consideração os diferentes estágios de carreira, o que fez englobar profissionais nesses três estágios desde a entrevista. Também contou com o apoio de tutoria/monitoria para que o curso pudesse se adaptar a cada um desses profissionais.

Huanca (2018) em sua dissertação de mestrado acompanhou a aplicação de MOOC sobre o tema "Saúde Bucal das Gestantes" e tanto a maioria de alunos que fizeram a inscrição quanto a maioria de alunos que finalizaram o curso eram provenientes da região Sudeste, assim como nesta tese. Contudo, no estudo aqui apresentado sabe-se que, o fato da região sudeste ser a região com maior número de fonoaudiólogos não é a única razão para que tenham mais alunos proveniente do mesmo, pois, proporcionalmente (considerando o número total de profissionais por região) ainda houve mais profissionais desta região inscritos no curso online. Porém, no estudo conduzido por Huanca, pelo fato do curso ser aberto a vários profissionais formados e estudantes de diversas áreas da saúde, a mesma comparação não pode ser realizada, uma vez que não há uma estratificação detalhada desses profissionais.

Medeiros (2016) em sua dissertação de mestrado utilizou o mesmo questionário sobre aquisição e desenvolvimento da linguagem em 17 médicos pediatras, onde a média de acertos percentual dos médicos foi de $41,17 \%$, ou seja, por mais que os acertos percentuais dos fonoaudiólogos neste estudo tenham sido baixos, ainda foi maior que a dos médicos pediatras. A autora também encontrou em seu estudo que a questão mais errada pelos médicos foi a qeustão sobre a aquisição da narrativa oral, que também foi a mais errada pelos fonoaudiólogos desta pesquisa no momento pré-curso.

Tobase (2016) em sua tese de doutorado criou e avaliou um curso online para estudantes de graduação em Enfermagem sobre manobras de reanimação 
cardiovascular. Participaram 62 alunos, estudantes do curso de graduação em Enfermagem e, ao comparar os resultados de uma avaliação de conhecimentos teóricos pré x pós-curso com alunos que já haviam realizado outros cursos de extensão (online ou presencial) na área de enfermagem, notou-se que os alunos com experiências prévias em cursos tiveram maior evolução durante o curso. Na tese aqui apresentada foi encontrado correlação entre conhecimentos prévios na área de aquisição e desenvolvimento da linguagem e evolução dos alunos no curso, o que corrobora com o estudo de Tobase (2016) no sentido que cursos de aprimoramento e atualização profissional são melhor aproveitados por aqueles que já possuem conhecimentos suficientes de base. 


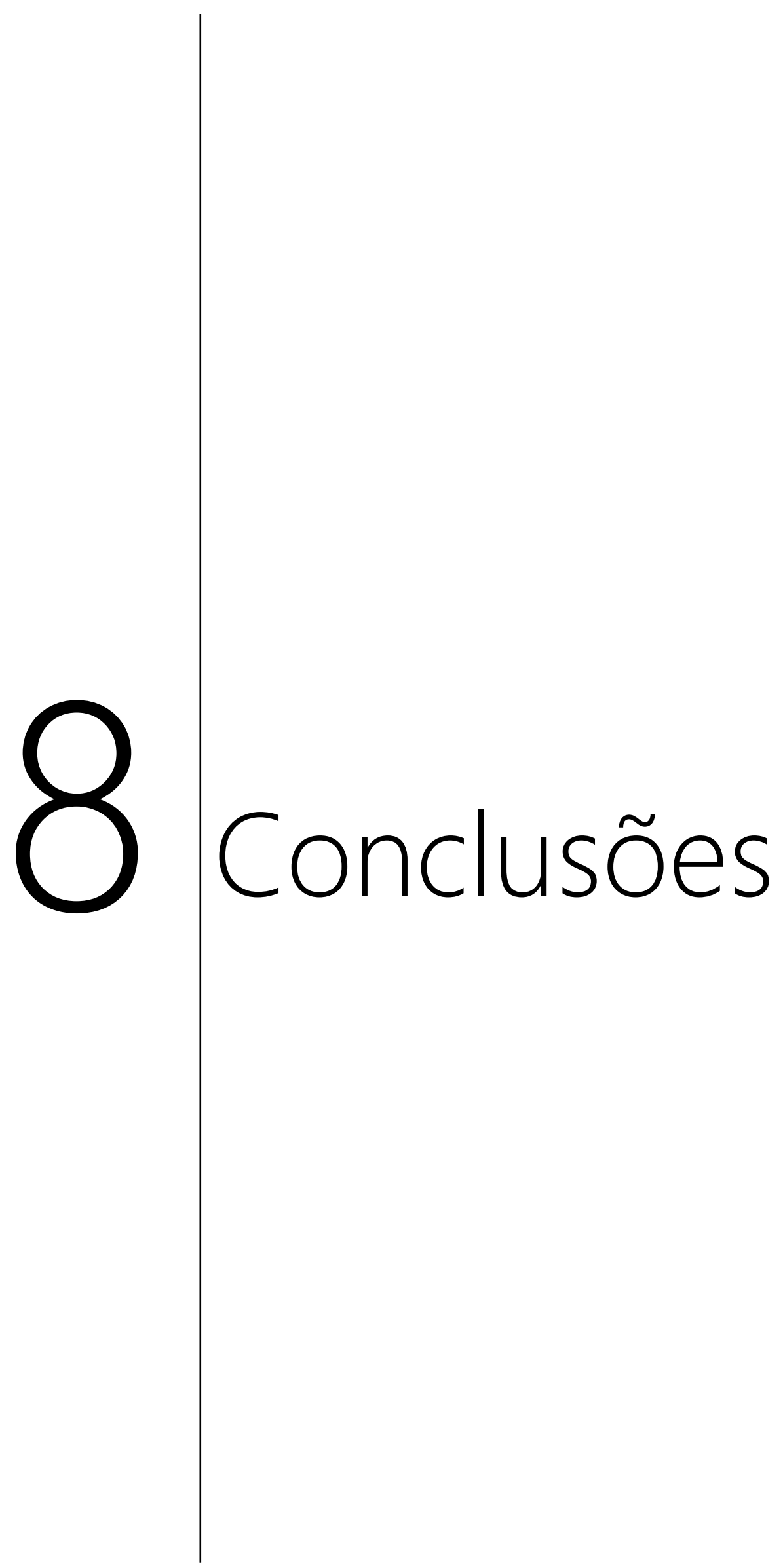





\section{8 - CONCLUSÕES}

Desenvolveu e aplicou um curso online intitulado "Curso de Intervenção fonoaudiológica em Linguagem Infantil" na modalidade atualização na plataforma Moodle. O mesmo teve uma turma com 74 fonoaudiólogos. Os fonoaudiólogos participantes do curso tiveram melhora em conhecimentos teóricos sobre o tema, sendo que tal evolução teve relação direta com a frequência e qualidade da participação do aluno durante o curso. Os participantes também relataram satisfação, principalmente pela importância do conteúdo do curso para a sua prática profissional. Para que mais informações e predições possam ser realizadas é necessário que o curso seja replicado com um número de participantes maior. Por fim, podemos concluir que o processo de elaboração do curso foi efetivo e cumpriu os objetivos planejados. 

Referências 



\section{REFERÊNCIAS}

ASHA - American Speech-Language-Hearing Association. Market Trends in Audiology and Speech-Language Pathology. https://www.asha.org/Careers/Market-Trends/. 2017.

AUSUBEL, D. P. The facilitation of meaningful verbal learning in the classroom. Educational psychologist, v. 12, n. 2, p. 162-178, 1977.

BARDIN, L. Análise de Conteúdo - primeira parte, história e teoria. Lisboa: Edições 70, 2002.

BEHLAU, M.; GASPARINI, G. Education of speech-language pathologists and audiologists in Brazil. Folia phoniatrica et logopaedica, v. 58, n. 1, p. 14-22, 2006.

BLOOM, B. S. et al. Taxonomy of educational objectives. New York: David Mckay, 1956. 262 p.

BRACKENBURY, T.; BURROUGHS, E.; HEWITT, L. E. A qualitative examination of current guidelines for evidence-based practice in child language intervention. Language, Speech, and Hearing Services in Schools. 2008.

BRASIL. Decreto № 7.175, de 12 de maio de 2010. Brasília, 2010.

Bureau of Labor Statistics. U.S. Department of Labor, Occupational Outlook Handbook, Speech-Language Pathologists, on the Internet. https://www.bls.gov/ooh/healthcare/speechlanguage-pathologists.htm. 2018.

BUSSAB, W. O.; MORETTIN, P. A. Estatística Básica. 7ª Edição. São Paulo: Saraiva, 2012. 
BYRNE, N. The personality of past, present and future speechlanguage pathology students. International journal of language \& communication disorders, v. 53, n. 2, p. 228-236, 2018.

CELESTE, L. C. et al. Mapeamento da Fonoaudiologia Educacional no Brasil: formação, trabalho e experiência profissional. CoDAS, v. 29, n. 1, :e20160029, 2017.

CGI-BR - CONSELHO GESTOR DE INTERNET NO BRASIL. Pesquisa sobre o uso das Tecnologias de Informação e Comunicação nos domicílios brasileiros - TIC Domicílios. São Paulo, 2016.

Conselho Federal de Fonoaudiologia. QUANTITATIVO DE FONOAUDIÓLOGOS NO BRASIL POR CONSELHO REGIONAL. 2017a. Disponível em:

http://www.fonoaudiologia.org.br/cffa/index.php/numero-por-regiao/. Acessado em 14 mai. 2019.

Conselho Federal de Fonoaudiologia. PESQUISA ESPECIALISTAS. 2017b. Disponível em:

http://www.fonoaudiologia.org.br/cffa/index.php/especialista-por-area/. Acessado em 14 mai. 2019.

CHAMBERS, L.W., STODDART, G.L. and SULLIVAN, B. Continuing Education for Health Professionals and Administrators: Workshops on Becoming a Critical User of Health Care Research. Canadian Journal of Public Health/Revue Canadienne de Sante'e Publique, p. 29-34, 1983.

COPPER, J. M.; SEMICH, G. W. Professional Development in the Twenty-First Century: YouTube Teacher Training and Professional Development, 2019. In Advanced Online Education and Training Technologies, p. 185-199. 
CYRINO, E. G.; TORALLES PEREIRA, M. L. Trabalhando com estratégias de ensino-aprendizado por descoberta na área da saúde: $A$ problematização e a aprendizagem baseada em problemas. Cadernos de Saúde Pública, v. 20, n. 3, p. 780-788, 2004.

DINIZ, R. D.; BORDIN, R. Demanda em Fonoaudiologia em um serviço público municipal da região Sul do Brasil. Revista da Sociedade Brasileira de Fonoaudiologia, v. 16, n. 2, p. 126-131, 2011.

ELO, S.; KYNGÄS, H. The qualitative content analysis process. Journal of advanced nursing, v. 62, n. 1, p. 107-115, 2008.

ERICKSON, S.; SERRY, T. A. Comparing alternate learning pathways within a problem-based learning speech-language pathology curriculum. International Journal of Speech-Language Pathology, v. 18, n. 1, p. 97-107, 2016.

FAREL, A., UMBLE, K., POLHAMUS, B. Impact of an online analytic skills course. Evaluation \& the health professions, v. 24, n. 4, p. 446459, 2001.

FARMER, R.; MILLER, D.; LAWRENSON, R. Epidemiology and Public Health Medicine. 4⿳亠丷a edição. Oxford: Blackwell Science, 1996.

FILATRO, A. Design instrucional na prática. São Paulo: Pearson Education do Brasil, 2008.

GIBBONS, J. G.; CHAKRABORTI, S. Nonparametric Statistical Inference, Fourth Edition: Revised and Expanded. Quarta edição. Publisher Taylor \& Francis, 2003.

GOMES, M. P. C. et al. O uso de Metodologias Ativas no ensino de graduação nas ciências sociais e da saúde - Avaliação dos estudantes. Ciência e Educação, v. 16, n. 1, p. 181-198, 2010. 
GOV-SP - GOVERNO DO ESTADO DE SÃO PAULO. Decreto № 45.057, de 11 de julho de 2000. São Paulo, 2000.

GUEST, G.; BUNCE, A.; JOHNSON, L. How many interviews are enough? An experiment with data saturation and variability. Field methods, v. 18, n. 1, p. 59-82, 2006.

HAIR, J. F. et al. Análise multivariada de dados. Bookman Editora, 2009.

HUANCA, C.M., 2018. Massive open online courses (MOOC) na odontologia: a experiência da oferta do curso Saúde bucal da gestante, (Tese). Universidade Aberta do SUS da UFMA.

Instituto Brasileiro de Geografia e Estatística. Sensu demográfico. 2011. Disponível em:

https://sidra.ibge.gov.br/bda/tabela/listabl.asp?z=cd\&to=3\&ti=P\&tc=1298 . Acessado em 14 mai. 2019.

ISO - INTERNATIONAL ORGANIZATION FOR STANDARDIZATION. ISO 9241 - 210:2010 - Ergonomics of human-system interaction. Geneva, 2010.

JAMIL, F. M.; HAMRE, B. K. Teacher Reflection in the Context of an Online Professional Development Course: Applying Principles of Cognitive Science to Promote Teacher Learning. Action in Teacher Education, v. 40, n. 2, p. 220-236, 2018.

KIMBAROW, M. L. Tending Your Professional Future: Creating a Strategic Plan for Continuing Education. The ASHA Leader, v. 9, n. 14, p. 4-19, 2004.

KNOWLES, M. S. The modern practice of adult education: Andragogy vs. pedagogy. Chicago: Association Press/Follett, 1970. 
LAM, M.K., NGUYEN, M., CAMPBELL, A.J. E-health as a life long learning process: How to prepare health professionals for this journey. In: GRAIN, H., SCHAPER, L. K. (org.). Health Informatics: Digital Health Service Delivery - The Future is now! IOS Press, 2013. p. 72-78.

MACBEAN, N. et al. Simulated learning environments in speechlanguage pathology: An australian response. International Journal of Speech-Language Pathology, v. 15, n. 3, p. 345-357, 2013.

MALONEY, S. et al. Translating evidence into practice via social media: a mixed-methods study. Journal of medical Internet research, v. 17, n. 10, p. e242, 2015.

MANDRÁ, P. P. et al. Percepção de estudantes de Fonoaudiologia sobre a Supervisão Clínica. Distúrbios da Comunicação, v. 31, n. 2, p. 246-254, 2019.

MARTÍN-BLAS, T.; SERRANO-FERNÁNDEZ, A. The role of new technologies in the learning process: Moodle as a teaching tool in Physics. Computer and Education, v. 52, p. 35-44, 2009.

MASTERS, S.C. et al. Using local clinical educators and shared resources to deliver simulation training activities across rural and remote South Australia and south-west Victoria: A distributed collaborative model. The Australian journal of rural health, v. 25, n. 5, p. 311-316, 2017.

MEDEIROS, A.N.C.D. 2016. Fonoaudiologia e pediatria:

conhecimento de pediatras sobre o desenvolvimento da linguagem. (Dissertação). Universidade de São Paulo.

MURRAY, J.; BICKFORD, J. INSPIRE: Inspiring practice innovation, research and engagement. International Journal of Speech-Language Pathology, v. 21, p. 225-227, 2019. 
PASCHOAL, A. S.; MANTOVANI, M. F.; MÉIER, M. J. Percepção da educação permanente, continuada e em serviço para enfermeiros de um hospital de ensino. Revista da Escola de Enfermagem da USP, v. 41, n. 3, p. 478-484, 2007.

Odom, S. L. et al. Evidence-based practices in interventions for children and youth with autism spectrum disorders. Preventing school failure: Alternative education for children and youth, v. 54, n. 4, p. 275-282, 2010.

OLIVEIRA, M. G.; PONTES, L. Metodologia Ativa no processo de aprendizado do conceito de cuidar: Um relato de experiência. In: EDUCERE, 20, 2011. Anal do $20^{\circ}$ Congresso Nacional de Educação - EDUCERE, 2011.

OSAKWE, A. et al. Impact of training on Nigerian healthcare professionals' knowledge and practice of pharmacovigilance. International journal of risk \& safety in medicine, v. 25, n. 4 , p. 219227, 2013.

PASUPATHY, R.; BOGSCHUTZ, R. J. An Investigation of Graduate Speech-Language Pathology Students' SLP Clinical Self-Efficacy. Contemporary Issues in Communication Science \& Disorders, v. 40, 2013.

POWELL, C. G.; BODUR, Y. Teachers' perceptions of an online professional development experience: Implications for a design and implementation framework. Teaching and Teacher Education, v. 77, p. 19-30, 2019.

R Development Core Team., R: a language and environment for statistical computing. R Foundation for Statistical Computing: Vienna, Austria, 2015. Disponível em:<http://www.R project.org>. 
SANTOS, C. S. S.; SANTOS, M. C. Telemedicina: O uso das tecnologias interativas para o ensino da medicina. Revista de Iniciação Científica, Tecnológica e Artística, v. 5, n. 4, p. 12-23, 2015.

SHARPLES, M. The design of personal mobile technologies for lifelong learning. Computers \& Education, v. 34, n. 3, p. 177-193, 2000.

SHESKIN, D. Handbook of Parametric and Nonparametric Statistical Procedures: Third Edition. Chapman \& Hall/CRC, 2003.

SILVA, G. M.; SEIFFERT, O. M. L. B. Educação continuada em enfermagem: uma proposta metodológica. Revista Brasileira de Enfermagem, 2009.

SOBRAL, F.; CAMPOS, C. J. G. Utilização de Metodologia Ativa no ensino e na assistência de enfermagem na produção nacional: Revisão integrativa. Revista Escola Enfermagem, v. 46, n. 1, p. 208-218, 2012.

SOUZA, E. P. S. de. Educação continuada baseada em aprendizagem independente (proativo): experiência da Revista Brasileira de Cirurgia Cardiovascular. 2013. 143 f. Tese (Programa de Pós-Graduação em Ciências da Saúde) - Faculdade de Medicina de São José do Rio Preto, São José do Rio Preto.

SPEARMAN, C. The Proof and Measurement of Association between Two Things. The American Journal of Psychology, v. 15, n. 1, p. 72101, 1904.

STARK, C.M. et al. Online course increases nutrition professionals' knowledge, skills, and self-efficacy in using an ecological approach to prevent childhood obesity. Journal of nutrition education and behavior, v. 43, n. 5, p. 316-322, 2011.

STRÖMBERGSSON, S.; Towards an Integrated Curriculum in a Speech and Language Pathology Education Programme: Development and 
Constituents' Initial Responses. Folia Phoniatrica et Logopaedica, p. 1-12, 2019.

TEIXEIRA, L. C. et al. Trajetória profissional de egressos em Fonoaudiologia. Revista CEFAC, v. 15, n. 6, p. 1591-600, 2013.

THOMSEN, A.S.S. et al. Update on simulation-based surgical training and assessment in ophthalmology: a systematic review.

Ophthalmology, v. 122, n. 6, p. 1111-1130, 2015.

THUKRAL, A. et al. Online Neonatal Training and Orientation Programme in India (ONTOP-IN) - the way forward for distance education in developing countries. Journal of tropical pediatrics, $v$. 58, n. 6, p. 486-490, 2012.

TOBASE, L. 2016. Desenvolvimento e avaliação do curso online sobre Suporte Básico de Vida nas manobras de reanimação cardiopulmonar do adulto. (Tese). Universidade de São Paulo.

TORI, R. Educação sem distância: As tecnologias interativas na redução da distância em ensino e aprendizagem. 1a edição. São Paulo: SENAC e Escola do Futuro da USP, 2010.

ZAMBONI, A. B. et al. StArt Uma Ferramenta Computacional de Apoio à Revisão Sistemática. In: BRAZILIAN CONFERENCE ON SOFTWARE: THEORY AND PRACTICE - TOOLS SESSION, 2010. Anais [...] Bahia, 2010. 
Apêndices 



\section{APÊNDICE A - TERMO DE CONSENTIMENTO LIVRE E ESCLARECIDO}

\section{TERMO DE CONSENTIMENTO LIVRE E ESCLARECIDO}

\section{PROJETO DE PESQUISA \\ AMBIENTE VIRTUAL DE APRENDIZAGEM PARA TREINAMENTO DE FONOAUDIÓLOGOS NA INTERVENÇÃO EM LINGUAGEM INFANTIL}

Convidamos o Sr. (a) a participar do estudo acima citado. O presente estudo tem como objetivo elaborar e aplicar um ambiente virtual de aprendizagem (um recurso virtual e online para suporte no ensino à distância) para o treinamento e atualização de fonoaudiólogos na intervenção em Linguagem Infantil, com o intuito de melhorar e distribuir os conhecimentos mais atuais da área acadêmica para a prática cotidiana dos profissionais. O treinamento será proposto no formato de curso de extensão universitária - modalidade de atualização, devidamente regulamentado pela USP, sendo oferecido totalmente a distância, com duração de aproximada de 120 horas, distribuídas em cinco meses, o que resultará numa dedicação semanal ao curso de seis horas. Este treinamento focará no planejamento, metas interventivas, estratégias e evolução terapêutica dos quadros clínicos fonoaudiológicos de Atraso de Linguagem, Distúrbio Específico de Linguagem (DEL) e Transtorno do Espectro Autista (TEA), caso seja verificado a necessidade outros temas poderão ser alvo de discussão. É importante lembrar que para obter melhores resultados, e ao final, proporcionar um treinamento com qualidade pediremos que o Sr. (a) participe assiduamente (sem faltas) das atividades propostas e responda com sinceridade os questionários e entrevistas conduzidos pelos pesquisadores. Todas as atividades do treinamento, bem como os questionários e avaliações serão utilizados para avaliar o desempenho do treinamento, verificando se ao decorrer os alunos fonoaudiólogos melhoram seu desempenho. A pesquisa oferece para o Sr. (a) apenas o risco de cansaço no decorrer das atividades do curso, sendo que pelo fato do mesmo ser realizado a distância e com atividades assíncronas (não há a necessidade dos alunos e proferes estarem realizando as atividades ao mesmo tempo), o Sr. (a) poderá salvar a atividade e continua-la quando e onde preferir. Todos os procedimentos serão realizados online e a distância, sendo eles não invasivos e sem causar qualquer tipo de desconforto ao Sr. (a). Com este treinamento poderemos beneficiar a sociedade propondo e disponibilizando um curso de atualização online, que poderá ser realizado por fonoaudiólogos em qualquer parte do Brasil, bem como, consequentemente melhorar o atendimento fonoaudiológico em Linguagem Infantil de maneira geral, já que os fonoaudiólogos terão acesso a novas descobertas científicas. Após o término do treinamento, será permitido ao Sr. (a) baixar os materiais didáticos para futura consulta e o pesquisador responsável irá disponibilizar um FAQ contendo as dúvidas frequentes e suas respectivas respostas. Em qualquer momento, você poderá fazer perguntas diversas sobre qualquer assunto relacionado ao estudo, bem como a liberdade de retirar seu consentimento a qualquer momento e deixar de autorizar a sua participação no estudo, sem prejuízo de continuidade deste e de qualquer outro curso vinculado à USP. Fica assegurado que não se identificará por nome o indivíduo, mantendo a informação confidencial. Fica assegurado também que o Sr. (a) receberá indenização caso o Sr. (a) tenha algum dano decorrente da pesquisa. 
*No caso de dúvidas sobre a pesquisa poderá entrar em contato com a pesquisadora responsável a qualquer momento:

Nome do Pesquisador responsável: Fga. Me. Camilla Guarnieri

Endereço do pesquisador: Al. Dr. Octávio Pinheiro Brisola 9-75

Cidade: Bauru Estado: SP CEP: 17012-901

Telefone: (14) 32358332

E-mail: camilla.guarnieri@usp.br

Pelo presente instrumento que atende às exigências legais, o $\mathrm{Sr}$. (a) No __ após leitura minuciosa das informações constantes neste TERMO DE CONSENTIMENTO LIVRE E ESCLARECIDO, devidamente explicada pelos profissionais em seus mínimos detalhes, ciente dos serviços e procedimentos aos quais será submetido, não restando quaisquer dúvidas a respeito do lido e explicado, DECLARA e FIRMA seu CONSENTIMENTO LIVRE E ESCLARECIDO concordando em participar da pesquisa proposta. Fica claro que 0 participante da pesquisa, pode a qualquer momento retirar seu CONSENTIMENTO LIVRE E ESCLARECIDO e deixar de participar desta pesquisa e ciente de que todas as informações prestadas tornar-se-ão confidenciais e guardadas por força de sigilo profissional (Cap. IV, Art. 23. do Código de Ética da Fonoaudiologia (Res. CFFa no 490/2016).

Por fim, como pesquisador(a) responsável pela pesquisa, DECLARO o cumprimento do disposto na Resolução CNS no 466 de 2012, contidos nos itens IV.3, item IV.5.a e na íntegra com a resolução CNS no 466 de dezembro de 2012.

Por estarmos de acordo com o presente termo o firmamos em duas vias igualmente válidas (uma via para o participante da pesquisa e outra para o pesquisador) que serão rubricadas em todas as suas páginas e assinadas ao seu término, conforme o disposto pela Resolução CNS no 466 de 2012, itens IV.3.f e IV.5.d.

Bauru, SP, de de

\footnotetext{
Assinatura do Participante da Pesquisa

Fga. Me.Camilla Guarnieri

Pesquisadora Responsável

O Comitê de Ética em Pesquisa - CEP, organizado e criado pela FOB-USP, em 29/06/98 (Portaria GD/0698/FOB), previsto no item VII da Resolução CNS no 466/12 do Conselho Nacional de Saúde do Ministério da Saúde (publicada no DOU de 13/06/2013), é um Colegiado interdisciplinar e independente, de relevância pública, de caráter consultivo, deliberativo e educativo, criado para defender os interesses dos participantes da pesquisa em sua integridade e dignidade e para contribuir no desenvolvimento da pesquisa dentro de padrões éticos.
} 
Qualquer denúncia e/ou reclamação sobre sua participação na pesquisa poderá ser reportada a este CEP:

\section{Horário e local de funcionamento:}

Comitê de Ética em Pesquisa

Faculdade de Odontologia de Bauru-USP - Prédio da Pós-Graduação (bloco E pavimento superior), de segunda à sexta-feira, no horário das $14 \mathrm{hs}$ às 17 horas, em dias úteis.

Alameda Dr. Octávio Pinheiro Brisolla, 9-75

Vila Universitária - Bauru - SP - CEP 17012-901

Telefone/FAX(14)3235-8356

e-mail: cep@fob.usp.br 


\section{APÊNDICE B - ROTEIRO DAS ENTREVISTAS}

1. Como foi sua experiência na graduação com a intervenção de Linguagem Infantil Aprofundamento:

a. A carga-horária teórica foi adequada?

b. A carga-horária prática foi adequada?

c. Você acredita que sua preparação foi suficiente para atender pacientes de Linguagem Infantil?

2. Você sentiu ou sente dificuldade na prática clínica da Linguagem Infantil?

Aprofundamento:

a. Quais?

b. Por que você acredita que estas dificuldades existem ou não?

c. O que você acha que poderia ser feito para sanar essa dificuldade?

3. Você se sente preparado para atender um caso de atraso de Linguagem?

Aprofundamento:

a. Por que?

b. Você já atendeu ou atende tais casos? Como foi sua experiência?

c. Você acredita que os casos por você atendidos tiveram boa evolução interventiva? Por que?

d. Qual abordagem ou técnica você utiliza nesses casos?

4. Você se sente preparado para atender um caso de DEL? Aprofundamento:

a. Por que?

b. Você já atendeu ou atende tais casos? Como foi sua experiência?

c. Você acredita que os casos por você atendidos tiveram boa evolução interventiva? Por que?

d. Qual abordagem ou técnica você utiliza nesses casos?

5. Você se sente preparado para atender um caso de TEA? 
Aprofundamento:

a. Por que?

b. Você já atendeu ou atende tais casos? Como foi sua experiência?

c. Você acredita que os casos por você atendidos tiveram boa evolução interventiva? Por que?

d. Qual abordagem ou técnica você utiliza nesses casos?

6. Você faria um curso de extensão na área de intervenção em Linguagem Infantil

Aprofundamento:

a. Por que?

b. Relate suas experiências anteriores

7. O que você acha, baseado na sua pratica clínica, que os profissionais precisam se aprofundar para atender adequadamente os casos de Linguagem Infantil?

Aprofundamento:

a. Por que?

8. Eu terminei meu roteiro, você gostaria de falar mais alguma coisa sobre o assunto? 


\section{APÊNDICE C - PROVA DIAGNÓSTICA}

1. Uma abordagem híbrida de terapia é aquela em que utiliza-se de conceitos existentes em duas ou mais abordagens para nortear 0 processo interventivo. [Verdadeiro | Falso]

2. $\mathrm{Na}$ intervenção fonoaudiológica em crianças com $\mathrm{DEL}$, a única abordagem terapêutica que pode ser utilizada é a abordagem neuropsicolinguistica. [Verdadeiro | Falso]

3. A abordagem Comportamentalista é uma abordagem funcional. [Verdadeiro | Falso]

4. Na abordagem neuropsicolinguista a intervenção é dividida em 3 etapas: [Verdadeiro | Falso]

a. Compreensão/Linguagem receptiva;

b. Processamento/Repertório Lexical;

c. Expressão.

5. O processo de avaliação e diagnóstico pouco interfere no planejamento terapêutico. [Verdadeiro | Falso]

6. Os termos Intervenção e Estimulação são sinônimos. [Verdadeiro | Falso]

7. A terapia fonoaudiológica deve sempre levar em consideração aspectos sociais. [Verdadeiro | Falso]

8. É mais importante a quantidade do que a qualidade do estímulo linguístico fornecido a criança. [Verdadeiro | Falso]

9. Além da intervenção com a própria criança é necessário também a realização de orientações para a família e a escola. [Verdadeiro | Falso]

10. A intervenção em Linguagem Infantil deve visar o treino de habilidades comunicativas, interativas e cognitivas. [Verdadeiro | Falso]

11. Os fonemas /f/ e /v/ são, ambos, fricativos orais, surdos e labiodentais. [Verdadeiro | Falso]

12. A criança com atraso ou distúrbio específico da linguagem apresenta como característica: [tempo de atenção curto | desenvolvimento sensório-motor sem alterações | falta de uso de comunicação 
linguística | atividade construtiva pouco desenvolvida | dificuldade para imitar sons em geral]

13. Os processos fonológicos identificáveis para as alterações do tipo: /kama/>/tama e /sopa/>/zopa/ são: [posteriorização de velar / ensurdecimento de fricativa | frontalização de velar / sonorização de fricativa | ensurdecimento de velar / ensurdecimento de fricativa | posteriorização de velar / sonorização de fricativa]

14. $\mathrm{Na}$ criança com autismo, a linguagem se encontra seriamente comprometida, pois não há intenção comunicativa. Tal fato se refere ao aspecto: [morfológico da linguagem | semântico da linguagem | sintático da linguagem | pragmático da linguagem]

15. Um menino de 6 anos, com diagnóstico de DEL, apresenta como características de sua linguagem os seguintes traços: mais facilidade para listar palavras ou situações do que para contar histórias; dificuldade com a linguagem figurada, incluindo a compreensão de metáforas e/ou piadas; ingenuidade em situações sociais, com dificuldade em se colocar no ponto de vista dos outros; tendência a superfocar em objetos ou assuntos em particular, em detrimento de uma visão mais global sobre a situação ou assunto. Essas dificuldades podem sinalizar uma alteração: [semânticopragmática | fonológica-pragmática | fonológica-semântica | fonética-fonológica | fonológica-sintática]

16. Uma criança com desvio fonológico apresenta substituições de fricativas por plosivas, em posição inicial, caracterizando um processo de plosivização. O fonoaudiólogo teve como alvo terapêutico, durante seis sessões, a palavra "chuta", considerando a posição inicial e o contexto fonológico seguinte. A criança conseguiu adquirir o fonema nessa palavra. Resta saber se houve estabilização do novo segmento no sistema fonológico e se a criança é capaz de generalizar esse novo padrão em palavras ainda não usadas em terapia. Considerando os possíveis próximos passos nessa intervenção, qual alternativa está INCORRETA? [Continuar estimulando a partir do mesmo alvo, até o final da terapia, de modo que a criança consolide esse novo segmento na aquisição | O 
próximo passo poderia ser o de usar contextos fonológicos seguintes bem distantes do até então usado como alvo, adotando a vogal anterior /i/ e a vogal /a/ como contexto fonológico seguinte, para observar como a criança lidaria com essa nova informação e, ainda, se seria capaz de generalizar | Usar o mesmo padrão (Calvo+V/u/+ CV) em não-palavras para minimizar o efeito lexical e verificar se, de fato, a criança generalizou a aquisição do novo segmento, independente do apoio semântico | Uma das formas de promover a generalização é utilizar palavras com características fonéticas semelhantes, de modo que a criança possa usar em diferentes contextos lexicais e fonológicos, então poderiam ser elencadas palavras com a mesma sílaba, na mesma posição, com tonicidade diferente e distintos graus de familiaridade, como "chupeta", "chuteira" e "chuveiro" | Como a escolha do alvo proporcionou uma resposta positiva da criança, poderiam ser escolhidas novas palavras, mantendo o contexto fonológico seguinte semelhante, como a vogal labial /u/, que comunga traços com a consoante em questão]

17. Em casos de atrasos de linguagem, o terapeuta deve orientar os pais e/ou os cuidadores para estimular o desenvolvimento da criança. Relacione as faixas etárias a seguir às atividades que devem ser desenvolvidas. [Cante canções simples e recite poesias infantis para mostrar o ritmo e o padrão da fala; use boa fala, que seja clara e simples para seu filho utilizar como modelo | Faça uma pausa após falar. Isso dá chance para que seu filho continue a conversa; ajudeo a realizar tarefas com dois ou três comandos | Converse com seu filho durante o banho, a alimentação, enquanto o veste; estimule-o a emitir sons com vogais e consoantes como "ma", "da", "ba"] [De 4 a 6 anos de idade | De 2 a 4 anos de idade | Do nascimento aos 2 anos de idade]

18. O primeiro aspecto das alterações da produção verbal - iniciativa para a comunicação e planejamento verbal - está usualmente correlacionado às lesões pré-frontais, uni ou bilaterais. Assinale a opção que indica a alteração que se caracteriza por redução da 
fluência, com discurso mais econômico, embora não agramatical, dificuldades de atenção e concentração, de generalização e abstração e dificuldades construtivas. [Alteração da apraxia verbal | Alteração linguístico-cognitiva | Alteração da compreensão verbal | Alteração da apraxia de fala | Alteração da função executiva]

19. A Avaliação Fonológica da Criança (AFC) é um instrumento proposto com objetivo de elicitar a amostra mais representativa da fala da criança. Nesse material, há cinco desenhos temáticos para a estimulação de 125 itens que formam a lista de palavras da AFC. Assinale a alternativa que corresponde à forma utilizada na AFC para chegar-se à produção linguística da criança. [Ditado | Fala espontânea | Repetição | Cópia | Nomeação espontânea]

20.Para a avaliação da linguagem oral, existem alguns instrumentos/tarefas normatizadas e padronizadas para a população brasileira. Qual dos testes abaixo, traz sua descrição corretamente: [Teste de nomeação de figuras: avalia a habilidade de discriminar palavras que diferem em apenas um fonema. Pode ser aplicado em crianças entre 3 e 6 anos de idade | Teste de discriminação fonológica: avalia o vocabulário receptivo de criança entre 2 anos e 6 meses até 18 anos|Teste de vocabulário por imagem peabody (TVIP) é composto por 60 figuras para o indivíduo nomear. Pode ser aplicado em crianças e adolescentes entre 3 e 4 anos | Teste de repetição de palavras e pseudopalavras: avalia a memória de curto prazo fonológico por meio de repetição de palavras e pseudopalavras. Pode ser aplicado em crianças e adolescentes de 3 a 14 anos]

21. O Atraso de Linguagem apresenta-se como uma alteração ou defasagem da oralidade que, porém, respeita as etapas habituais do desenvolvimento. Como orientação para o diagnóstico diferencial, qual das opções abaixo NÃO condiz com o quadro de Atraso de Linguagem? [Resposta positiva ao processo de intervenção | Vocabulário restrito e simplificações fonológicas | Sintaxe primitiva e telegráfica | Manifestações linguísticas desviantes] 
22. Analise as asserções a seguir: $O$ quadro de Distúrbio Específico de Linguagem (DEL) tem sido estudado sob o ponto de vista neurobiológico, por meio de pesquisas genéticas e por neuroimagem PORQUE as manifestações linguísticas do DEL são variadas e possibilitam formas clínicas distintas, o que levou os pesquisadores a propor subclassificações para o quadro. Acerca dessas asserções, é CORRETO afirmar: [As duas asserções são proposições verdadeiras e a segunda é uma justificativa correta da primeira | A primeira asserção é uma proposição verdadeira e a segunda uma proposição falsa | A primeira asserção é uma proposição falsa e a segunda uma proposição verdadeira | As duas asserções são proposições verdadeiras, mas a segunda não é uma justificativa correta da primeira]

23. Com o intuito de diferenciar o Distúrbio Específico de Linguagem, o Transtorno do Espectro Autista, o Distúrbio Pragmático-semântico e a Síndrome de Asperger, Bishop (2000) considerou a afetação de três aspectos: a estrutura linguística, o uso social da linguagem e o interesse restrito. Considerando a proposta de Bishop, analise as afirmativas que se seguem: I. Crianças com Síndrome de Asperger não apresentam tantos problemas com a estrutura linguística nem em interesses restritos. II. Crianças com Distúrbio Pragmáticosemântico apresentam dificuldades no uso social da linguagem. III. Crianças com Síndrome de Asperger apresentam problemas no uso social da linguagem. IV. Crianças com Transtorno do Espectro Autista são as que apresentam mais dificuldade nos três aspectos. V. Crianças com Distúrbio Pragmático-semântico têm dificuldades na compreensão de estruturas linguísticas. Estão de acordo com a diferenciação proposta por Bishop, apenas as afirmações: [I e IV | I, III e IV | II, III e V | II, III, IV e V]

24. Estudos que tangem o espectro autístico apontam uma grande variedade de alterações comportamentais em que a linguagem está profundamente relacionada às dinâmicas sociais e aos procedimentos repetitivos. De acordo com esta afirmação, marque a alternativa correta: [Há um prejuízo na compreensão de significado 
e uso da linguagem verbal, não havendo atraso em etapas ou níveis de complexidade, mas desvio no processo de evolução | Há atraso em etapas ou níveis de complexidade, levando a grande dificuldade de expressão | Os sujeitos verbais do espectro autístico apresentam maior prejuízo que os não verbais no uso funcional de objetos e do próprio corpo | Os sujeitos verbais não apresentam alterações na comunicação verbal e não verbal no sistema fonético-fonológico, de prosódia e processos lexicais | A ecolalia é pouco vista como característica marcante no espectro autístico]

25. As crianças com Distúrbio Específico de Linguagem (DEL) tardam a falar na maioria das vezes, havendo ausência de vocalizações articuladas, por exemplo. Assinale a alternativa incorreta no que se refere aos tipos de DEL. [A dispraxia verbal apresenta compreensão normal ou próxima do normal e a fluência pode estar prejudicada | O distúrbio léxico-sintático trata da dificuldade de evocação e fixação do léxico, com uso constante de perífrases e dêiticos | O distúrbio fonológico-sintático possui compreensão prejudicada quando o enunciado é longo ou emitido com rapidez | O distúrbio de programação fonológica refere-se a compreensão abaixo do normal, aparecimento da fala muito atrasada, com disfluência | A agnosia auditivo-verbal refere-se a compreensão da linguagem oral gravemente afetada ou ausente, sendo normal a compreensão para gestos]

26. Caso clínico: Os pais de um menino, V., de 3 anos e 1 mês procuram um fonoaudiólogo, preocupados com o fato de que a criança está falando muito errado. O fonoaudiólogo fez uma entrevista inicial e uma observação da criança. Na entrevista, os pais revelam que a criança teve problemas de adenóide desde bebê, com repetidos episódios de otite média. Disseram que fazia 4 meses que $\mathrm{V}$. havia feito uma adenoidectomia e a partir de então não tivera mais os quadros de otite, inclusive tinha realizado avaliação audiológica e estava dentro dos padrões de normalidade. Disseram que V. estava tão bem que até estava falando mais, aliás, para eles "parece que tinha começado a falar" (sic), já que antes quase ninguém entendia 
o que ele falava. V. frequenta escola maternal desde os dois anos, e os professores também notaram mudança significativa na fala dele depois da cirurgia. Na observação da criança, o fonoaudiólogo identificou que ela estabelecia diálogo, brincava adequadamente com os brinquedos e com o próprio fonoaudiólogo. Era muito falante, mas apresentava muitos erros nos sons da fala, muitas vezes sendo difícil entendê-la. Abaixo, segue a transcrição de um trecho de conversa entre os dois no momento em que a criança $(C)$ mostrava para o pai $(P)$ como funcionava um dos brinquedos. Trata-se de um brinquedo eletrônico, no qual, ao se girar uma manivela, o tabuleiro gira, apontando a figura de um bicho, cuja onomatopéia (som que o bicho faz) se faz ouvir.

$P$ : Nossa filho, que brinquedo legal!

C: Óia, tem papo! (aponta uma figura e vira a manivela; o tabuleiro gira, a seta aponta para a figura da vaca e ouve-se um "MUUU").

$P:$ Tem sapo, mas esse que falou não é o sapo.

C: Não, é baca!

$P$ : E agora?

C: Bô biá! Ai ! Nu cutigo!

Óia ... piú...

U piú ... lá do hotel.

P: É!! você conseguiu virar! É... esse barulho é do peru, igual você viu lá no hotel.

Ao analisar os dados da entrevista e os dados de avaliação de linguagem, o fonoaudiólogo esclareceu aos pais que a criança não ficaria em atendimento naquele momento, apesar de que, de fato, $\mathrm{V}$. falasse bastante errado. Ele iria acompanhar mensalmente a criança, durante 3 meses, e, depois, se fosse o caso ele entraria em terapia fonoaudiológica. Ressaltou a necessidade de V. continuar na escola e pontuou para eles que, mesmo que $V$. falasse errado, eles sempre deveriam falar certo com ele e que, quando não o entendessem deveriam dizer que não o haviam entendido e pedir para ele thes explicar de novo e nunca "fazer de conta" que o haviam entendido quando isso não fosse verdade. 
Considerando-se o processo de aquisição de linguagem, os dados de fala apresentados e os dados da entrevista e da observação, assinale a alternativa correta sobre a conduta do terapeuta em questão. [A conduta foi inadequada, pois pelos dados apresentados, fica evidente que a criança tem um atraso de linguagem e precisa de tratamento pelo menos duas vezes por semana. Do contrário, futuramente ela pode até desenvolver um problema de escrita | A conduta está correta, mas ela deveria fazer uma orientação para os pais e para escola para que estes estimulassem mais a linguagem da criança, a fim de verificar como a criança se comporta frente a esta estimulação | A conduta está correta, pois a criança tem apresentado mudanças significativas na linguagem, indicativas de desenvolvimento e não de instalação de um quadro patológico, após a cirurgia. Assim sendo, o acompanhamento mensal é suficiente para verificar se vai se instalar um quadro patológico ou não e daí decidir sobre a necessidade de intervenção direta | A conduta está inadequada, pois a criança deveria entrar em terapia para trabalhar a respiração nasal, mobilidade, tonicidade e postura dos OFA e as funções de mastigação, pois, tendo realizado adenoidectomia, deve ser um respirador bucal | A conduta está inadequada, pois a criança já apresenta um quadro de desvio fonológico e precisa de tratamento imediatamente, para fazer a colocação dos fonemas e completar o seu inventário fonético]

27. Assinale a alternativa correta com relação à terapêutica dos atrasos de linguagem. [A terapia, a partir de uma abordagem discursiva, deve ter como base a interação e a construção conjunta da significação | Pelo viés da abordagem inatista, o terapeuta deve ter uma escuta para relacionar a queixa da mãe e o sintoma da criança, analisando também as implicações desse sintoma na família | A abordagem behaviorista recomenda favorecer um desenvolvimento cognitivo para que a criança venha a falar | $\mathrm{Na}$ entrevista inicial, devem-se coletar dados essencialmente orgânicos para a investigação das causas do atraso de linguagem | A avaliação, na 
abordagem discursiva, parte sempre de testes fechados para a elaboração do diagnóstico]

28. Um fonoaudiólogo elaborou proposta de atuação para uma escola de Educação Infantil. Após a apresentação da proposta, surgiram demandas da equipe pedagógica e dúvidas acerca das competências atribuídas ao fonoaudiólogo em ambiente escolar. Considerando essa situação e o disposto na Resolução n. 387/2010 do Conselho Federal de Fonoaudiologia, avalie as afirmações a seguir, relativas à atuação do fonoaudiólogo educacional. I. As ações do fonoaudiólogo na escola devem ser independentes do planejamento educacional, para não interferirem no cronograma curricular. II. A partir das demandas da escola, cabe ao fonoaudiólogo propor intervenções nas turmas em que há alunos com dificuldades fonológicas, para adequação dos processos alterados. III. Compete ao fonoaudiólogo propor ações de saúde e cuidado vocal para os professores da escola, tais como o ensino de técnicas de relaxamento muscular da cintura escapular e cervical, para aqueles com queixa de rouquidão. IV. Diante de queixas sobre o barulho intenso no espaço escolar, o fonoaudiólogo deve propor melhorias no ambiente físico, como, por exemplo, adequações acústicas. É correto apenas o que se afirma em: [III e IV | I, II e IV | II e III | I e IV | I, II e III]

29. Na charge a seguir, Cebolinha conta ao Dinofauro, um simpático dinossauro azul sem mandíbula, seu sonho de ser o dono da rua.

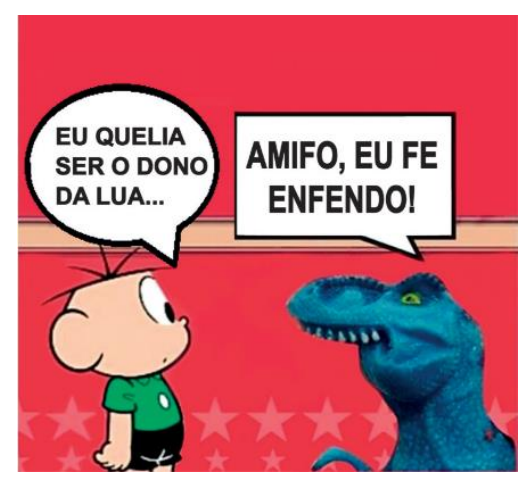

Considerando o desenvolvimento da linguagem oral e a conversa entre os personagens dessa charge, avalie as afirmações a seguir. 
I. Ao substituir o fonema /r/, da palavra "rua", pelo ///, Cebolinha realiza o processo fonológico denominado simplificação da fricativa velar, comum em crianças com até 4 anos de idade.

II. Ao substituir o fonema /r/, da palavra "queria", pelo /I/, Cebolinha realiza o processo fonológico denominado simplificação de líquida, comum em crianças com até 4 anos de idade.

III. Ao substituir o fonema /g/, da palavra "amigo", pelo /f/, Dinofauro realiza o processo fonológico denominado ensurdecimento de fricativa, o qual não é esperado no desenvolvimento de crianças.

IV. Ao substituir o fonema /t/, da palavra "entendo", pelo /f/, Dinofauro realiza um desvio fonético não esperado no desenvolvimento de crianças.

É correto apenas o que se afirma em [I e III | I, II e III | II e IV | I, II e IV | III e IV]

30. A gagueira é um distúrbio da fluência e da temporalização da fala. $A$ fluência refere-se à suavidade, facilidade, falta de esforço com que sons, sílabas, palavras e frases são ligados durante a fala. Para uma pessoa que gagueja, a produção da fala é uma atividade trabalhosa, não sendo automática tal como ocorre para uma pessoa considerada fluente. A temporalização refere-se ao tempo de execução dos sons, sílabas, palavras e frases. Cada som da fala possui um tempo usual para ser dito. Na fala gaguejada, alguns sons são pronunciados em tempo maior que o habitual. Com relação à gagueira, infere-se que [pessoas que gaguejam apresentam concomitantemente as características físicas de bloqueios, prolongamentos e repetições | pessoas que gaguejam apresentam troca de palavras durante a fala e pouco movimento corporal ao falar, embora consigam produzir frases complexas | a repetição de sons e sílabas é sintoma de alteração na temporalização da fala | os bloqueios de sons são sintomas de alteração na temporalização da fala | entre os sintomas de alteração na temporalização da fala estão excluídos os prolongamentos de sons]

31. Ao visitar uma escola de educação infantil, uma fonoaudióloga é indagada sobre uma criança de 2 anos que está gaguejando muito 
e, por isso, é motivo de preocupação da professora. Acerca dessa situação, assinale a opção correta. [Pedir à criança que fale devagar e respire antes de falar são consideradas atitudes benéficas nesses casos | Considerando-se que, quanto mais precoce for 0 atendimento terapêutico maior a chance de sucesso, é recomendável que essa criança inicie terapia de fala 0 mais brevemente possível. | Em razão da faixa etária dessa criança é desnecessário orientar os educadores e os familiares em relação a como lidar com essa situação | Recomenda-se não interromper a fala da criança, mas sim, prestar atenção ao conteúdo da fala e não à sua forma | A gagueira nessa idade é considerada uma disfluência natural de fala, ou gagueira fisiológica, não havendo necessidade de qualquer orientação por parte do fonoaudiólogo]

32. Faz parte do desenvolvimento típico uma criança entre 8 e 12 meses de idade acenar dando "tchau". A qual nível de linguagem este marco está relacionada? [Sintático | Fonológico | Pragmático Semântico]

33. Qual destes diz respeito aos padrões, sistemas e regras da fala em um idioma? [Fonética | Fonemas | Fonologia | Todas as alternativas | Nenhuma das alternativas]

34. Relacione o tipo de memória às respectivas características. [Armazena grande quantidade de informação por período indefinido de tempo. A atenção pode se desviar sem ocasionar prejuízo na retenção | Memória transitória que pode manter informações por períodos variáveis de tempo, em função da utilidade da informação | Armazena pequena quantidade de informação por período de tempo limitado e, nesse período, a informação pode ser mantida por repetição no sistema de memória, em processo que depende da atenção | Subtipo de memória de longa duração que pode ser classificada em semântica e episódica | Subtipo de memória de longa duração que se expressa por meio do desempenho. A informação é adquirida e acumulada lentamente pela repetição] [Memória de longa duração | Memória operacional | Memória de 
curta duração | Memória explícita ou declarativa | Memória implícita ou de procedimentos]

35. Cite dez orientações pertinentes a pais e professores de crianças que apresentam alterações específicas de linguagem.

36. Leia o Caso a seguir e responda as questões relacionadas a ele:

"A mãe de V.C.B., do sexo masculino, 3 anos e 5 meses de idade, procurou a clinica relatando que se filho está falando muito pouco, ainda não forma frases e muitas das palavras que ele fala só são compreendidas pelos familiares. A criança tem dois irmãos e ambos fizeram tratamento fonoaudiológico, o mais velho teve Atraso de Linguagem e a outra irmã disfluência gaga. Ao passar pelo Diagnóstico foi observado que a criança tem vocabulário receptivo e expressivo aquém do esperado para sua idade, além de que a maior parte das palavras que ele fala são ininteligíveis, principalmente trissílabos e polissílabos. Ele não forma frases e nem narra fatos e é capaz de executar ordens simples. O diagnóstico dado para a criança foi de Atraso de Linguagem com risco para DEL".

a. As informações fornecidas são suficientes para a elaboração de um bom planejamento interventivo? Se não, quais informações ficaram faltando?

b. Considerando as informações dadas qual abordagem interventiva você utilizaria neste caso? Justifique.

c. Elenque as metas de intervenção/estimulação que você trabalharia no caso acima descrito.

d. Escolha uma das metas da questão acima e descreva uma estratégia para trabalhar tal meta para esta criança. 
Anexos 



\section{ANEXO A - APROVAÇÃO PELO COMITÊ DE ÉTICA EM PESQUISA}

DETALHAR PROJETO DE PESQUISA

- DADOS DA VERSÃo DO PROJETO DE PESQUISA

Título da Pesquisa: AMBIENTE VIRTUAL DE APRENDIZAGEM PARA TREINAMENTO DE FONOAUDIÓLOGOS NA INTERVENÇÃO EM LINGUAGEM INFANTIL Pesquisador Responsável: Camilla Guarnier

Versão: 2

CAAE: 66267017.7 .0000 .5417

Submetido em: 20/04/2017

Instituição Proponente: Universidade de Sao Paulo

Situaçao da Versão do Projeto: Aprovado

Localização atual da Versảo do Projeto: Pesquisador Responsáve

Comprovante de Recepção:

- DOCUMENTOS DO PROJETO DE PESQUISA

३s̃o Atual Aprovada (PO) - Versão 2

Pendência de Parecer (PO) - Versão 2

Documentos do Projeto

Comprovante de Recepção - Submissã

$\square$ Folha de Rosto - Submissão 2

$\bigcirc$ Informações Básicas do Projeto - Subm

Outros - Submissão 2

Projeto Detalhado / Brochura Investiga

$\square$ TCLE / Termos de Assentimento / Justi

Apreciação 2 - USP - Faculdade de Odontc

$\checkmark$ Pareceres

- $\square$ Pesquisador Responsável pela Aprecia

eto Completo

\begin{tabular}{|l|l|c|l|l|}
\hline Tipo de Documento & Situação & Arquivo * & Postagem * Açōes \\
\hline $\begin{array}{l}\text { Parecer } \\
\text { Consubstanciado do } \\
\text { CEP }\end{array}$ & Aceito & 2a PB_PARECER_CONSUBSTANCIADO_CEP_2062999.pdf & $\begin{array}{l}\text { 15/05/2017 } \\
09: 48: 37\end{array}$ & D \\
\hline
\end{tabular}

,


ANEXO B - APROVAÇÃ O DO CURSO PELA PRÓ-REITORIA DE CULTURA E EXTENSÃO DA USP

\begin{tabular}{|c|c|c|}
\hline \multirow{2}{*}{ Püblico } & \multicolumn{2}{|l|}{ Cunsos e Abvidabes de Extensiso } \\
\hline & \multirow{2}{*}{\multicolumn{2}{|c|}{250300008 - Intervençăo Fonoaudiológica em Linguagem Infantil }} \\
\hline Inscrikso oneline & & \\
\hline Edrats & Unidade: & Frculdsde de Odontologia de Baunu \\
\hline Fomento & Modalidade: & Atualicaplo \\
\hline \multirow[t]{18}{*}{$\begin{array}{l}\text { Acessio Restrito } \\
\text { Entrar } \\
\text { Esquedi a Senha } \\
\text { Primeiro Acesso }\end{array}$} & $\begin{array}{l}\text { Público Alvo: } \\
\text { Objetivo: }\end{array}$ & 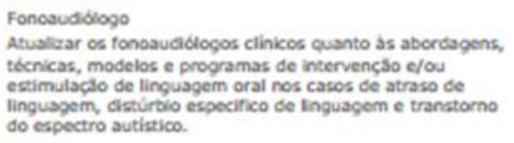 \\
\hline & Pre-requisito Graduaçato: & Sim \\
\hline & Area de Conhecimento: & Fonouvidologis \\
\hline & Ediça & 17001 \\
\hline & Número đo Oferecimento & 1 \\
\hline & Periodo de Realizaça: & de 20/09/2017 ate 31/01/2018 \\
\hline & Local do curso: & Totalmente a CistSincia vis Moodle \\
\hline & Vagas: & 75 \\
\hline & Inscriçà & \\
\hline & On-Line: & de 15/08/2017 00:00 att 15/09/2017 23:59 \\
\hline & $\begin{array}{l}\text { Presencial: } \\
\text { Procedimento de inscriça: }\end{array}$ & 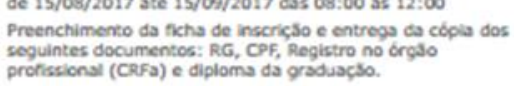 \\
\hline & Conteúdos/Disciplinas & Intervençso Fonosudioliogica em Lingusgem Infantil \\
\hline & Responsáveis & \\
\hline & Coordenador: & Simone Aparecida Lopes Herrera \\
\hline & Vice-Coordenador: & Aline Roberta Aceituno da Costa \\
\hline & Critérios & \\
\hline & de selesso: & 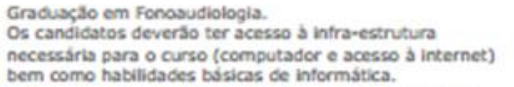 \\
\hline & de aprovaçaso: & 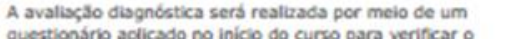 \\
\hline
\end{tabular}




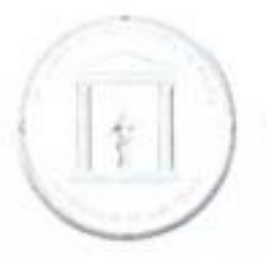

\author{
Universidade de São Paulo \\ Faculdade de Odontologia de Bauru
}

Comissāo de Cultura e Extensāo Universitária

PROCESSO 2017.1.1664.25.3

\begin{abstract}
Encaminhe-se a Profa. Dra. Simone Aparecida Lopes Herrera, do Departamento de Fonoaudiologia Coordenadora dessa atividade, para conhecimento e providencias das informaçøes as fls. 09.10

Seja anexada aos autos a documentaçāo necessária referente a matricula dos alunos participantes da atividade, conforme normas internas vigentes, divulgadas pelo COMUNICADO - CCEX-FOBIUSP $001 / 2016$, de 05.10 .2016

Sendo necessária a liberaçăo no sistema para acesso dos alunos ao serviço de VPN e e-mail pela Universidade de Sáo Paulo (mediante autorizaçao do coordenador do curso), encaminhar a esta Comissabo, o documento "Termo de Compromisso' (modelo da CCEx), devidamente preenchido $e$ assinado.

Em seguida devolva-se a esta Comissào para arquivo do processo até o término da atividade, em que o Coordenador devera enviar o relatório final contendo o formulario de avaliação dos participantes e os relatorics academico e financeiro, quando for o caso. para analise desta CCEx e posteriormente peio CoCEX
\end{abstract}

Bauru, 4 de julho de 2017

Profa Dra Dionisiá Aparecida Cusin Lamónica

Presidente da Comissáo de Cultura e Extensåo Universitária 


\section{ANEXO C - QUESTIONÁRIO DE INCIDENTES CRÍTICOS}

\section{Avaliação das Atividades do Módulo 1}

Reflita sobre os eventos recentes deste curso para responder às próximas questões.

Todas as questões são obrigatórias e devem ser respondidas.

1 Como participante, em que momento você esteve mais envolvido?

2 Como participante, em que momento você esteve menos envolvido?

3 Qual das ações de outros participantes nos fóruns você achou mais elucidante ou útil?

4 Qual das ações de outros participantes nos fóruns você achou mais desconcertante ou confusa?

5 Qual evento foi mais surpreendente? 


\section{ANEXO D - QUESTIONÁRIO ATTLS}

\section{Auto-avaliação do Módulo 1}

COMO RESPONDER AO QUESTIONÁRIO O objetivo deste questionário é fazer uma pesquisa sobre as posturas dos participantes do curso perante a aprendizagem e a reflexão crítica. Cada ítem abaixo consiste em uma declaração que descreve posturas e atitudes que você pode assumir ao longo deste curso. Reflita sobre cada ítem e decida se as afirmações são válidas em relação a você mesmo, e em que medida. Depois, escolha a opção correspondente às suas conclusões. Não há respostas certas ou erradas; nós estamos interessados apenas na sua opinião. Todas as respostas dadas são confidenciais e não tem nenhum impacto sobre a avaliação do participante. Agradecemos a sua colaboração.

Todas as questões são obrigatórias e devem ser respondidas.

\section{Posturas perante a Aprendizagem e a Reflexão Crítica}

Respostas

$\begin{array}{cccccc}\text { Ainda não } & \text { Discordo } & \text { Discordo } & \begin{array}{c}\text { Não } \\ \text { concordo }\end{array} & \text { Concordo } & \text { Concordo } \\ \text { respondeu } & \text { completamente } & \text { em parte } & \begin{array}{c}\text { nem } \\ \text { discordo }\end{array} & \text { em parte } & \text { plenamente }\end{array}$

Minhas posturas e atitudes...

1 Quando avalio uma argumentação, me concentro na qualidade do discurso, e não na pessoa que o apresenta.

2 Eu gosto de fazer a parte do advogado do diabo argumentar em modo contrário ao que alguém está dizendo.

3 Gosto de entender a experiência prévia das outras pessoas, e o que levou-as a sentirem o que sentem.

$4 \mathrm{O}$ aspecto mais importante da minha educação tem sido aprender a entender pessoas que são diferentes de mim.

5 Sinto que a melhor forma de atingir a minha própria identidade é interagir com diversos tipos de pessoas. 
6 Gosto de ouvir as opiniões de outras pessoas com background diferente do meu isto me ajuda a compreender porque as mesmas coisas são vistas de formas tão diversas.

7 Acho que posso reforçar a minha posição discutindo com alguém que não concorda comigo.

8 Estou sempre interessado(a) em saber por que as pessoas dizem e acreditam em certas coisas.

9 Freqüentemente discordo de autores de livros que leio, e procuro uma explicação lógica que comprove que eles estão errados.

10 Quando faço análises, procuro ser muito objetivo.

11 Procuro refletir junto com os outros em vez de ser contrário a eles.

12 Avalio as argumentações segundo critérios precisos.

13 Sou mais propenso(a) a tentar compreender a opinião de alguém do que a julgá-la.

14 Tento indicar o ponto fraco dos argumentos dos outros para ajudá-los a esclarecer as idéias apresentadas.

15 Quando discuto questões polêmicas, tendo a colocar-me na posição dos outros para entender o ponto de vista deles.

16 Pode-se afirmar que o meu modo de analisar as coisas é como 'submetê-las a julgamento' porque considero todas as evidências com muita atenção. 
17 Quando resolvo

problemas, dou mais valor ao uso da lógica e da razão do que à satisfação dos meus interesses pessoais.

18 A empatia facilita a compreensão das opinões de outros, diferentes das minhas.

19 Quando as opiniões de uma pessoa me parecem totalmente estranhas, procuro me colocar no lugar dessa pessoa, para entender o porquê dessas opiniões.

20 Eu me dedico a descobrir o que está 'errado' nas coisas. Por exemplo, procuro argumentações insuficientes em interpretações literárias. 


\section{Anexo E - Questionário COLLES versão "expectativas e experiência efetiva"}

\section{Questionário de Avaliação do Curso}

COMO RESPONDER AO QUESTIONÁRIO O objetivo deste questionário é fazer uma pesquisa sobre a medida em que o seu processo de aprendizagem neste curso corresponte às suas expectativas. Cada ítem abaixo consiste na comparação entre as suas expectativas e a sua experiência efetiva ao freqüentar este curso. Reflita sobre cada declaração e, depois, selecione a opção que descreve melhor a freqüência em que você gostaria que as situações descritas ocorressem neste curso (freqüência desejada) e a freqüência em que as situações descritas ocorrem atualmente neste curso (freqüência atual). Não há respostas certas ou erradas; nós estamos interessados apenas na sua opinião. Todas as respostas dadas são confidenciais e não tem nenhum impacto sobre a avaliação do participante. Agradecemos a sua colaboração.

Todas as questões são obrigatórias e devem ser respondidas.

\section{Relevância}

Respostas

Neste curso..

1 Freqüência desejada $\mathrm{A}$ minha aprendizagem é

focalizada em assuntos que me interessam.

2 Freqüência atual A minha aprendizagem é focalizada em assuntos que me interessam.

3 Freqüência desejada $\mathrm{O}$ que eu estou aprendendo é importante para a prática da minha profissão.

4 Freqüência atual $\mathrm{O}$ que eu estou aprendendo é importante para a prática da minha profissão.

5 Freqüência desejada Eu aprendo como fazer para melhorar o meu desempenho profissional.

6 Freqüência atual Eu aprendo como fazer para melhorar o meu desempenho profissional.

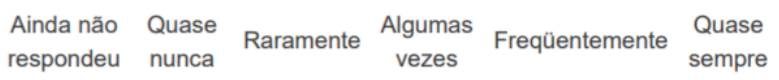

nunca

sempre 
7 Freqüência desejada $\mathrm{O}$ que eu aprendo tem boas conexões com a minha atividade profissional.

8 Freqüência atual $\mathrm{O}$ que eu aprendo tem boas conexões com a minha atividade profissional.

\section{Reflexão Crítica}

Respostas

Neste curso...

9 Freqüência desejada Eu reflito sobre como eu aprendo.

10 Freqüência atual Eu reflito sobre como eu aprendo.

11 Freqüência desejada Faço reflexões críticas sobre as minhas próprias idéias.

12 Freqüência atual Faço reflexões críticas sobre as minhas próprias idéias.

13 Freqüência desejada Faço reflexões críticas sobre as idéias dos outros participantes.

14 Freqüência atual Faço reflexões críticas sobre as idéias dos outros participantes.

15 Freqüência desejada Faço reflexões críticas sobre os conteúdos do curso...

16 Freqüência atual Faço reflexões críticas sobre os conteúdos do curso...

\section{Interatividade}

Respostas

Neste curso..

17 Freqüência desejada Eu explico as minhas idéias aos outros participantes.

18 Freqüência atual Eu explico as minhas idéias aos outros participantes.

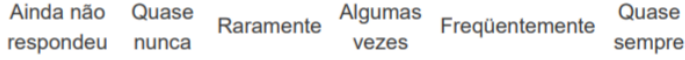


19 Freqüência desejada Peço aos outros estudantes explicações sobre as idéias deles.

20 Freqüência atual Peço aos outros estudantes explicações sobre as idéias deles.

21 Freqüência desejada Os outros participantes me pedem explicações sobre as minhas idéias.

22 Freqüência atual Os outros participantes me pedem explicações sobre as minhas idéias.

23 Freqüência desejada Os outros participantes reagem às minhas idéias.

24 Freqüência atual Os outros participantes reagem às minhas idéias.

\section{Apoio dos Tutores}

Respostas

Ainda não respondeu

Raramente Algumas Freqüentemente Quase Neste curso...

25 Freqüência desejada $\mathrm{O}$ tutor me estimula a refletir.

26 Freqüência atual $\mathrm{O}$ tutor me estimula a refletir.

27 Freqüência desejada $\mathrm{O}$ tutor me encoraja a participar.

28 Freqüência atual $\mathrm{O}$ tutor me encoraja a participar.

29 Freqüência desejada $O$ tutor ajuda a melhorar a qualidade dos discursos.

30 Freqüência atual $\mathrm{O}$ tutor ajuda a melhorar a qualidade dos discursos.

31 Freqüência desejada $\mathrm{O}$ tutor ajuda a melhorar o processo de reflexão autocrítica. 
32 Freqüência atual $\mathrm{O}$ tutor ajuda a melhorar o processo de reflexão autocrítica.

\section{Apoio dos Colegas}

Respostas

Neste curso...

33 Freqüência desejada Os outros participantes me encorajam a participar.

34 Freqüência atual Os outros participantes me encorajam a participar.

35 Freqüência desejada Os outros participantes elogiam as minhas contribuições.

36 Freqüência atual Os outros participantes elogiam as minhas contribuições.

37 Freqüência desejada Os outros participantes estimam as minhas contribuições.

38 Freqüência atual Os outros participantes estimam as minhas contribuições.

39 Freqüência desejada Os outros participantes demonstram empatia quando me esforço para aprender.

40 Freqüência atual Os outros participantes demonstram empatia quando me esforço para aprender.

\section{Compreensão}

Respostas

Neste curso...

41 Freqüência desejada Eu compreendo bem as mensagens dos outros participantes.

42 Freqüência atual Eu compreendo bem as mensagens dos outros participantes. Ainda não
respondeu $\begin{gathered}\text { Quase } \\ \text { nunca }\end{gathered} \quad$ Raramente $\begin{gathered}\text { Algumas } \\ \text { vezes }\end{gathered}$ Freqüentemente $\begin{gathered}\text { Quase } \\ \text { sempre }\end{gathered}$

\section{(}

(

(

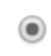

$$
(
$$

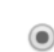

(n)


43 Freqüência desejada Os outros participantes compreendem bem as minhas mensagens.

44 Freqüência atual Os outros participantes compreendem bem as minhas mensagens.

45 Freqüência desejada Eu compreendo bem as mensagens do tutor

46 Freqüência atual Eu compreendo bem as mensagens do tutor.

47 Freqüência desejada $\mathrm{O}$ tutor compreende bem as minhas mensagens.

48 Freqüência atual $\mathrm{O}$ tutor compreende bem as minhas mensagens.

49 Em quanto tempo você concluiu este questionário?

50 Você quer fazer outros comentários? 